\title{
The effects of a multiple step antioxidant nutritional supplementation protocol on high-intensity cycling performance
}

Ryan Hobbs

West Virginia University

Follow this and additional works at: https://researchrepository.wvu.edu/etd

\section{Recommended Citation}

Hobbs, Ryan, "The effects of a multiple step antioxidant nutritional supplementation protocol on highintensity cycling performance" (2009). Graduate Theses, Dissertations, and Problem Reports. 2762.

https://researchrepository.wvu.edu/etd/2762

This Thesis is protected by copyright and/or related rights. It has been brought to you by the The Research Repository @ WVU with permission from the rights-holder(s). You are free to use this Thesis in any way that is permitted by the copyright and related rights legislation that applies to your use. For other uses you must obtain permission from the rights-holder(s) directly, unless additional rights are indicated by a Creative Commons license in the record and/ or on the work itself. This Thesis has been accepted for inclusion in WVU Graduate Theses, Dissertations, and Problem Reports collection by an authorized administrator of The Research Repository @ WVU. For more information, please contact researchrepository@mail.wvu.edu. 
The effects of a multiple step antioxidant nutritional supplementation protocol on high-intensity cycling performance

$$
\text { Ryan Hobbs }
$$

Thesis submitted to the School of Medicine at West Virginia University in partial fulfillment of the requirements for the degree of

\author{
Master of Science \\ in \\ Exercise Physiology
}

G. Gregory Haff, Ph.D., Chair

Stephen E. Alway, Ph.D.

Randy W. Bryner, Ed.D.

Department of Human Performance

Division of Exercise Physiology

\author{
Morgantown, West Virginia \\ 2009
}

Key Words: Bicycling/physiology, Energy Metabolism, Sports/physiology, Physical Endurance/physiology, Oxidative Stress, Glutathione/blood 


\begin{abstract}
The effects of a multiple step antioxidant nutritional supplementation protocol on high-intensity cycling performance
\end{abstract}

Ryan Hobbs

PURPOSE: To determine if 5 days of antioxidant supplementation coupled with a preride antioxidant/energy supplement improves cycling performance or reduces oxidative stress in trained cyclists.

METHODS: Eight well-trained cyclists participated in a double-blind cross-over placebo-controlled study. Maximal oxygen consumption $\left(\mathrm{VO}_{2 \mathrm{Max}}\right)$, peak power output $\left(\mathrm{W}_{\mathrm{Max}}\right)$ and total work during a 15-minute time trial were determined. Subjects consumed an antioxidant supplement $(\mathrm{S})$ or a placebo $(\mathrm{P})$ for 5 days before each trial and a pre-exercise supplement or isocaloric placebo $\left(4 \mathrm{kcal} \cdot \mathrm{kg}^{-1}\right) 45$ minutes before each trial. Subjects performed an endurance ride of 90 minutes followed immediately by a time trial requiring accumulation of total work equal to the initial time trial.

RESULTS: The GSH:GSSG ratio remained constant prior to both experimental trials, while resting total GSH concentrations exhibited a main effect $(p=0.038)$ in response to step-one of the supplement protocol for basal (S: $1020.2 \pm 135.8 \mu \mathrm{mol} \cdot \mathrm{L}^{-1}$; P: $1000.2 \pm$ $252.9 \mu \mathrm{mol} \cdot \mathrm{L}^{-1}$ ) vs. pre-endurance (S: $979.2 \pm 155.1 \mu \mathrm{mol} \cdot \mathrm{L}^{-1}$; P: $867.3 \pm 231.2 \mu \mathrm{mol} \cdot \mathrm{L}^{-}$ $\left.{ }^{1}\right)$. During the endurance ride, no differences were observed in average power (S: $224.0 \pm$ $36.5 \mathrm{~W}$; P: $219.1 \pm 19.2 \mathrm{~W}$ ), oxygen consumption (S: $2.8 \pm 0.4 \mathrm{~L} \cdot \mathrm{min}^{-1}$; P: $2.8 \pm 0.4$ $\left.\mathrm{L} \cdot \mathrm{min}^{-1}\right)$, heart rate $\left(\mathrm{S}: 148.4 \pm 3.5\right.$ beats $\cdot \mathrm{min}^{-1}$; $\mathrm{P}: 146.3 \pm 4.5$ beats $\left.\cdot \mathrm{min}^{-1}\right)$, or GSH:GSSG ratio (S: $1.4 \pm 0.7 ; \mathrm{P}: 1.4 \pm 0.9)$. During the time trial tests, supplementation did not lead to any differences between average power (S: $303.6 \pm 59.2 \mathrm{~W}$; P: $306.1 \pm$ 47.0 W), oxygen consumption (S: $3.5 \pm 0.4 \mathrm{~L} \cdot \mathrm{min}^{-1}$; P: $\left.3.3 \pm 0.6 \mathrm{~L} \cdot \mathrm{min}^{-1}\right)$, heart rate (S: $171.1 \pm 6.5$ beats $\cdot \mathrm{min}^{-1}$; P: $170.3 \pm 3.5$ beats $\cdot \mathrm{min}^{-1}$ ), or GSH:GSSG ratio (S: $1.1 \pm 0.6$; P: $0.9 \pm 0.7)$.

CONCLUSION: Consuming an antioxidant supplement for 5 days coupled with a preexercise antioxidant/energy supplement does not result in significant improvements in cycling performance. However, the multiple-step supplementation may attenuate oxidative stress during the cycling bout when compared to a placebo, possibly due to the maintenance of glutathione levels. 


\section{$\underline{\text { Table of Contents }}$}

Section

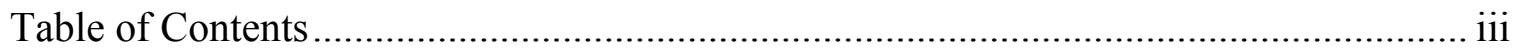

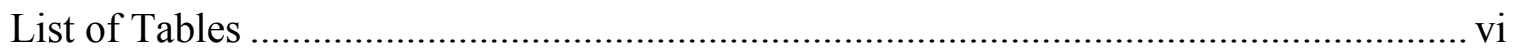

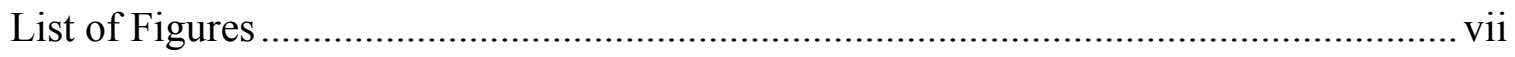

Chapter 1. Introduction ..................................................................................... 1

1.1. Purpose \& Specific Aims.............................................................................. 1

1.1.1. Purpose

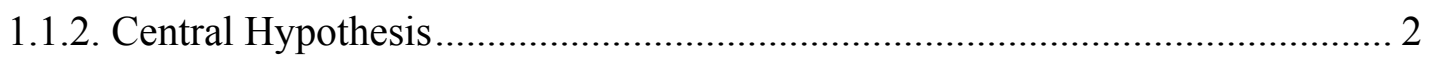

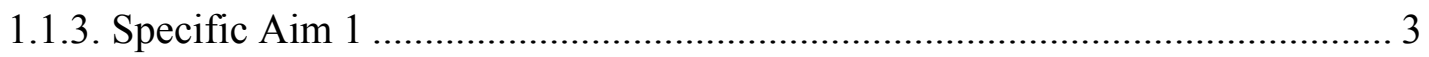

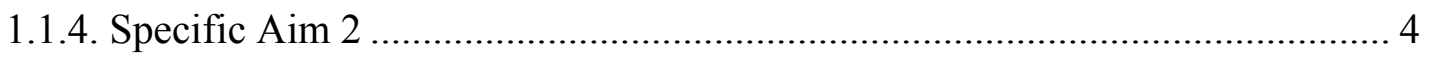

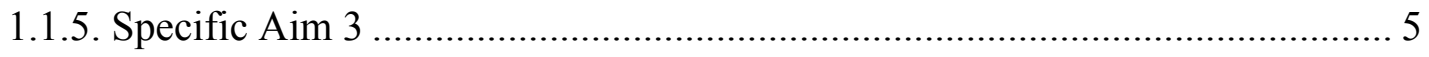

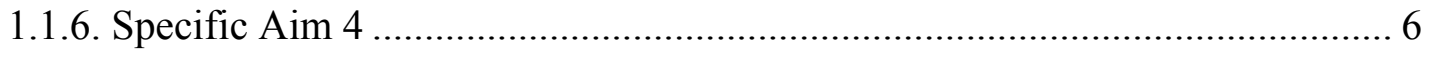

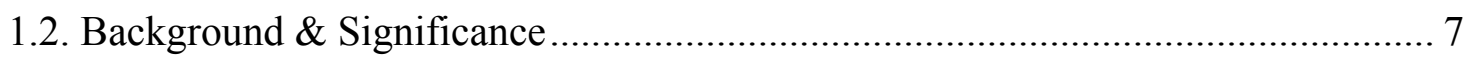

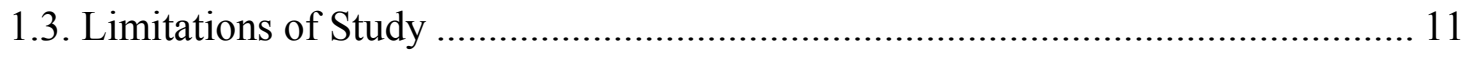

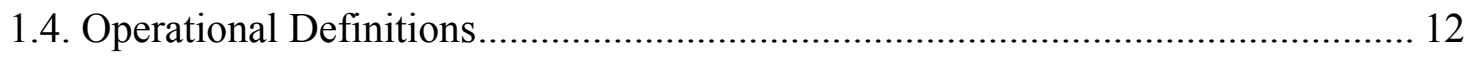

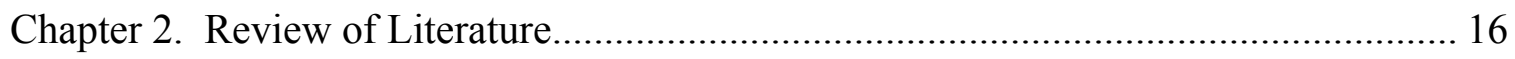

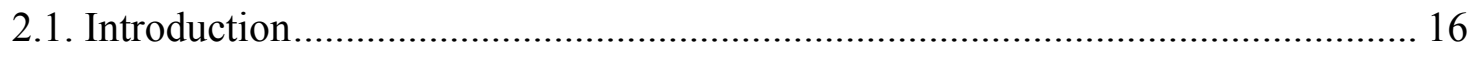

2.2. Free Radicals, Oxygen Radicals, and Nitrogen Radicals ..................................... 16

2.3. Production of Reactive Oxygen and Nitrogen Species during Exercise................ 18

2.3.1. Reactive Oxygen Species Production .......................................................... 18

2.3.2. Reactive Nitrogen Species Production During Exercise/ Interaction with

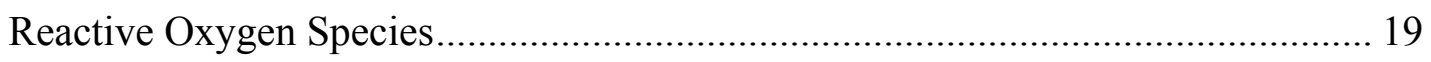


2.4. Determining Reactive Oxygen and Nitrogen production during exercise 19

2.5. Antioxidants Fluctuations, Cell Damage, and Oxidative Stress .......................... 21

2.5.1. Non-Enzymatic Antioxidants: Ascorbic Acid and $\alpha$-Tocopherol................. 22

2.5.2. Non-Enzymatic Antioxidant: Glutathione ................................................. 24

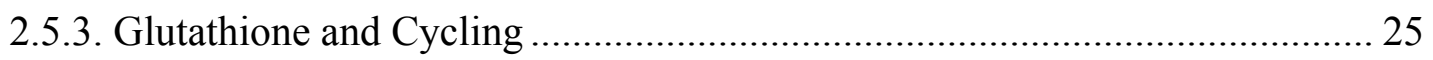

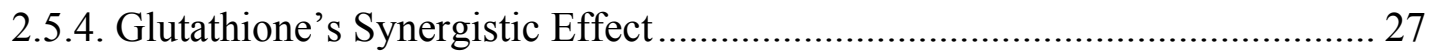

2.6. Reactive Oxygen and Nitrogen Species and Signal Transduction....................... 27

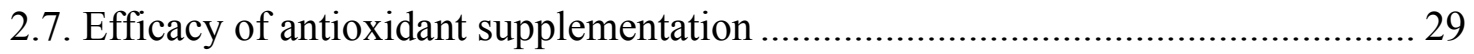

2.8. Antioxidant and Energy Substrate Supplementation ....................................... 30

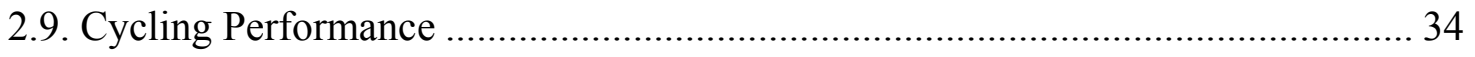

2.10. Appropriate protocol for examining nutritional intervention ........................... 36

2.11. Limitations in Current Supplement Research ............................................... 38

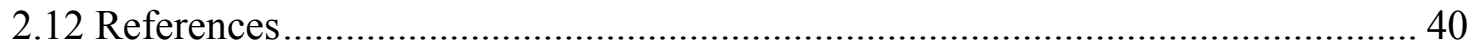

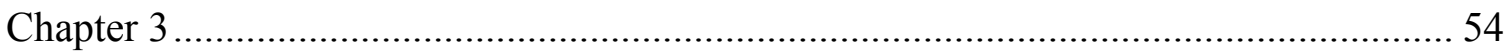

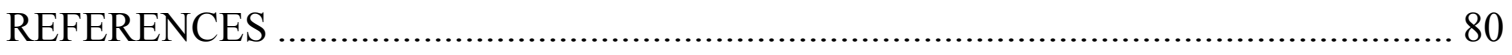

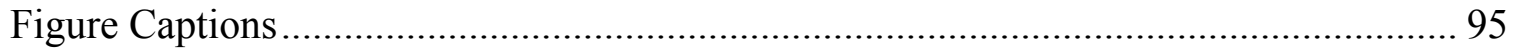

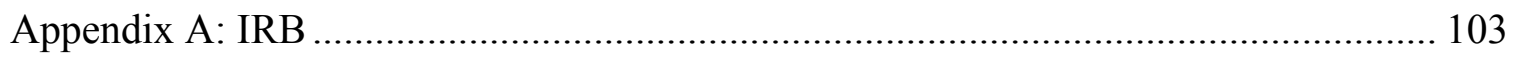

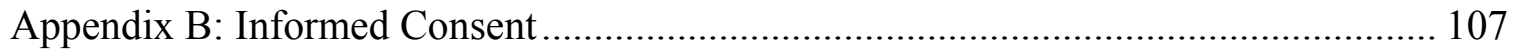

Appendix C: Health History Questionnaire ...................................................... 112

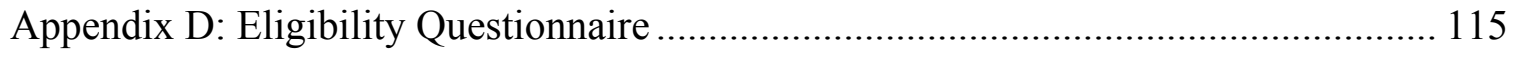

Appendix E: Relevant Supplementation Studies ................................................. 117

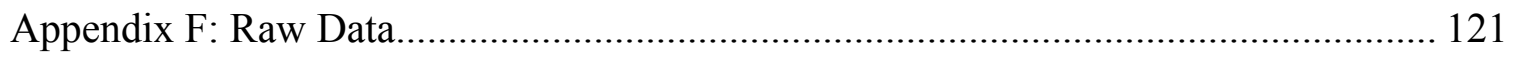

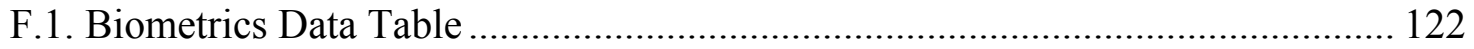


F.2. $\mathrm{VO}_{2 \max }$ Testing Data Table

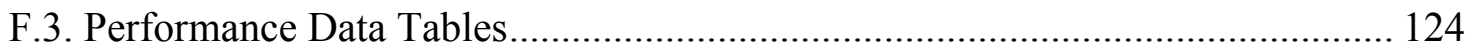

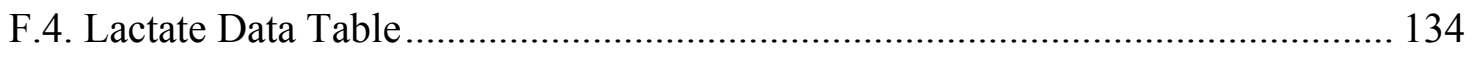

F.5. Glucose Data Table................................................................................... 135

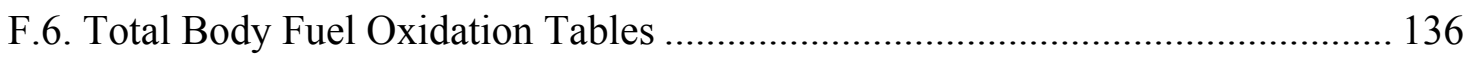

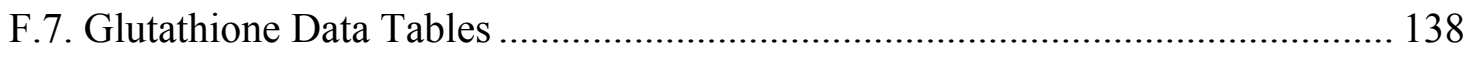

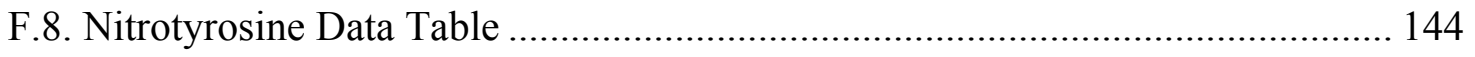

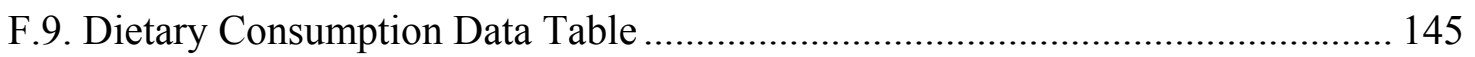




\section{List of Tables}

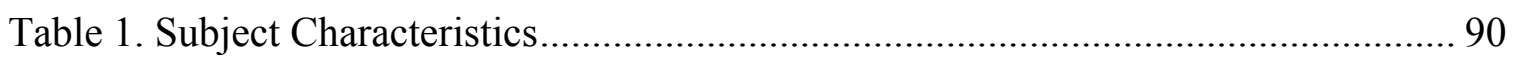

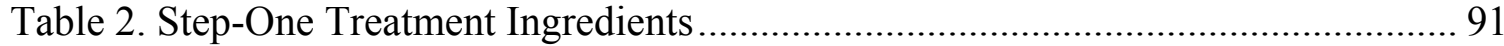

Table 3. Step-One and Step-Two Placebo Ingredients .............................................. 92

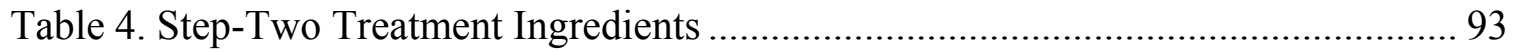

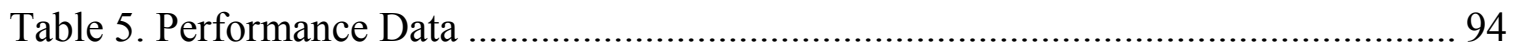




\section{$\underline{\text { List of Figures }}$}

Figure 1. Experimental Approach ......................................................................... 96

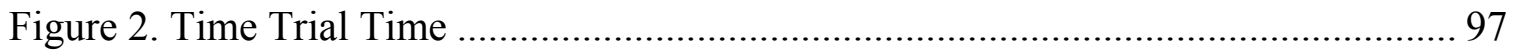

Figure 3. Relative Average Power ........................................................................... 98

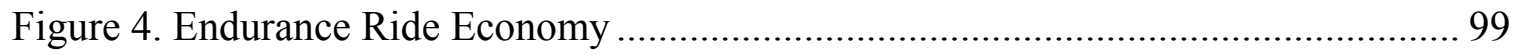

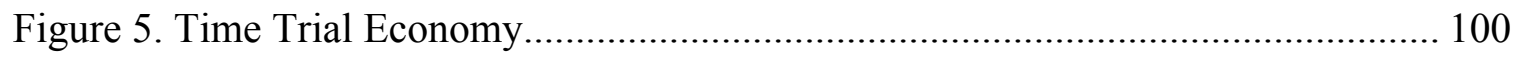

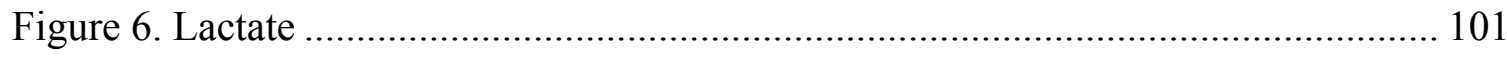

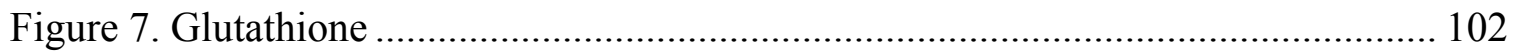




\section{Chapter 1. Introduction}

\subsection{Purpose \& Specific Aims}

\subsubsection{Purpose}

The ability to perform high intensity aerobic endurance activity requires a significant increase in oxygen consumption $\left(\mathrm{VO}_{2}\right)$ and is clearly demonstrated by the linear increase in $\mathrm{VO}_{2}$ which occurs as intensity increases during a graded cycle ergometry test. ${ }^{81}$ In order to meet the work demand, a constant supply of energy to the working muscles must be provided to maintain performance during high intensity aerobic exercise. ${ }^{59,72}$ These activities can result in accumulation of reactive oxygen species, ${ }^{39}$ oxidative stress, ${ }^{64}$ and oxidative muscle damage ${ }^{42,100}$ due to increased radical production associated with increased oxygen consumption. ${ }^{63}$ Recent studies have examined the effect of various dietary supplements on their ability to enhance endurance performance, ${ }^{81}$ alter fuel metabolism, ${ }^{36,86}$ decrease markers of oxidative stress, ${ }^{82,108}$ and decrease markers of post-exercise muscle damage. ${ }^{42,97}$ These dietary supplements include carbohydrate ${ }^{59,72}$ protein, ${ }^{79,110,122}$ arginine, ${ }^{1,86}$ carnitine, ${ }^{12}$ aspartate, ${ }^{1}$ tartrate, ${ }^{12}$ vitamins A, C, and $\mathrm{E},{ }^{2,19,20,82,93,113}$ selenium, ${ }^{97,118}$ allopurinol, ${ }^{42}$ Siberian ginseng, ${ }^{30}$ and reduced glutathione. ${ }^{108}$ Most of these supplements have required long-term ( $\sim 4$ weeks $)$ use to provide the desired effects, ${ }^{2,20,42,81}$ and most have been studied independently of one another. ${ }^{19,42,86,93,118}$ It has been suggested that because most of these supplements work synergistically, they should be consumed in combination as an antioxidant energy substrate cocktail, rather than independently. ${ }^{112}$ Thus, supplementation with antioxidant energy substrate cocktails has also been evaluated in regards to providing ergogenic effects. ${ }^{81,119}$

There is evidence that consumption of antioxidant energy substrate cocktails increase endurance performance, ${ }^{81}$ but no underlying mechanisms have been identified. In addition, recent research has suggested that long-term supplementation could be detrimental to cellular 
adaptations that lead to improvements in endurance capacity. ${ }^{41}$ Thus, short-term antioxidant supplementation could lead to improvements in performance without interrupting cellular adaptations that occur as a result of training. Therefore, the purpose of this project was to determine if a multiple step antioxidant nutritional supplement protocol which includes a 5 day antioxidant cocktail loading phase coupled with a pre-event antioxidant/energy beverage increases performance, reduces markers of oxidative stress, or enhances fuel metabolism during a high-intensity cycle ergometry exercise test in trained competitive cyclists.

\subsubsection{Central Hypothesis}

This study examined the effects of a short-term multiple step antioxidant nutritional supplement protocol in high-intensity cycling. The central hypothesis was that a multiple step antioxidant nutritional supplement protocol would result in increased cycling performance via enhancement of fuel metabolism and by reducing levels of oxidative stress. This central hypothesis was tested by addressing the following four specific aims. 


\subsubsection{Specific Aim 1}

The first aim was to determine whether supplementation would alter cycling performance in trained male cyclists when compared to a multiple step isocaloric placebo. The aim was examined by determining the amount of time to achieve a pre-determined amount of work, the average power output, and oxygen consumption during a validated repeated measure cycle ergometry test (preload+time trial).

\section{Hypothesis 1:}

A multiple step antioxidant nutritional supplement protocol would result in a decreased time to complete the set amount of work during the time trial, an increase in average power output per given average heart rate and a decrease in relative oxygen consumption per given power output during the cycle ergometry test at $30 \mathrm{~min}, 60 \mathrm{~min}$, and $90 \mathrm{~min}$ of the preload and throughout the time trial when compared with a placebo protocol. 


\subsubsection{Specific Aim 2}

The second aim was to determine whether a five day loading phase of an all-natural antioxidant supplement during a summer cycling competition phase alters the basal level of indicators of oxidative stress when compared to a placebo loading phase. The aim was examined by determining the basal concentration of whole blood reduced glutathione, the ratio of whole blood reduced glutathione/oxidized glutathione, and the concentration of plasma nitrotyrosine.

\section{Hypothesis 2:}

The antioxidant loading phase would result in an increase in the basal whole blood concentrations of reduced glutathione, an increase in the basal whole blood reduced glutathione/oxidized glutathione ratio, and a decrease in the basal concentration of plasma nitrotyrosine as compared with a placebo protocol. 


\subsubsection{Specific Aim 3}

The third aim was to determine whether supplementation would alter the exercise-induced acute oxidative stress in response to a high intensity cycling time trial after the performance of 90 minutes of cycling. The aim was addressed by examining the immediate post-exercise concentration of whole blood reduced glutathione, the ratio of whole blood reduced glutathione/oxidized glutathione ratio, and the concentration of plasma nitrotyrosine.

\section{Hypothesis 3:}

A multiple step antioxidant nutritional supplement protocol would result in the attenuation of the decrease in whole blood reduced glutathione and the reduced glutathione/oxidized glutathione ratio and the attenuation of the increase in plasma nitrotyrosine that may occur in response to the cycle ergometry test as compared with a placebo protocol. 


\subsubsection{Specific Aim 4}

The fourth aim was to determine whether supplementation would alter fuel metabolism in trained male cyclists when compared to a multiple step isocaloric placebo. The aim was examined by determining the concentration of plasma glucose, whole blood lactate production, respiratory exchange ratio, and whole-body rates of fat and carbohydrate oxidation calculated from the nonprotein respiratory exchange ratio during a validated repeated measure cycle ergometry test.

\section{Hypothesis 4:}

A multiple step antioxidant nutritional supplement protocol would result in the attenuation of the decrease in plasma glucose concentration and carbohydrate oxidation, attenuation of the increase in whole blood lactate concentration, respiratory exchange ratio, and fat oxidation during the cycle ergometry test as compared with a placebo protocol. 


\subsection{Background \& Significance}

Exercise results in an increased metabolic rate, which is associated with an increase in oxygen consumption in the exercising tissues. ${ }^{63}$ Cycling is a mode of exercise that results in significant increases in oxygen consumption as intensity increases ${ }^{49}$ and requires the athlete to maintain high performance intensities for prolonged durations during competition. ${ }^{31}$ This fact is best represented by the analysis of an individual time trial where competitive cyclists spend an average of 20 minutes at $>90 \%$ maximal oxygen consumption $\left(\mathrm{VO}_{2 \mathrm{max}}\right){ }^{31}$ Additionally, it has been reported that the winner of an individual time trial during the Tour de France cycled at $>90 \% \mathrm{VO}_{2 \max }$ for 70 minutes. ${ }^{77}$ The constant demand for energy is supplied to the working muscle by the mitochondria, where oxygen is the final electron acceptor. ${ }^{63}$ The catabolic processes in the mitochondria result in the formation of free radicals and other reactive oxygen species, ${ }^{44}$ which subsequently leads to the formation of reactive nitrogen species. ${ }^{84}$ Metabolic processes that occur during cycling intensities of $\geq 75 \% \mathrm{VO}_{2 \max }$ result in high rates of carbohydrate oxidation, and supplementation with carbohydrate during an hour of cycling at $75 \% \mathrm{VO}_{2 \max }$ has resulted in a $2.3 \%$ increase in performance, determined by a decreased time during a time trial. ${ }^{56}$ This increase in performance is considered an ergogenic benefit which is stimulated by carbohydrate supplementation.

An ergogenic aid, such as energy substrates found in dietary supplements, generally result in performance improvements during endurance exercise. ${ }^{5}$ The use of ergogenic aids has been documented since ancient times. ${ }^{6}$ Current ergogenic aids include: energy sources, such as carbohydrate; anabolic enhancers, such as protein and amino acids; and dietary antioxidant cocktails. 5, 81,119 Antioxidants are substances that quench free radicals and reactive oxygen and nitrogen species, thereby reducing the severity of oxidative stress. ${ }^{38}$ Oxidative stress occurs as a 
result of an imbalance between reactive oxygen and nitrogen species and the antioxidant defense system. ${ }^{63}$ During high-intensity exercise, such as an individual time trial, the accumulation of reactive oxygen and nitrogen species can occur. ${ }^{39}$

The accumulation of reactive oxygen and nitrogen species during a state of oxidative stress can lead to oxidative injury during and after acute bouts of strenuous exercise, ${ }^{63}$ such as intense aerobic exercise. $^{5}$ Oxidative injuries can include lipid peroxidation ${ }^{18,18}$ and protein oxidation, ${ }^{13,78,10}$ which may lead to oxidative muscle damage ${ }^{61}$ that can contribute to altered cellular integrity and muscle metabolism and result in impaired muscular performance. ${ }^{70}$ Markers of muscle damage are routinely increased after prolonged high-intensity cycling. ${ }^{42,109,110}$ Furthermore, the red blood cell is also susceptible to oxidative damage. ${ }^{75,79}$ Thus, when the antioxidant defense system is inadequate and reactive oxygen and nitrogen species are not controlled, accumulating levels of reactive oxygen and nitrogen species can result in oxidative damage that could result in a chronic decrease in endurance performance due to muscle tissue loss and decreased capacity to transport oxygen. The accumulation of oxidative damage is relative to the production of reactive oxygen and nitrogen species ${ }^{63}$ and the collective success of the antioxidant defense and muscle repair systems. ${ }^{65}$

The antioxidant defense system encompasses both nonezymatic and enzymatic antioxidants. The nonenzymatic antioxidants include the exogenous antioxidant vitamins and endogenous glutathione. The antioxidant vitamins are considered non-inducible antioxidants, meaning that their concentrations are not altered with training adaptations. ${ }^{63}$ Inducible antioxidants respond to training by adapting to quench higher levels of reactive oxygen and nitrogen species. Inducible antioxidants include the enzymatic antioxidants and the glutathione antioxidant system. ${ }^{63}$ Enzymatic antioxidants superoxide dismutase and glutathione peroxidase have been shown to 
have increased activity levels after controlled endurance training. ${ }^{89}$ It is relevant to mention that glutathione and Vitamins $\mathrm{C}$ and $\mathrm{E}$ are synergistic in their actions, meaning that these antioxidants work together to neutralize reactive oxygen species. ${ }^{33,53}$ This indicates that alterations in one of these antioxidants can have an effect on the others (i.e. the use of $\alpha$-tocopherol can compensate for inadequacies in the glutathione antioxidant system). The only way to alter the antioxidant vitamin concentrations is through modulation of dietary intake or dietary supplementation. ${ }^{63}$ Dietary antioxidants are susceptible to deficiency, ${ }^{63}$ and it is not uncommon for competitive endurance athletes such as cyclists to have an inadequate dietary intake of antioxidants and calories ${ }^{78,80}$ due to high caloric expenditure during training and competition. Furthermore, many cyclists attempt to reduce body weight which may contribute to the effects stimulated by an inadequate dietary intake. This maintenance of low body weight could create a scenario of inadequate exogenous antioxidant intake. Based upon this line of reasoning it appears that antioxidant supplementation could be beneficial for the maintenance of the exogenous antioxidant system in these types of situations.

A few studies have investigated the effect of short term ( $\leq 14$ days) antioxidant supplementation on oxidative stress and performance. ${ }^{120,47,7}$ The supplementation protocols varied in timing from 2 hours ${ }^{7}$ to 14 days ${ }^{47}$ prior to exercise. A graded cycling max test coupled with ascorbic acid supplementation taken 2 hours prior to the high intensity aerobic exercise bout was evaluated. ${ }^{7}$ Results indicated an increase in plasma ascorbic acid levels and a decrease in oxidative stress at rest and in response to the exercise in healthy untrained subjects. ${ }^{7}$ This indicates that short-term supplementation maybe beneficial in reducing oxidative stress by attenuating uncontrolled production of reactive oxygen and nitrogen species that can lead to an oxidative stress condition. Uncontrolled levels of reactive oxygen and nitrogen species during 
oxidative stress can result in oxidative damage which could lead to decreases in high intensity aerobic exercise performance of longer duration or in subsequent performances during a competitive season. An antioxidant energy substrate cocktail may provide increased levels of protection beyond that of independently supplementing with only ascorbic acid, but there currently exists no scientific literature evaluating this concept. Thus, more research on the effects of short term antioxidant cocktail supplementation protocols on cycling performance in trained athletes is warranted.

Exogenous antioxidant supplementation for 6 weeks has lead to improvements in cycling performance during a laboratory time trial. ${ }^{81}$ However, it has recently been suggested that longterm antioxidant supplementation may be detrimental to cellular adaptations that lead to improvements in endurance capacity. ${ }^{31}$ A number of cellular signaling pathways respond to reactive oxygen and nitrogen species, which ultimately contributes to improvements in endurance performance. ${ }^{65}$ So, the efficacy of long-term or chronic antioxidant supplementation is currently being questioned in the scientific literature. ${ }^{65}$

It has also been speculated that long-term or chronic antioxidant supplementation could prevent desirable adaptations in inducible antioxidants, limiting the adaptive capacity to deal with reactive oxygen and nitrogen species. ${ }^{65}$ However, this may not occur in all situations. For example, if an athlete has inadequate nutrient intake, the inclusion of an antioxidant supplementation protocol may be warranted as it likely will attenuate oxidative stress-associated muscle damage that can occur in athletes with low exogenous antioxidant intake during simulated competitions, ${ }^{97}$ high intensity training, or during actual competitive events.

Regardless of exogenous antioxidant status, supplementation with dietary antioxidants routinely results in decreased muscle damage in response to strenuous cycling in trained 
cyclists. $^{42,109,110}$ This attenuation of muscle damage results in decreased muscular fatigue and could preserve performance in times of intense competition, during periods of intensified training such as overreaching, or at the onset of overtraining syndrome. ${ }^{33}$ Therefore, the timing of antioxidant supplementation seems to be essential for allowing reactive oxygen and nitrogen signaling to facilitate training adaptations, but high concentrations of reactive oxygen and nitrogen generated during competition and during periods of overreaching must be controlled to eliminate the possibility of the development of a chronic oxidative stress condition that would result in detriments to performance. ${ }^{33}$

\subsection{Limitations of Study}

There were limitations within the implementation of this study. The ability to control for the cyclists' nutritional intake and training was limited. A dietary and training recall provided some level of control, but this is only if the subjects took this practice seriously and accurately recorded dietary intake and training rides. The consumption of foods and consistent training without documentation into the supplied logs could have taken place and could be a confounding variable. The lack of consumption of the desired dose of capsules during the loading phase treatment period could further confound the results. The consumption of a single dose of the antioxidant/energy substrate during step-two of the supplementation protocol may not be adequate; it is possible that multiple daily doses prior to training could produce superior results. Furthermore, a placebo effect could have resulted if subjects believed that they had the treatment during the placebo trial. If the cyclist believed he was on the supplement, the level of motivation may have been increased. This would have been due to expectations that the supplement improves performance. Such motivational factors could indeed lead to false performance improvements. The cyclists were also provided with data during the experimental trials and as a 
pacing strategy they may attempt to reproduce levels of the same power or heart rate values during the experimental time trial, which could have resulted in similar performances. Some basic assumptions include that the athletes gave a maximal effort throughout all testing procedures and that they were unaware of the treatment given.

\subsection{Operational Definitions}

Antioxidant: Antioxidants are substances that quench free radicals and reactive oxygen and nitrogen species thereby reducing the severity of oxidative stress. ${ }^{13,27,38}$

Dietary Antioxidant: A dietary antioxidant is a substance gained from food that may assist in reducing the concentration of oxidative species and the muscle damage caused by free radicals and reactive oxygen and nitrogen and has also been used as a therapeutic agent for muscle repair processes during recovery. ${ }^{39}$

Endogenous Antioxidant: An endogenous antioxidant is a tissue antioxidant enzyme that is important in the protection of cells against free-radical-mediated damage. The primary antioxidant enzymes include superoxide dismutase, catalase, glutathione peroxidase, and glutathione reductase. These enzymes are also referred to as the oxygen radical scavenger enzymes. ${ }^{39}$

Exogenous Antioxidant: Exogenous antioxidants are dietary antioxidants that must be obtained through the diet or dietary supplements. ${ }^{63}$

Ergogenic Aid: An ergogenic aid, such as a dietary supplement, results in performance improvements. ${ }^{6}$

Free Radical: A free radical is a chemical species that contains at least one unpaired electron and is produced in all living cells. ${ }^{15,27}$ 
Glutathione Peroxidase: Glutathione peroxidase is the enzyme that uses reduced glutathione to reduce hydrogen peroxide resulting in the formation of oxidized glutathione. ${ }^{87}$

Glutathione Reductase: Glutathione reductase is the enzyme that uses $\beta$-nicotinamide adenine dinucleotide phosphate to convert oxidized glutathione back into reduced glutathione. ${ }^{87}$

Isocaloric: Isocaloric means equating caloric content of two different supplement treatments though the concentration of macronutrients is not the same (i.e. a carbohydrate+protein beverage (200 kilocalories) and a carbohydrate-only beverage (200 kilocalories)). ${ }^{105}$

Lipid Peroxidation: Lipid peroxidation is the process of oxidizing fatty-acid side chains found in membrane lipids to hydroperoxides; membrane lipids that contain two or more carbon-carbon double bonds, a.k.a. polyunsaturated, have increased susceptibility to oxidation. ${ }^{45}$

Oxidation: Oxidation is the process of gaining oxygen or donating electrons (e.g. in the situation of hydrogen peroxide formation where $\mathrm{H}_{2}$ reacts with $\mathrm{O}_{2}{ }^{2-}$, the $\mathrm{H}_{2}$ is said to have undergone oxidation because it donates electrons to $\mathrm{O}_{2}{ }^{2-}$ resulting in the formation of hydrogen peroxide). In this reaction, $\mathrm{H}_{2}$ gains the oxygen. ${ }^{85}$

Oxidative stress: Oxidative stress occurs as a result of an imbalance between reactive oxygen and nitrogen and the antioxidant defense system. Oxidative stress can result due insufficient quenching of reactive oxygen and nitrogen by antioxidants, an overproduction of reactive oxygen and nitrogen, or a drop in antioxidant defenses. Exercise is known to stimulate oxidative stress. $^{15,27,52,53}$

Oxidized Glutathione (Glutathione Disulfide): Oxidized glutathione is produced during the reactions of reduced glutathione with hydrogen peroxide. ${ }^{87}$ Oxidized glutathione is routinely found to increase in response to exercise-induced oxidative stress. ${ }^{111}$ 
Protein Oxidation: Protein oxidation is the process where cellular proteins are altered by reactive oxygen and nitrogen species primarily at peptide bonds or amino acid side chains, leading to the loss of catalytic or structural functions and leaving the protein highly susceptible to proteolytic degradation. ${ }^{27}$

Reactive Nitrogen Species: Reactive nitrogen species include free radicals that are nitrogen bases (e.g. nitric oxide $(\mathrm{NO})$, nitrogen dioxide $\left(\mathrm{NO}_{2}{ }^{\circ}\right)$, and peroxynitrite $\left.\left(\mathrm{ONOO}^{-}\right)\right){ }^{15}$

Reactive Oxygen Species: Reactive oxygen species include free radicals that are oxygen based (e.g. superoxide $\left(\mathrm{O}_{2}^{\circ}\right)$, hydroxyl $\left(\mathrm{OH}^{\circ}\right)$, alkoxyl ( $\left.\mathrm{RO}\right)$, peroxyl (ROO), and hydrogen peroxyl $\left.\left(\mathrm{ROOH}^{\prime}\right)\right)$ and non-radicals such as hydrogen peroxide. ${ }^{15}$

Reduction: Reduction is the process of losing oxygen or accepting electrons (e.g. in the situation of hydrogen peroxide formation where $\mathrm{H}_{2}$ reacts with the peroxide ion $\left(\mathrm{O}_{2}{ }^{2-}\right)$, the $\mathrm{O}_{2}{ }^{2-}$ is said to have undergone reduction because it accepts electrons as it reacts with $\mathrm{H}_{2}$ resulting in the formation of hydrogen peroxide). In this reaction molecular oxygen is lost in the formation of molecular hydrogen peroxide. ${ }^{85}$

Reduced Glutathione: Reduced glutathione ( $\gamma$-glutamylcysteinylglycine) is the most important nonenzymatic antioxidant found in erythrocytes; reduced glutathione serves as substrate for glutathione peroxidase and also directly quenches singlet oxygen and hydrogen peroxide. ${ }^{62,87}$

Time Trial: A time trial in competitive cycling is either an individual or team event in which a specific distance is covered as fast as possible. ${ }^{57}$ Laboratory time trials are endurance performance tests with a known end point, such as a target amount of work or time, give the subject control of resistance and pedal cadence, and are highly reproducible. ${ }^{58}$ Maximal oxygen uptake: Maximal oxygen uptake $\left(\mathrm{VO}_{2 \max }\right)$ is a physiological characteristic that is bound by the parametric limits of the Fick equation [(left ventricular end-diastolic volume) - 
(left ventricular end-systolic volume) $\mathrm{x}$ heart rate $\mathrm{x}$ arterio-venous oxygen difference] and is continually found to be high in endurance athletes, most likely due to a high cardiac output, but is not necessarily indicative of endurance athletic performance. ${ }^{75}$ 


\section{Chapter 2. Review of Literature}

\subsection{Introduction}

Competitive endurance athletes routinely engage in strenuous exercise during competition ${ }^{31}$ that results in increases in oxygen consumption, ${ }^{81}$ increases in free radical associated damage, ${ }^{76}$ and disruption of the oxidant/antioxidant balance. ${ }^{64}$ This disruption favors the production of oxidants, such as reactive oxygen and nitrogen species, which challenge the cellular antioxidant defense system. ${ }^{33,99}$ If the antioxidant defense system is inadequate or the exercise intensity or duration is extreme, depletion of antioxidants can occur leaving reactive oxygen and nitrogen species biologically active to react with cellular tissues and resulting in a situation known as oxidative stress. ${ }^{15}$ Exercise increases metabolism and subsequently results in increased levels of free radical and reactive oxygen and nitrogen species. ${ }^{32}$ Unrepressed reactive oxygen and nitrogen species can result in cellular oxidative stress in which tissues are susceptible to oxidative damage. $^{63,102}$

\subsection{Free Radicals, Oxygen Radicals, and Nitrogen Radicals}

During resting conditions the oxygen content in arterial and venous blood of skeletal muscle tissue is 20 and $15 \mathrm{ml}$ per $100 \mathrm{ml}$ of blood, respectively; during exercise of an aerobic nature, skeletal muscle arterial-venous oxygen differences increases by 3 -fold, and skeletal muscle blood flow increases by 30 -fold. ${ }^{111}$ This large increase of blood flow during aerobic exercise is necessary to support the increase in oxygen metabolism, as indicated by the arterial-venous oxygen difference, due to increased energy consumption in the working skeletal tissue. Oxygen radicals can be produced from the metabolism of oxygen during energy production. ${ }^{63}$ When a biomolecule undergoes oxidation, it accepts an electron and is then considered to be oxidized. If the electron is unpaired, the biomolecule is considered to be a free radical. According to Pauli's 
principle, electrons should be accepted in anti-parallel fashion. Since the biomolecule dioxygen already contains two unpaired electrons in a different anti-bonding orbital, the electrons being accepted must have parallel spin to fit into the vacant orbital spaces. This imposes a restriction on dioxygen and causes it to routinely accept only one electron at a time, resulting in formation of the superoxide radical. ${ }^{46}$

The addition of a second electron to the superoxide radical results in the formation of a peroxide ion, which is not a free radical because it contains no unpaired electrons. ${ }^{46}$ This biomolecule is protonated immediately at physiological $\mathrm{pH}$, resulting in the formation of hydrogen peroxide. ${ }^{46}$ Like a peroxide ion, hydrogen peroxide cannot be considered a free radical because it does not host an unpaired electron, but it can be considered a reactive oxygen species because of its capacity to generate reactive oxygen species. ${ }^{33}$ For example, one product from Fenton's reaction between hydrogen peroxide and ferrous ion is a hydroxyl radical, which reacts with tissues causing the oxidation of membrane lipids, termed lipid peroxidation, and protein oxidation. $^{74}$

Reactive oxygen species are not the only biomolecules that interact with tissues causing lipid peroxidation and protein oxidation. Nitrogen radicals form when reactive oxygen species interact with nitric oxide to produce reactive nitrogen species. ${ }^{123}$ Reactive nitrogen species include nitrogen dioxide, and peroxynitrite. Reactive nitrogen species also react with biomolecules, causing lipid peroxidation ${ }^{126}$ and premature protein degradation due to nitrosylation. ${ }^{115}$ Thus, when reactive oxygen species accumulate there is a greater chance in the formation of reactive nitrogen species. 


\subsection{Production of Reactive Oxygen and Nitrogen Species during Exercise}

Healthy resting muscle produces low amounts of reactive oxygen species, ${ }^{91}$ which is easily handled by the antioxidant system. ${ }^{33}$ However, in conditions of disease and chronic stress, such as exercise, the antioxidant system can become overwhelmed by the accumulation of reactive oxygen species, leading to cellular damage. ${ }^{33}$ This damage may occur as a result of the oxidation of membrane lipids ${ }^{45}$ and proteins, ${ }^{115}$ which increases in exercising muscle due to the increases in free radicals. ${ }^{18}$ If the damage is excessive, a loss of muscle function may occur. ${ }^{91}$

Mitochondria are known to be a significant source of reactive oxygen species in working muscle tissue during exercise. ${ }^{21}$ Other sources of reactive oxygen species due to oxidation include myoglobin and hemoglobin. ${ }^{125}$ In addition to reactive oxygen species, reactive nitrogen species are also produced during exercise. ${ }^{40}$

\subsubsection{Reactive Oxygen Species Production}

It is postulated that the increase in oxygen demand of the skeletal muscle during acute bouts of aerobic exercise results in increased concentration of superoxide. ${ }^{39}$ Intense physical exercise results in increased free radical production from the muscle mitochondria,${ }^{74}$ which is mostly due to increased oxygen flux through the electron transport chain. ${ }^{63}$ Reactive oxygen species formation has been found to be proportional to electron transport chain activity. ${ }^{21}$ Generally oxygen is the final acceptor of two electrons at the end of the electron transport chain and 95$99 \%$ of the time is reduced to water. ${ }^{32}$ However, it actually prefers to receive one electron at a time, due to Pauli's principle requiring the incoming electrons to have parallel spin. ${ }^{46}$ Thus, the remaining $1-5 \%$ oxygen receives only one electron, ${ }^{54}$ leading to the generation of a superoxide radical ${ }^{55}$ at complex I and $\mathrm{III}^{90}$ which may result in damage to the mitochondria. ${ }^{35,74}$ This mitochondrial damage can then cause alterations in the function of the electron transport chain ${ }^{35}$ and increased oxygen loss. ${ }^{53}$ Mitochondrial damage can lead to further reactive oxygen species 
production and additional mitochondrial damage, which can contribute to an energetic decline ${ }^{35}$ as a result of the mitochondria no longer being able efficiently produce ATP due to oxygen loss. It is proposed that during exhaustive exercise, mitochondrial disruption can lead to a further loss of cell function, cell necrosis, muscle damage, and inflammation..$^{30,59,19}$

The oxidation of hemoglobin can also be a source of reactive oxygen species; about $3 \%$ of total hemoglobin undergoes auto-oxidation, resulting in the formation of superoxide. ${ }^{52}$ The oxidation of the red blood cell is of particular interest due to their concentration of polyunsaturated fatty acids and heme iron, which makes erythrocytes particularly susceptible to oxidative damage. ${ }^{113}$ Myoglobin is susceptible to both free radical oxidation and autooxidation. ${ }^{125}$ Auto-oxidation occurs when ferrous iron, present in myoglobin and hemoglobin, reacts with oxygen to form superoxide. ${ }^{125}$

\subsubsection{Reactive Nitrogen Species Production During Exercise/Interaction with Reactive Oxygen Species}

Acute exercise has been found to result in increases in reactive nitrogen species formation, specifically nitric oxide, and to alter nitric oxide synthase activity. ${ }^{104,68}$ During physical exercise, increases in blood flow and shear stress in the vascular system triggers the release of nitric oxide in order to enhance vascular function. ${ }^{92}$ It has also been proposed that nitric oxide may be influenced by repetitive muscle contractions during exercise. ${ }^{103}$ In addition to the influence of reactive oxygen species, nitric oxide may also influence the oxidant-antioxidant balance in skeletal muscle. ${ }^{103}$ It has been speculated that increases in reactive oxygen and nitrogen during aerobic exercise contributes to increased oxidative cellular damage. ${ }^{102}$

\subsection{Determining Reactive Oxygen and Nitrogen production during exercise}

The direct quantification of free radical production in response to oxidative stress is difficult to perform due to the extremely short half life of the free radical biomolecule. ${ }^{15}$ The most 
sensitive direct measure of free radical concentration is electron spin resonance spectroscopy, which is performed in conjunction with spin trapping techniques. ${ }^{121}$ This technique has been used to examine free radical concentrations in the blood of exercising humans. The results of these blood analyses demonstrate an increase in the free radical adduct, $\alpha$-phenyl-tertbutylnitrone, and consequent free radical damage as assessed by lipid peroxidation. ${ }^{8}$ However, most studies investigating the effects of cycling exercise on oxidative stress have generally used secondary measures such as free radical induced lipid and protein oxidation to estimate free radical production. ${ }^{10,89}$

Expired pentane, a possible by-product of lipid peroxidation, was one of the first measurements made to associate reactive oxygen and nitrogen damage and cycling exercise. ${ }^{22}$ The accumulation of reactive oxygen and nitrogen results in lipid peroxidation and may also contribute to cellular protein oxidation. ${ }^{17}$ An increase in protein oxidation has been observed in response to a single day of a cycling stage race that was considered to be of moderate intensity, ${ }^{14}$ indicating the presence of oxidative stress in response to a single day of cycling competition. The damage sustained by the muscle cell through this lipid and protein oxidation could contribute to altered cellular integrity and metabolism, resulting in impaired muscular performance. ${ }^{106}$

The oxidation of muscle cells is one of the processes that leads to altered protein function, but tyrosine nitration during inflammatory conditions is also linked to altered protein function. ${ }^{27}$ It is suggested that reactions between nitric oxide and reactive oxygen species result in the formation of nitrogen oxide intermediates, such as peroxynitrite, which nitrate proteins. ${ }^{123}$ Tyrosine residues found on proteins are susceptible to nitration by peroxynitrite, resulting in alteration of the physiological functions of these proteins and ultimately degradation. ${ }^{115}$ More specifically, 
peroxynitrite reacts directly with thiols, such as glutathione at its disulfide bonds, and hemoproteins at their metal centers and lipid membranes. ${ }^{99,88}$ The product of tyrosine nitration, nitrotyrosine, can therefore also be used as a marker of oxidative stress ${ }^{3,123}$ and provide an indication of the potential for oxidation of thiols and hemoproteins.

Levels of serum nitrotyrosine have been shown to rise significantly during a four-day supermarathon. ${ }^{100}$ This rise in protein nitration indicates the occurrence of oxidative stress to proteins in well-trained endurance athletes. The event was extreme in nature, in that it lasted for four consecutive days totaling $328 \mathrm{~km}$, and one might argue that an event this extreme may not relate to usual competitions in which most endurance athletes engage. With that in mind, it is necessary to point out that the levels of serum nitrotyrosine increased after the first day from 9 $\mathrm{mmol} \cdot \mathrm{L}^{-1}$ to $17 \mathrm{mmol} \cdot \mathrm{L}^{-1}$, which consisted of $93 \mathrm{~km}$ of running, where they remained for the duration of the competition. ${ }^{100}$ So, it is plausible that endurance exercise lasting only one day will still increase oxidative stress as indicated by increases in nitrotyrosine ${ }^{100}$ and markers of protein oxidation. ${ }^{14}$ Ultimately, the accumulation of the oxidative damage is relative to the collective success of the antioxidant and muscle repair systems, ${ }^{101}$ training status, ${ }^{82,96}$ and intensity of the exercise. ${ }^{49}$

\subsection{Antioxidants Fluctuations, Cell Damage, and Oxidative Stress}

The antioxidant defense system is the body's endogenous defense mechanism that can neutralize reactive oxygen and nitrogen species $^{64}$ and attenuate reactive oxygen and nitrogen species induced oxidative damage. Oxidative stress results when the antioxidant system is overloaded and can no longer neutralize the concentration of reactive oxygen and nitrogen species being produced. ${ }^{64,13}$ In a state of oxidative stress, reactive species are not controlled and spontaneous reactions of reactive oxygen and nitrogen species with other oxygen, nitrogen, and 
sulfur species occurs and causes a cascade of free radical formation, ${ }^{33}$ which exhausts the antioxidant defense system and leads to muscle cell ${ }^{96}$ and red blood cell damage. ${ }^{113,116,117}$ Thus, when the antioxidant defense system is inadequate, damage can occur that might result in decreased endurance performance due to muscle tissue loss and decreased capacity to transport oxygen. Although not directly indicative of tissue damage, a popular technique for determining oxidative stress includes measurement of antioxidant concentration fluctuations because changes in the concentration of antioxidants can point to impairment in the antioxidant defense system. ${ }^{94}$ The antioxidant defense system consists of enzymatic (endogenous in origin) and non-enzymatic (exogenous in origin) antioxidants, ${ }^{98}$ and it is usually the exogenous antioxidants that are susceptible to deficiency. ${ }^{63}$

\subsubsection{Non-Enzymatic Antioxidants: Ascorbic Acid and $\alpha$-Tocopherol}

Some of the non-enzymatic, exogenous antioxidants include ascorbic acid and $\alpha-$ tocopherol. ${ }^{33}$ Ascorbic acid is known to scavenge free radicals in the aqueous phases of cells and in the circulatory system, as well as to protect cell membranes from oxidative damage. ${ }^{9}$ It has been demonstrated that supplementation with ascorbic acid attenuates the release of creatine kinase after muscle-damaging eccentric exercise. ${ }^{13}$ It is plausible that ascorbic acid decreases oxidative stress by scavenging reactive oxygen species or by regenerating the antioxidant form of $\alpha$-tocopherol ${ }^{9}$ to result in the decreased muscle damage.

Endurance-trained cyclists who were supplemented with ascorbic acid for a period of two weeks, and after 2.5 hours of cycling at $60 \% \mathrm{VO}_{2 \max }$ demonstrated no reduction in oxidative stress, as indicated by markers of lipid peroxidation. This suggests that ascorbic acid supplementation alone is ineffective at reducing oxidative stress. ${ }^{19}$ However, interpretation of this data must be taken with caution. Cycling at $60 \% \mathrm{VO}_{2 \max }$ may not be of adequate intensity to 
invoke oxidative stress and is therefore not ideal for determining beneficial effects of antioxidant supplementation on oxidative stress that might be seen in response to competition or high intensity training. This contention may be supported by the fact that the authors were unable to report significant differences in levels of oxidative stress in response to the cycling bout during the treatment or placebo intervention. ${ }^{19}$ Without invoking oxidative stress during the exercise, it is difficult to determine the effect of supplementing with ascorbic acid on oxidative stress during cycling.

A similar study design was employed to investigate the effects of coupled ascorbic acid and $\alpha$ -tocopherol supplementation on oxidative stress in response to cycling. ${ }^{20}$ This protocol consisted of consumption of the antioxidants or placebo for four weeks and investigated the oxidative stress response to 2.5 hours of cycling at $60 \% \mathrm{VO}_{2 \max }$ in recreationally active males. The determining measures of oxidative stress were indicators of lipid peroxidation, $\mathrm{F}_{2^{-}}$ isoprostanes and thiobarbituric acid reactive substances. Results indicate an increase in $\mathrm{F}_{2}$ isoprostanes after exercise but no difference in the increases between treatment groups. The thiobarbituric acid reactive substances did show an alteration due to the supplementation, which resulted in a significant decrease in thiobarbituric acid reactive substances after the exercise versus the placebo group. The authors conclude that although a decrease in thiobarbituric acid reactive substances was observed as a result of supplementation, there was no conclusive evidence between the two measures to suggest that oxidative stress was attenuated as a result of the supplementation protocol. ${ }^{20}$

It is likely that the cycling protocol was not of a high enough intensity to induce oxidative stress. The intensity used is not comparable to the intensities observed during actual competitive cycling. Cycling intensities encountered during competitions are $\geq 75 \% \mathrm{VO}_{2 \max },{ }^{31}$ a higher 
intensity than what was used in this study. Therefore it is difficult to conclude that the combination of ascorbic acid and $\alpha$-tocopherol supplementation would not make a difference in reducing oxidative stress during a cycling competition.

However, data exists that suggests $\alpha$-tocopherol is an important antioxidant in maintaining endurance performance. It has been demonstrated that rested $\alpha$-tocopherol deficient animals exhibit similar concentrations of free radicals and lipid peroxidation as exercise-exhausted animals. ${ }^{18}$ During exercise, the $\alpha$-tocopherol deficient animals exhibited a $40 \%$ lower endurance capacity than non-deficient controls. ${ }^{18}$ Thus, an increase in lipid peroxidation, as seen during oxidative stress conditions, may contribute to decreased endurance capacity.

Supplementation with ascorbic acid has also been demonstrated to prevent increases in oxidative stress during exercise. The attenuation of the increase in the ratio of blood oxidized glutathione to total glutathione, an indicator of oxidative stress, was reported during muscledamaging exercise as indicated by increases in concentrations of creatine kinase. ${ }^{13}$ Endurance exercise at the intensities encountered during competitive cycling are known to significantly increase creatine kinase. ${ }^{42}$ Thus, it appears that antioxidant Vitamins $\mathrm{C}$ and $\mathrm{E}$ are important in endurance capacity by decreasing oxidative stress, leading to attenuation of oxidative tissue damage.

\subsubsection{Non-Enzymatic Antioxidant: Glutathione}

The non-enzymatic antioxidant reduced glutathione is relevant to oxidative stress. ${ }^{87}$ Reduced glutathione is able to protect cells from the toxic effects of reactive oxygen species by detoxification of reactive oxygen species and reactive oxygen species products (i.e. peroxides) ${ }^{87}$ and is used by glutathione peroxidase to neutralize hydrogen peroxide, resulting in the formation of oxidized glutathione. ${ }^{87}$ Reduced glutathione is considered the most important non-enzymatic 
antioxidant found in erythrocytes. Blood reduced glutathione concentrations are generally between $800-2000 \mu \mathrm{M},{ }^{28,29,66}$ and oxidized glutathione concentrations vary depending on free radical induced oxidative stress but have been found to be between $2.0-800 \mu \mathrm{M}^{28,29,66}$ Concentrations also vary depending on the subject's level of training, ${ }^{71}$ nutritional intake,,${ }^{51,66}$ as well as in response to different types of exercise intensities ${ }^{34,49}$ and durations of exercise. ${ }^{24,26,37}$ Training increases the basal reduced glutathione concentration in the blood ${ }^{28}$ thereby providing increased protection against oxidative species during exercise. It has been reported that fluctuations in the glutathione antioxidant system are sensitive to exercise intensities, with greater intensities resulting in greater decreases in reduced glutathione. ${ }^{34}$

Under conditions of oxidative stress, a consistent determining marker is blood glutathione oxidation. ${ }^{112}$ A decrease in the reduced glutathione/oxidized glutathione ratio and total gluthation concentration is routinely shown in the blood of exercising humans, ${ }^{28,29,37,71,118}$ while oxidized glutathione/total glutathione increases. ${ }^{13,108}$ This indicates an increase in oxidized glutathione, while the reduced glutathione is decreased, which occurs as glutathione reacts with reactive oxygen and nitrogen and attenuates further increases in reactive oxygen and nitrogen species that could result in oxidative stress.

\subsubsection{Glutathione and Cycling}

Research indicates that cycling at $65 \% \mathrm{VO}_{2 \max }$ for 90 minutes over three consecutive days in moderately trained subjects can decrease the reduced glutathione/oxidized glutathione ratio during the bout of cycling. ${ }^{124}$ This reduction in reduced glutathione/oxidized glutathione ratio appears to rebound back to pre-exercise levels within 15 minutes after cessation of exercise. This rapid rebound is due to the recycling nature of the glutathione antioxidant system. Oxidized glutathione reacts with NADPH to reform reduced glutathione. Measuring the reduced 
glutathione/oxidized glutathione ratio level chronically over the consecutive days did not result in any significant deviations from baseline. Thus, there appears to be no cumulative effective on the reduced glutathione/oxidized glutathione ratio level, making it ideal to examine acute exercise induced oxidative stress in trained cyclists. ${ }^{124}$ Cycling at $65 \% \mathrm{VO}_{2 \max }$ can result in oxidative stress but does not result in increased oxidative damage, as assessed by RNA damage. The authors conclude that although oxidative stress occurs during submaximal prolonged endurance cycling, the stress encountered does not have any cumulative effects. ${ }^{124}$

In another study, cycling at $65 \% \mathrm{VO}_{2 \max }$ for 90 minutes in moderately trained subjects resulted in a $60 \%$ decrease in reduced glutathione and a $100 \%$ increase in oxidized glutathione concentrations when compared to non-exercise levels. ${ }^{37}$ Although these exercise models did induce oxidative stress, they do not model intensities that competitive endurance cyclists usually encounter during high intensity training or competition, making it difficult to determine if oxidative damage results from oxidative stress during high intensity cycling.

Intensities of greater than $75 \% \mathrm{VO}_{2 \max }$ are reported for 93 minutes on typical flat stages and 123 minutes during hilly stages of a competitive professional stage race. ${ }^{31}$ These intensities and time frames are reported from cycling competitions that engage the world's best cyclists, so it is unlikely that researchers will have access to athletes that are able to reproduce these exact intensities for a similar period of time. It seems appropriate to reproduce these intensities because oxidative stress is increased with increases in exercise intensities as determined by the glutathione antioxidant system. ${ }^{34}$ Thus, it is important to define at intensities of $75 \% \mathrm{VO}_{2 \max }$ or greater. 


\subsubsection{Glutathione's Synergistic Effect}

Glutathione is considered to be a key antioxidant due to its ability to detoxify reactive oxygen species directly and enhance the function of other exogenous antioxidants, such as ascorbic acid and $\alpha$-tocopherol. ${ }^{43,84}$ Enhancing the reduced glutathione concentration in cells may increase their resistance to oxidative damage. ${ }^{87}$ Mitochondrial oxidative damage has been associated with muscle degeneration in reduced glutathione depleted animals; ${ }^{83}$ as such, a cellular deficiency of reduced glutathione can be associated with oxidative damage. The administration of ascorbic acid and $\alpha$-tocopherol in a reduced glutathione deficient state results in attenuation of cellular damage ${ }^{114}$ which demonstrates the cooperative effectiveness of the exogenous antioxidants and the importance of reduced glutathione in preventing oxidative damage. Therefore, one could reason that the administration of not one but many exogenous antioxidants would result in greater attenuation of oxidative stress-induced damage, possibly through maintenance of the glutathione antioxidant system during acute exercise. During induced overtraining in trained triathletes the basal concentration of reduced glutathione was actually increased in response to antioxidant supplementation with ascorbic acid, $\alpha$-tocopherol, and selenium. ${ }^{96}$ Furthermore, reduced glutathione is a very important molecule to the cell in that it prevents oxidative damage but also in regulation of redox-sensitive tissue signal transduction. ${ }^{111}$

\subsection{Reactive Oxygen and Nitrogen Species and Signal Transduction}

Although most of the research on reactive oxygen and nitrogen species has focused on the deleterious effects associated with disease and tissue damage, ${ }^{102}$ reactive oxygen and nitrogen species have also been shown to regulate an increasing number of signal transduction pathways. ${ }^{91}$ During exercise the increase in reactive oxygen and nitrogen species could induce adaptive mechanisms involving antioxidant and repair systems. ${ }^{102}$ Regulatory elements such as kinases, phosphatases, and transcription factors appear to be redox-sensitive. Fluctuating 
concentrations of reactive oxygen and nitrogen species exert effects on cell signaling pathways through these regulatory mechanisms, which can alter gene expression and muscle adaptation. ${ }^{91}$

Oxidative stress-sensitive signal transduction pathways include the nuclear factor (NF) $\kappa \mathrm{B}$ and mitogen-activated protein kinases (MAPKs). MAPKs are involved in cell functions that include cellular growth, proliferation, and adaptation. NF- $\mathrm{B}$ activation by reactive oxygen and nitrogen species signals for enhanced gene expression of important antioxidant enzymes (e.g. mitochondrial superoxide dismutase) due to NF- $\mathrm{B}$ binding sites in these gene promoter regions. Furthermore, acute treadmill running ( $58 \pm 7$ minutes) in animals results in significant increases in the protein levels of extracellular signal-regulated kinases (ERK) 1/ERK2 and p38 MAPK in the upstream NF- $\mathrm{B}$ signaling pathway, providing further support that reactive oxygen and nitrogen species are involved in activating MAPK. This is evident when the administration of allopurinol abolishes production of reactive oxygen and nitrogen species, ultimately attenuating the phosphorylation of these enzymes and resulting in decreased ERK1/ERK2 and p38 MAPK protein levels. ${ }^{65}$ This demonstrates that reactive oxygen and nitrogen species are important in cellular adaptations that signal for enhanced antioxidant defenses and muscle adaptation.

Furthermore, NF- $\kappa$ B activation is also sensitive to intracellular thiol redox status. Low levels of cytosolic oxidized glutathione are associated with diminished activation of NF- $\mathrm{B}$. On the contrary, high oxidized glutathione or low reduced glutathione concentrations inhibit the binding site of activated NF- $\kappa$ B to antioxidant gene promoter regions. Subsequently, either condition is limiting appropriate signals that would result in upregulation of antioxidant defenses. This highlights the concept that there seems to be an intermediate, ideal, intracellular concentration of oxidized glutathione needed to facilitate effective NF- $\mathrm{B}$ activation. ${ }^{23,111}$ This is important when considering the use of antioxidants during exercise and their effects on the glutathione 
antioxidant system. It could be reasoned that cellular adaptations will be blunted if treatment with antioxidants results in extremely low levels of oxidized glutathione. But, if too high of a concentration of reactive oxygen and nitrogen species results from a cascade of free radicals during exercise-induced oxidative stress, copious amounts of reduced glutathione will be oxidized to oxidized glutathione, resulting in inhibition of the appropriate cellular signals that are necessary to increase the antioxidant defense system. Therefore, it is ideal to examine the glutathione antioxidant system when investigating the effects of antioxidant supplementation.

Although it appears an ideal physiological level is necessary for desirable signaling events the specific concentrations have not been reported. Cellular research leading to this hypothesis of an ideal concentration is based on the administration of buthionine sulfoximine to deplete reduced glutathione and pyrrolidinedithiocarbamate to replenish reduced glutathione. ${ }^{111}$ The actual concentration of reduced glutathione or oxidized glutathione was not measured.

\subsection{Efficacy of antioxidant supplementation}

The efficacy of antioxidant supplementation is currently in question due to the concept that attenuation of reactive oxygen and nitrogen species by antioxidant quenching mechanisms will result in diminished cellular adaptations that are seen to be beneficial to oxidant-antioxidant homeostasis. ${ }^{65}$ However, long-term supplementation of six weeks has resulted in improvement in cycling time trial performance. ${ }^{81}$ It is conceptualized that antioxidant supplementation will reduce oxidative stress and oxidative stress-associated muscle damage, though research in this area provides varying results. ${ }^{69}$ An underlying reason for discrepancies in the literature could be a result of the exogenous antioxidant intake by the subjects independent of the

supplementation. ${ }^{39}$ There exists a delicate balance between reactive oxygen and nitrogen species eliciting adaptation and reactive oxygen and nitrogen species resulting in accumulation of 
oxidants. For individuals who engage in high-intensity aerobic exercise, antioxidant supplementation may provide a larger protective margin against the detrimental effects of reactive oxygen and nitrogen species. ${ }^{63}$

Cyclists routinely engage in high-intensity aerobic exercise during training and competitions. ${ }^{31}$ Additionally, competitive cyclists must maintain a low body weight by decreasing caloric intake to achieve maximal relative power measures. This is imperative when evaluating uphill cycling performance where a gain of 3 kilograms of body weight could decrease performance by 1:15 (minutes:seconds) during a 20 kilometer time trial on a $6 \%$ grade ${ }^{61}$ Complicating the matter further is the fact the cyclists burn a huge number of kilocalories, approximately 500 per hour depending on intensity, and without supplementation can have inadequate nutritional intake of antioxidants during days of intense competition. ${ }^{107}$ Even though some adaptation of the antioxidant systems can occur, ${ }^{102}$ the adaptations may not be adequate to prevent oxidative damage in a nutrient-deficient state. ${ }^{97}$ Thus a nutritional supplement that provides antioxidants and energy does seem to be ideal for some endurance athletes. ${ }^{80,63}$

\subsection{Antioxidant and Energy Substrate Supplementation}

Using a two day protocol $\left[75 \% \mathrm{VO}_{2 \text { peak }}\right.$ for Day $1,85 \% \mathrm{VO}_{2 \text { peak }}$ Day 2$]$ in 15 male cyclists $\left(\mathrm{VO}_{2 \max } 52.6 \pm 10.3 \mathrm{ml} \cdot \mathrm{kg}^{-1} \cdot \mathrm{min}^{-1}\right)$, researchers demonstrated that time to fatigue can be increased by $29 \%$ for the first ride and by $40 \%$ for the subsequent ride with the consumption of a carbohydrate + protein drink compared to carbohydrate only. This finding could possibly be due to the higher caloric content of the carbohydrate + protein beverage used in the study. The carbohydrate + protein beverage contained $25 \%$ more calories than the carbohydrate beverage, 4:1 carbohydrate:protein, $7.3 \%$ carbohydrate and $1.8 \%$ protein. The beverage was consumed 
every 15 minutes during the cycling bout $\left(1.8 \mathrm{ml} \cdot \mathrm{kg}^{-1}\right)$ and immediately after $\left(10 \mathrm{ml} \cdot \mathrm{kg}^{-1}\right) .{ }^{109}$ Although the performance data from this study could be due to higher energy content, another relevant finding was a decrease in creatine kinase levels. The concentration of creatine kinase was $83 \%$ lower when comparing the post-exercise values between carbohydrate + protein and carbohydrate $\left(216.3 \pm 122.0\right.$ versus $\left.1318.1 \pm 1935.6 \mathrm{U} \cdot \mathrm{L}^{-1}\right) .{ }^{109}$ Thus, consumption of a beverage with carbohydrate + protein during and after cycling seems to attenuate muscle damage resulting in improved performance.

Using a similar study design, the same group examined the effect of a carbohydrate + protein gel versus carbohydrate gel on performance in 8 male and 5 female cyclists $\left(\mathrm{VO}_{2 \text { Peak }}=57.9 \mathrm{ml} \cdot \mathrm{kg}\right.$ $\left.{ }^{1} \cdot \mathrm{min}^{-1}\right)$. In this study the cyclists rode $13 \%$ longer with the carbohydrate + protein gel $(116.6 \pm$ 28.5 minutes $)$ versus the carbohydrate gel (102.8 \pm 25.0 minutes $)$. The supplement design maintained a 4:1 carbohydrate:protein ratio. Again, the supplements were matched for carbohydrate concentration and the carbohydrate + protein had a higher caloric content, which may have accounted for part of the performance difference seen between treatments. The gels both contained $0.15 \mathrm{~g} \cdot \mathrm{kg}^{-1}$ of carbohydrate, and the carbohydrate + protein gel also contained $0.038 \mathrm{~g} \cdot \mathrm{kg}^{-1}$ of protein. The creatine kinase levels were increased after exercise for both treatments, but the increase was only significant for the carbohydrate treatment. ${ }^{110}$ Thus, the carbohydrate + protein gel may have attenuated muscle damage, which lead to improvements in performance.

These studies demonstrate that the use of a supplement containing both carbohydrate and protein can decrease markers of muscle damage. The addition of extra calories in the form of protein seems to prolong exercise to exhaustion, and this performance improvement is enhanced over subsequent days. A longitudinal study comparing the effects of isocaloric carbohydrate and 
carbohydrate + protein supplements in two groups of cyclists matched for performance could provide the answer as to whether there are any benefits of using a carbohydrate + protein beverage or gel to decrease creatine kinase levels. One could reason that a reduction in muscle damage between bouts of fatiguing exercise could decrease recovery time leading to a higher training volume and intensity. This increase in training quality could ultimately lead to measurable improvements in performance.

Recent research ${ }^{109}$ reports a decrease in muscle damage from the use of a carbohydrate + protein beverage versus carbohydrate only, suggesting that this decrease in muscle damage should lead to performance maintenance in subsequent rides. This lead to the examination of the effects of two different isocaloric drink supplements, carbohydrate-protein-antioxidants versus carbohydrate, on cycle ergometry to fatigue in 14 moderately fit male cyclists $\left(\mathrm{VO}_{2 \mathrm{Max}}=59.8 \pm\right.$ $\left.11.9 \mathrm{ml} \cdot \mathrm{kg}^{-1} \cdot \mathrm{min}^{-1}\right) \cdot{ }^{105}$ Cyclists underwent two rides to fatigue, one at $70 \% \mathrm{VO}_{2 \text { peak }}$ on day 1 and another at $80 \% \mathrm{VO}_{2 \text { peak }}$ on day 2 (22-24 hours later) to examine the effects of the supplements on performance during subsequent fatiguing rides. This protocol was also chosen to mimic day-today training and dietary practices that are common in competitive cyclists. Blood samples were drawn for determination of plasma lactate dehydrogenase at baseline and $72 \mathrm{~h}$ after the first bout of fatiguing exercise and for plasma creatine kinase at baseline and 24 hours after the first exercise bout. These sampling points were chosen because the examined measures should exhibit peak concentrations at these time points. ${ }^{105}$ The supplements consisted of a 12 ounce beverage to be consumed during the exercise [carbohydrate-protein-antioxidants: $139 \mathrm{kcal}, 7.5 \%$ carbohydrate, $1.8 \%$ protein, $200 \%$ RDA for Vitamins C and E; carbohydrate: $140 \mathrm{kcal}, 12 \mathrm{oz}$, $9.3 \%$ carbohydrate] and another 12 ounce beverage of higher nutrient density to be consumed immediately after the exercise [carbohydrate-protein-antioxidants: $277 \mathrm{kcal}, 15 \%$ carbohydrate, 
3.6\% protein, $1330 \%$ RDA for $\alpha$-tocopherol , 780\% RDA for ascorbic acid; carbohydrate: 277 kcal, $18.6 \%$ carbohydrate]. There was no difference in performance between the carbohydrate and carbohydrate-protein-antioxidants according to the total performance time $(138.1 \pm 39.3$ versus $140.9 \pm 43.7$ minutes). However, the concentration of creatine kinase revealed a significant attenuation of muscle damage when comparing baseline versus 24 hours with the carbohydrate-protein-antioxidants supplement $\left(187.5 \pm 119.0\right.$ versus $\left.272.9 \pm 169.4 \mathrm{U} \cdot \mathrm{L}^{-1}\right)$ when compared to the carbohydrate supplement $\left(202.6 \pm 120.0\right.$ versus $\left.582.0 \pm 474.9 \mathrm{U} \cdot \mathrm{L}^{-1}\right)$. Lactate dehydrogenase was significantly elevated at 72 hours after the first bout of exercise in the carbohydrate versus carbohydrate-protein-antioxidants $\left(495.1 \pm 63.7 \mathrm{U} \cdot \mathrm{L}^{-1}\right.$ versus $450.7 \pm 43.1$ $\left.\mathrm{U} \cdot \mathrm{L}^{-1}\right) \cdot{ }^{105}$

Increased creatine kinase and oxidative stress have been associated with triathletes during induced overreaching. These athletes presented with higher creatine kinase values at rest and in response to a duathlon test after four weeks of overreaching. ${ }^{96}$ Oxidative stress was shown to increase in response to the overreaching as indicated by decreases in the reduced glutathione/oxidized glutathione ratio, which was reduced further in response to a cycling and running duathlon test. ${ }^{96}$ Thus, it appears that increased levels of muscle damage occur in conjunction with oxidative stress. This study also demonstrates that in times of increased training stress, specifically induced overreaching, the antioxidant system may not adequately adapt, leaving the body susceptible to oxidative damage.

In a similar study of induced overreaching in triathletes, antioxidant supplementation with selenium $\left(150 \mu \mathrm{g} \cdot\right.$ day $\left.^{-1}\right)$, retinyl acetate $\left(1 \mathrm{mg} \cdot \mathrm{day}^{-1}\right)$, ascorbic acid $\left(120 \mathrm{mg} \cdot \mathrm{day}^{-1}\right), \alpha$-tocopherol $\left(1 \mathrm{mg} \cdot \mathrm{day}^{-1}\right)$ enhanced the glutathione antioxidant systems adaptations. The level of reduced glutathione increased significantly during overreaching in the supplemented group. Furthermore, 
creatine kinase was attenuated in the supplemented group in response to the duathlon test. It is important to note that these athletes did present with inadequate antioxidant nutritional intake

prior to supplemenatation. ${ }^{97}$ So, it appears that in athletes with deficient exogenous antioxidant intake, supplementation can enhance the adaptations of the endogenous glutathione antioxidant system during periods of induced overreaching and result in attenuation of muscle damage in response to a mock competitive event. The increases in reduced glutathione levels provide an extra level of protection against exercise-induced oxidative injury.

There is evidence that consumption of antioxidant energy substrate cocktail increases endurance performance. The cycling protocol engaged trained cyclists in a maximal effort 30 $\mathrm{km}$ time trail. After supplementation for 6 weeks the test group demonstrated a 3\% increase in performance. ${ }^{81}$ This could have been due to a reduction in muscle damage, alterations in the endogenous antioxidant systems, or an increase in exogenous antioxidant consumption.

For an overview of relevant supplement studies according to ingredients in the planned treatment intervention refer to Table 1 in appendix D.

\subsection{Cycling Performance}

Cycling is a dynamic sport, and currently no one laboratory measure predicts the best competition performer out of a group. Many direct and indirect methods exist to determine aerobic endurance performance capacity. ${ }^{11}$ One measure of aerobic capacity uses a graded exercise test to determine $\mathrm{VO}_{2 \max }$. This measure provides a good indication of the capacity of the cardiovascular system and is sometimes referred to as maximal aerobic power. ${ }^{75}$ Maximal aerobic power is of some importance to cyclists, but many other variables also contribute to cycling performance in addition to $\mathrm{VO}_{2 \max }$, such as skeletal muscle adaptations and alterations in fuel metabolism. ${ }^{48}$ 
The discussion of performance in cycling should consider aerobic endurance capacity and the ability to cycle at a high percentage of $\mathrm{VO}_{2 \max }$ for a prolonged duration. ${ }^{11}$ But many factors contribute to a cyclist's success; power-to-weight ratio and power production at lactate threshold $(\mathrm{LT})^{16}$ are also important factors. Furthermore, the cyclist's economy is relative to the power that can be sustained at a given percentage of the $\mathrm{VO}_{2 \max },{ }^{67}$ which is related to the cyclist's LT.

Another indicator of performance is the ventilatory threshold (VT) determined by breakpoint of ventilatory equivalent of oxygen or carbon dioxide $\left(\mathrm{VE} / \mathrm{VO}_{2}\right.$ or $\left.\mathrm{VE} / \mathrm{VCO}_{2}\right)$ and respiratory exchange ratio (RER). ${ }^{4}$ The VT has been identified as being accurate in predicting cycling 40 kilometer time trial performance. ${ }^{4}$ Furthermore, LT is correlated with performance but is not representative of race pace for cycling time trials. ${ }^{70}$ During a simulated 20 kilometer time trial, cyclists were able to ride at intensities greater than their predicted LT of $2 \mathrm{mmol} \cdot \mathrm{L}^{-1}$ above baseline, as determined during a graded max test, for over 30 minutes. ${ }^{70}$ It must also be emphasized that motivational and psychological factors can contribute to a cyclist's athletic performance, and there is currently no test to determine the contribution of these factors to performance. Therefore, there is no scientific method that totally examines the performance of a competitive cyclist in the lab. ${ }^{67}$

During competition, cycling requires the athlete to maintain high intensities for prolonged durations. ${ }^{31}$ This fact is best represented by the analysis of an individual time trial where competitive cyclists spend an average of 20 minutes at $>90 \% \mathrm{VO}_{2 \mathrm{Max}} \cdot{ }^{31}$ Additionally, it has been reported that the winner of an individual time trial during the Tour de France cycled at $>90 \%$ $\mathrm{VO}_{2 \mathrm{Max}}$ for 70 minutes. ${ }^{77}$ Thus, intensities taken from actual cycling competitions can be reproduced in the testing laboratory to simulate realistic racing conditions. In previous studies, cycling during a 30 minute time trial in the laboratory setting resulted in a heart rate that was 
consistently $90 \%$ of max. ${ }^{25}$ Furthermore, it had been reported that heart rate at the onset of blood lactate (OBLA) and power output at a fixed blood lactate level of $4 \mathrm{mmol} \cdot \mathrm{L}^{-1}$ is similar to the heart rate achieved during performance of approximately 10-39 minutes in elite cyclists. ${ }^{95}$

The analysis of cross-country mountain bike competitions reveals similar intensities as during competitive road cycling time trials. ${ }^{50}$ The cross-country cyclists spent $31 \%$ of the mountain bike competitions above OBLA. The average heart rate during 5 competitive cross-country races averaged out to be $90 \%$ of HRmax for 147 minutes. ${ }^{50}$ Thus, cycling at high intensities is welldocumented during both mountain bike competitions and road cycling time trials.

The classification of the athletes' performance level may also be a contributing factor to the difficulty in drawing comparisons between studies. ${ }^{60}$ A non-systematic approach of quantifying performances has lead to some confusion among outcome measures during cycling studies. Thus, performance classifications such as "elite" have variable meanings between colleagues, making comparisons among studies unreliable. In 2000, a unified classification system was

proposed by Jeukendrup et al. ${ }^{60}$ that allows for the universal comparison of cycling research. Using this systematic approach for classification of the cyclists' level of performance will allow data to be compared across multiple publications. Thus, the systematic approach including both performance measures and quantification of training and racing history ${ }^{60}$ allows for better classification of a cyclist's actual performance level.

\subsection{Appropriate protocol for examining nutritional intervention}

The use of test/re-test protocols during cross-over study designs to measure the effect of supplementation and training implementation on performance is widely accepted. ${ }^{105,109,110}$ However, just because a test offers some measure of performance (i.e. $\mathrm{VO}_{2 \max }$ or LT) does not mean that improvements in test performance will translate to competitive performances, or that 
the athlete has improved at all. It could simply be that the athlete has improved performance during the test due to increased motivation or due to familiarization with the test protocol during previous testing procedures. Tests must be reliable and validated, and the athlete must be familiarized with the test prior to performance data is collected.

One of the most reliable methods of determining improvements in cycling performance is to first provide the athlete with a preliminary familiarization ride where the subject is preloaded with a set time and work rate (i.e. 45 minutes at $70 \%$ maximal power output). The cyclist subsequently undergoes a work time trial at simulated race pace, performing as much work as possible within a pre-set amount of time (i.e. 15 minutes) normally at intensities of $\sim 90 \%$ HRmax, which is similar to those encountered during competitive cycling competitions. ${ }^{29,74,25 \text {, }}$ 95, 50 During the treatment period, the actual testing protocol includes the preload, followed by a timed bout reaching the previously determined amount of work that was completed in the final 15 minutes during the familiarization ride ${ }^{58}$ This preload+time trial technique is a reliable test/retest protocol, as indicated by a coefficient of variance of $3.49 \%{ }^{58}$

Another consideration is the familiarity of the cyclists to the testing protocol. Usually the more familiar the cyclist becomes with the test, the better his performance will be ${ }^{58,73} \mathrm{~A}$ control used to minimize this problem is the familiarization ride. The cyclist will complete the testing protocol without any treatment intervention (i.e. a preliminary ride). This ride will act as the learning curve so that under the treatment conditions that athlete will have already experienced the test. The cyclist will then repeat the protocol under the treatment or placebo conditions for an actual measure of performance. ${ }^{73}$ 


\subsection{Limitations in Current Supplement Research}

Some limitations of the above research reviewed include variability in the duration of fasting prior to the bout of exercise, the control of outside diet and exercise, and time between administrations of the treatment or placebo in the crossover designs (washout periods). Generally the literature reports recovery/washout periods varying in length of time, from 6-14 days ${ }^{110,109,} 105$ between treatment trials. This variable length of time can make it difficult when analyzing data from different studies. When comparing dietary and training controls, some studies report that athletes had limited food intake for four hours prior to testing sessions, but failed to report any control over exercise outside of the study. ${ }^{105}$ Furthermore, other studies do not report any control over the diet or exercise outside of the study, ${ }^{109}$ yet others report dietary control for 24 hours prior to testing and exercise limitations for 48 hours prior to testing. ${ }^{110}$ Training and food intake should be documented in the event that a study administers a cross-over design and analysis should be performed to determine if there existed any difference prior to the testing sessions. In the event that a difference is found in training or diet prior to the trials the subjects data must be eliminate or test re-administered. An ideal research design should examine the effect of supplementation in a manner which is consistent with the typical training practices of athletes. These include hard and light days of training and familiarity with the standardized guidelines prior to data collection. In addition, the diet should be what the athlete regularly consumes for the duration of the study with controlled intake 12-24 hours prior to the exercise trial. Furthermore, this method could in turn promote accurate record keeping among the athletes in the study by allowing them to train without restrictions, as long as they train similarly prior to all testing and experiment protocols. This method does include some guidelines, such as only light exercise 48 hours prior to testing and refraining from exercise 24 hours prior to testing. 
Another limitation of these studies is the testing protocol. Although one commonly used method to measure alterations in performance is cycling until exhaustion at a pre-determined intensity level, ${ }^{110,109,105}$ this method is not appropriate for practical application in athletes. ${ }^{122}$ Exercise time-to-fatigue is a poor measure for the analysis of cycling performance because the athlete very rarely engages in this type of activity. However, fixed distance time trials closely simulate training practices and/or racing events. ${ }^{58}$ Overall, it is difficult to compare data collected on supplement studies because the protocols between studies vary for recalling exercise and diet prior to testing and inappropriate performance protocols, like exercise to exhaustion. 


\subsection{References}

1. Abel, T., B. Knechtle, C. Perret, P. Eser, P. von Arx, and H. Knecht. Influence of chronic supplementation of arginine aspartate in endurance athletes on performance and substrate metabolism - a randomized, double-blind, placebo-controlled study. Int J Sports Med. 26:344-349, 2005.

2. Aguilo, A., P. Tauler, A. Sureda, N. Cases, J. Tur, and A. Pons. Antioxidant diet supplementation enhances aerobic performance in amateur sportsmen. J Sports Sci. 25:1203-1210, 2007.

3. Ahn, E. S., C. L. Robertson, V. Vereczki, G. E. Hoffman, and G. Fiskum. Normoxic ventilatory resuscitation following controlled cortical impact reduces peroxynitritemediated protein nitration in the hippocampus. J Neurosurg. 108:124-131, 2008.

4. Amann, M., A. W. Subudhi, and C. Foster. Predictive validity of ventilatory and lactate thresholds for cycling time trial performance. Scand J Med Sci Sports. 16:27-34, 2006.

5. Applegate, E. Effective nutritional ergogenic aids. Int J Sport Nutr. 9:229-239, 1999.

6. Applegate, E. A.andL. E. Grivetti. Search for the competitive edge: a history of dietary fads and supplements. J Nutr. 127:869S-873S, 1997.

7. Ashton, T.,I. S. Young,G. W. Davison, et al. Exercise-induced endotoxemia: the effect of ascorbic acid supplementation. Free Radic Biol Med. 35:284-291, 2003.

8. Ashton, T.,I. S. Young,J. R. Peters, et al. Electron spin resonance spectroscopy, exercise, and oxidative stress: an ascorbic acid intervention study. J Appl Physiol. 87:2032-2036, 1999. 
9. Beyer, R. E. The role of ascorbate in antioxidant protection of biomembranes: interaction with vitamin E and coenzyme Q. J Bioenerg Biomembr. 26:349-358, 1994.

10. Bloomer, R. J., P. G. Davis, L. A. Consitt, and L. Wideman. Plasma protein carbonyl response to increasing exercise duration in aerobically trained men and women. Int $J$ Sports Med. 28:21-25, 2007.

11. Bosquet, L., L. Leger, and P. Legros. Methods to determine aerobic endurance. Sports Med. 32:675-700, 2002.

12. Broad, E. M., R. J. Maughan, and S. D. Galloway. Effects of four weeks L-carnitine Ltartrate ingestion on substrate utilization during prolonged exercise. Int J Sport Nutr Exerc Metab. 15:665-679, 2005.

13. Bryer, S. C.andA. H. Goldfarb. Effect of high dose vitamin C supplementation on muscle soreness, damage, function, and oxidative stress to eccentric exercise. Int J Sport Nutr Exerc Metab. 16:270-280, 2006.

14. Cases, N.,A. Sureda,I. Maestre, et al. Response of antioxidant defences to oxidative stress induced by prolonged exercise: antioxidant enzyme gene expression in lymphocytes. Eur J Appl Physiol. 98:263-269, 2006.

15. Cooper, C. E., N. B. Vollaard, T. Choueiri, and M. T. Wilson. Exercise, free radicals and oxidative stress. Biochem Soc Trans. 30:280-285, 2002.

16. Coyle, E. F. Physiological determinants of endurance exercise performance. J Sci Med Sport. 2:181-189, 1999.

17. Davies, K. J.andA. L. Goldberg. Proteins damaged by oxygen radicals are rapidly degraded in extracts of red blood cells. J Biol Chem. 262:8227-8234, 1987. 
18. Davies, K. J., A. T. Quintanilha, G. A. Brooks, and L. Packer. Free radicals and tissue damage produced by exercise. Biochem Biophys Res Commun. 107:1198-1205, 1982.

19. Davison, G.andM. Gleeson. The effect of 2 weeks vitamin C supplementation on immunoendocrine responses to $2.5 \mathrm{~h}$ cycling exercise in man. Eur J Appl Physiol. 97:454-461, 2006.

20. Davison, G., M. Gleeson, and S. Phillips. Antioxidant supplementation and immunoendocrine responses to prolonged exercise. Med Sci Sports Exerc. 39:645-652, 2007.

21. Di Meo, S.andP. Venditti. Mitochondria in exercise-induced oxidative stress. Biol Signals Recept. 10:125-140, 2001.

22. Dillard, C. J., R. E. Litov, W. M. Savin, E. E. Dumelin, and A. L. Tappel. Effects of exercise, vitamin E, and ozone on pulmonary function and lipid peroxidation. $J \mathrm{Appl}$ Physiol. 45:927-932, 1978.

23. Droge, W.,K. Schulze-Osthoff,S. Mihm, et al. Functions of glutathione and glutathione disulfide in immunology and immunopathology. Faseb J. 8:1131-1138, 1994.

24. Dufaux, B., O. Heine, A. Kothe, U. Prinz, and R. Rost. Blood glutathione status following distance running. Int J Sports Med. 18:89-93, 1997.

25. Dumke, C. L., D. W. Brock, B. H. Helms, and G. G. Haff. Heart rate at lactate threshold and cycling time trials. J Strength Cond Res. 20:601-607, 2006.

26. Duthie, G. G., J. D. Robertson, R. J. Maughan, and P. C. Morrice. Blood antioxidant status and erythrocyte lipid peroxidation following distance running. Arch Biochem Biophys. 282:78-83, 1990. 
27. Eiserich, J. P., R. P. Patel, and V. B. O'Donnell. Pathophysiology of nitric oxide and related species: free radical reactions and modification of biomolecules. Mol Aspects Med. 19:221-357, 1998.

28. Elokda, A. S.andD. H. Nielsen. Effects of exercise training on the glutathione antioxidant system. Eur J Cardiovasc Prev Rehabil. 14:630-637, 2007.

29. Elokda, A. S., R. K. Shields, and D. H. Nielsen. Effects of a maximal graded exercise test on glutathione as a marker of acute oxidative stress. J Cardiopulm Rehabil. 25:215-219, 2005.

30. Eschbach, L. F., M. J. Webster, J. C. Boyd, P. D. McArthur, and T. K. Evetovich. The effect of siberian ginseng (Eleutherococcus senticosus) on substrate utilization and performance. Int J Sport Nutr Exerc Metab. 10:444-451, 2000.

31. Faria, E. W., D. L. Parker, and I. E. Faria. The science of cycling: factors affecting performance - part 2. Sports Med. 35:313-337, 2005.

32. Fehrenbach, E.andH. Northoff. Free radicals, exercise, apoptosis, and heat shock proteins. Exerc Immunol Rev. 7:66-89, 2001.

33. Finaud, J., G. Lac, and E. Filaire. Oxidative stress : relationship with exercise and training. Sports Med. 36:327-358, 2006.

34. Gambelunghe, C., R. Rossi, A. Micheletti, G. Mariucci, and S. Rufini. Physical exercise intensity can be related to plasma glutathione levels. J Physiol Biochem. 57:9-14, 2001.

35. Genova, M. L.,M. M. Pich,A. Bernacchia, et al. The mitochondrial production of reactive oxygen species in relation to aging and pathology. Ann N Y Acad Sci. 1011:86-100, 2004. 
36. Glazier, L. R., T. Stellingwerff, and L. L. Spriet. Effects of microhydrin supplementation on endurance performance and metabolism in well-trained cyclists. Int J Sport Nutr Exerc Metab. 14:560-573, 2004.

37. Gohil, K., C. Viguie, W. C. Stanley, G. A. Brooks, and L. Packer. Blood glutathione oxidation during human exercise. J Appl Physiol. 64:115-119, 1988.

38. Goldfarb, A. H. Antioxidants: role of supplementation to prevent exercise-induced oxidative stress. Med Sci Sports Exerc. 25:232-236, 1993.

39. Goldfarb, A. H. Nutritional antioxidants as therapeutic and preventive modalities in exercise-induced muscle damage. Can J Appl Physiol. 24:249-266, 1999.

40. Gomez-Cabrera, M. C., C. Borrás, F. V. Pallardó, J. Sastre, L. L. Ji, and J. Viña. Decreasing xanthine oxidase-mediated oxidative stress prevents useful cellular adaptations to exercise in rats. $J$ Physiol. 567:113-120, 2005.

41. Gomez-Cabrera, M. C., E. Domenech, and J. Vina. Moderate exercise is an antioxidant: Upregulation of antioxidant genes by training. Free Radic Biol Med. 44:126-131, 2008.

42. Gomez-Cabrera, M. C., F. V. Pallardo, J. Sastre, J. Vina, and L. Garcia-del-Moral. Allopurinol and markers of muscle damage among participants in the Tour de France. Jama. 289:2503-2504, 2003.

43. Groussard, C.,F. Rannou-Bekono,G. Machefer, et al. Changes in blood lipid peroxidation markers and antioxidants after a single sprint anaerobic exercise. Eur J Appl Physiol. 89:14-20, 2003.

44. Halliwell, B.andJ. M. Gutteridge. Free radicals in Biology and Medicine (2nd ed.) Oxford: Clarendon Press, pp 136-158. 1989. 
45. Halliwell, B.andJ. M. Gutteridge. Lipid peroxidation, oxygen radicals, cell damage, and antioxidant therapy. Lancet. 1:1396-1397, 1984.

46. Halliwell, B.andJ. M. Gutteridge. Oxygen toxicity, oxygen radicals, transition metals and disease. Biochem J. 219:1-14, 1984.

47. Hartmann, A., A. M. Niess, M. Grunert-Fuchs, B. Poch, and G. Speit. Vitamin E prevents exercise-induced DNA damage. Mutat Res. 346:195-202, 1995.

48. Hawley, J. A.andN. K. Stepto. Adaptations to training in endurance cyclists: implications for performance. Sports Med. 31:511-520, 2001.

49. Ilhan, N., A. Kamanli, R. Ozmerdivenli, and N. Ilhan. Variable effects of exercise intensity on reduced glutathione, thiobarbituric acid reactive substance levels, and glucose concentration. Arch Med Res. 35:294-300, 2004.

50. Impellizzeri, F., A. Sassi, M. Rodriguez-Alonso, P. Mognoni, and S. Marcora. Exercise intensity during off-road cycling competitions. Med. Sci. Sports Exerc. 34:1808-1813, 2002.

51. Jackson, A. A., N. R. Gibson, Y. Lu, and F. Jahoor. Synthesis of erythrocyte glutathione in healthy adults consuming the safe amount of dietary protein. Am J Clin Nutr. 80:101$107,2004$.

52. Jaffe, E. R.andG. Neurmann. A Comparision of the Effect of Menadione, Methylene Blue and Ascorbic Acid on the Reduction of Methemoglobin in Vivo. Nature. 202:607-608, 1964.

53. James, A. M., R. A. Smith, and M. P. Murphy. Antioxidant and prooxidant properties of mitochondrial Coenzyme Q. Arch Biochem Biophys. 423:47-56, 2004. 
54. Jenkins, R. R. Exercise, oxidative stress, and antioxidants: a review. Int J Sport Nutr. 3:356-375, 1993.

55. Jenkins, R. R. Free radical chemistry. Relationship to exercise. Sports Med. 5:156-170, 1988.

56. Jeukendrup, A., F. Brouns, A. J. Wagenmakers, and W. H. Saris. Carbohydrateelectrolyte feedings improve $1 \mathrm{~h}$ time trial cycling performance. Int $J$ Sports Med. 18:125-129, 1997.

57. Jeukendrup, A., editor. High-performance cycling: Human Kinetics, 2002

58. Jeukendrup, A., W. H. Saris, F. Brouns, and A. D. Kester. A new validated endurance performance test. Med Sci Sports Exerc. 28:266-270, 1996.

59. Jeukendrup, A. E. Carbohydrate intake during exercise and performance. Nutrition. 20:669-677, 2004.

60. Jeukendrup, A. E., N. P. Craig, and J. A. Hawley. The bioenergetics of World Class Cycling. J Sci Med Sport. 3:414-433, 2000.

61. Jeukendrup, A. E.andJ. Martin. Improving cycling performance: how should we spend our time and money. Sports Med.31:559-569, 2001.

62. Ji, L. L. Antioxidant enzyme response to exercise and aging. Med Sci Sports Exerc. 25:225-231, 1993.

63. Ji, L. L. Antioxidants and oxidative stress in exercise. Proc Soc Exp Biol Med. 222:283292, 1999.

64. Ji, L. L. Oxidative stress during exercise: implication of antioxidant nutrients. Free Radic Biol Med. 18:1079-1086, 1995. 
65. Ji, L. L., M. C. Gomez-Cabrera, and J. Viña. Exercise and hormesis: activation of cellular antioxidant signaling pathway. Ann N Y Acad Sci. 1067:425-435, 2006.

66. Ji, L. L., A. Katz, R. Fu, M. Griffiths, and M. Spencer. Blood glutathione status during exercise: effect of carbohydrate supplementation. $J$ Appl Physiol. 74:788-792, 1993.

67. Joyner, M. J.andE. F. Coyle. Endurance exercise performance: the physiology of champions. J Physiol. 586:35-44, 2008.

68. Jungersten, L., A. Ambring, B. Wall, and A. Wennmalm. Both physical fitness and acute exercise regulate nitric oxide formation in healthy humans. J Appl Physiol. 82:760-764, 1997.

69. Kanter, M. M. Free radicals, exercise, and antioxidant supplementation. Int J Sport Nutr. 4:205-220, 1994.

70. Kenefick, R. W., C. O. Mattern, N. V. Mahood, and T. J. Quinn. Physiological variables at lactate threshold under-represent cycling time-trial intensity. $J$ Sports Med Phys Fitness. 42:396-402, 2002.

71. Kretzschmar, M., D. Müller, J. Hübscher, E. Marin, and W. Klinger. Influence of aging, training and acute physical exercise on plasma glutathione and lipid peroxides in man. Int J Sports Med. 12:218-222, 1991.

72. Lambert, E. V., J. A. Hawley, J. Goedecke, T. D. Noakes, and S. C. Dennis. Nutritional strategies for promoting fat utilization and delaying the onset of fatigue during prolonged exercise. J Sports Sci. 15:315-324, 1997.

73. Laursen, P. B., C. M. Shing, and D. G. Jenkins. Reproducibility of a laboratory-based 40$\mathrm{km}$ cycle time-trial on a stationary wind-trainer in highly trained cyclists. Int $J$ Sports Med. 24:481-485, 2003. 
74. Leeuwenburgh, C., P. A. Hansen, J. O. Holloszy, and J. W. Heinecke. Hydroxyl radical generation during exercise increases mitochondrial protein oxidation and levels of urinary dityrosine. Free Radic Biol Med. 27:186-192, 1999.

75. Levine, B. D. .VO2max: what do we know, and what do we still need to know? $J$ Physiol. 586:25-34, 2008.

76. Lovlin, R., W. Cottle, I. Pyke, M. Kavanagh, and A. N. Belcastro. Are indices of free radical damage related to exercise intensity. Eur J Appl Physiol Occup Physiol. 56:313$316,1987$.

77. Lucia, A., J. Hoyos, A. Carvajal, and J. L. Chicharro. Heart rate response to professional road cycling: the Tour de France. Int J Sports Med. 20:167-172, 1999.

78. Lukaski, H. C. Vitamin and mineral status: effects on physical performance. Nutrition. 20:632-644, 2004.

79. Macdermid, P. W.andS. R. Stannard. A whey-supplemented, high-protein diet versus a high-carbohydrate diet: effects on endurance cycling performance. Int J Sport Nutr Exerc Metab. 16:65-77, 2006.

80. Machefer, G.,C. Groussard,H. Zouhal, et al. Nutritional and plasmatic antioxidant vitamins status of ultra endurance athletes. J Am Coll Nutr. 26:311-316, 2007.

81. MacRae, H. S.andK. M. Mefferd. Dietary antioxidant supplementation combined with quercetin improves cycling time trial performance. Int J Sport Nutr Exerc Metab. 16:405419, 2006.

82. Margaritis, I., S. Palazzetti, A. S. Rousseau, M. J. Richard, and A. Favier. Antioxidant supplementation and tapering exercise improve exercise-induced antioxidant response. $J$ Am Coll Nutr. 22:147-156, 2003. 
83. Mårtensson, J.andA. Meister. Mitochondrial damage in muscle occurs after marked depletion of glutathione and is prevented by giving glutathione monoester. Proc Natl Acad Sci U S A. 86:471-475, 1989.

84. May, J. M., Z.-C. Qu, R. R. Whitesell, and C. E. Cobb. Ascorbate recycling in human erythrocytes: Role of GSH in reducing dehydroascorbate. Free Radic Biol Med. 20:543$551,1996$.

85. McArdle, W. D., F. I. Katch, and V. L. Katch. Exercise physiology: energy, nutrition, and human performance. Fifth ed: Lippincott Williams \& Wilkins, 2001

86. McConell, G. K., N. N. Huynh, R. S. Lee-Young, B. J. Canny, and G. D. Wadley. LArginine infusion increases glucose clearance during prolonged exercise in humans. Am J Physiol Endocrinol Metab. 290:E60-E66, 2006.

87. Meister, A. Glutathione metabolism and its selective modification. J Biol Chem. 263:17205-17208, 1988.

88. Minetti, M., D. Pietraforte, V. Carbone, A. M. Salzano, G. Scorza, and G. Marino. Scavenging of peroxynitrite by oxyhemoglobin and identification of modified globin residues. Biochemistry. 39:6689-6697, 2000.

89. Miyazaki, H.,S. Oh-ishi,T. Ookawara, et al. Strenuous endurance training in humans reduces oxidative stress following exhausting exercise. Eur J Appl Physiol. 84:1-6, 2001.

90. Muller, F. L., Y. Liu, and H. Van Remmen. Complex III releases superoxide to both sides of the inner mitochondrial membrane. J Biol Chem. 279:49064-49073, 2004.

91. Murrant, C. L.andM. B. Reid. Detection of reactive oxygen and reactive nitrogen species in skeletal muscle. Microsc Res Tech. 55:236-248, 2001. 
92. Niebauer, J.andJ. P. Cooke. Cardiovascular effects of exercise: role of endothelial shear stress. J Am Coll Cardiol. 28:1652-1660, 1996.

93. Nieman, D. C.,D. A. Henson,S. R. McAnulty, et al. Vitamin E and immunity after the Kona Triathlon World Championship. Med Sci Sports Exerc. 36:1328-1335, 2004.

94. Packer, L. Oxidants, antioxidant nutrients and the athlete. J Sports Sci. 15:353-363, 1997.

95. Padilla, S., I. Mujika, J. Orbananos, and F. Angulo. Exercise intensity during competition time trials in professional road cycling. Med. Sci. Sports Exerc. 32:850-856, 2000.

96. Palazzetti, S., M. J. Richard, A. Favier, and I. Margaritis. Overloaded training increases exercise-induced oxidative stress and damage. Can J Appl Physiol. 28:588-604, 2003.

97. Palazzetti, S., A. S. Rousseau, M. J. Richard, A. Favier, and I. Margaritis. Antioxidant supplementation preserves antioxidant response in physical training and low antioxidant intake. Br J Nutr. 91:91-100, 2004.

98. Powers, S. K.andS. L. Lennon. Analysis of cellular responses to free radicals: focus on exercise and skeletal muscle. Proc Nutr Soc. 58:1025-1033, 1999.

99. Quijano, C., B. Alvarez, R. M. Gatti, O. Augusto, and R. Radi. Pathways of peroxynitrite oxidation of thiol groups. Biochem J. 322 ( Pt 1):167-173, 1997.

100. Radák, Z.,H. Ogonovszky,J. Dubecz, et al. Super-marathon race increases serum and urinary nitrotyrosine and carbonyl levels. Eur J Clin Invest. 33:726-730, 2003.

101. Radak, Z., J. Pucsuk, S. Boros, L. Josfai, and A. W. Taylor. Changes in urine 8hydroxydeoxyguanosine levels of super-marathon runners during a four-day race period. Life Sci. 66:1763-1767, 2000. 
102. Radak, Z., A. W. Taylor, H. Ohno, and S. Goto. Adaptation to exercise-induced oxidative stress: from muscle to brain. Exerc Immunol Rev. 7:90-107, 2001.

103. Reid, M. B. Role of nitric oxide in skeletal muscle: synthesis, distribution and functional importance. Acta Physiol Scand. 162:401-409, 1998.

104. Roberts, C. K., R. J. Barnard, A. Jasman, and T. W. Balon. Acute exercise increases nitric oxide synthase activity in skeletal muscle. Am J Physiol. 277:E390-394, 1999.

105. Romano-Ely, B. C., M. K. Todd, M. J. Saunders, and T. S. Laurent. Effect of an isocaloric carbohydrate-protein-antioxidant drink on cycling performance. Med Sci Sports Exerc. 38:1608-1616, 2006.

106. Sacheck, J. M.andJ. B. Blumberg. Role of vitamin E and oxidative stress in exercise. Nutrition. 17:809-814, 2001.

107. Saris, W. H., J. Schrijver, M. A. van Erp Baart, and F. Brouns. Adequacy of vitamin supply under maximal sustained workloads: the Tour de France. Int J Vitam Nutr Res Suppl. 30:205-212, 1989.

108. Sastre, J.,M. Asensi,E. Gascó, et al. Exhaustive physical exercise causes oxidation of glutathione status in blood: prevention by antioxidant administration. Am J Physiol. 263:R992-995, 1992.

109. Saunders, M. J., M. D. Kane, and M. K. Todd. Effects of a carbohydrate-protein beverage on cycling endurance and muscle damage. Med Sci Sports Exerc. 36:1233-1238, 2004.

110. Saunders, M. J., N. D. Luden, and J. E. Herrick. Consumption of an oral carbohydrateprotein gel improves cycling endurance and prevents postexercise muscle damage. $J$ Strength Cond Res. 21:678-684, 2007. 
111. Sen, C. K. Glutathione homeostasis in response to exercise training and nutritional supplements. Mol Cell Biochem. 196:31-42, 1999.

112. Sen, C. K.andL. Packer. Thiol homeostasis and supplements in physical exercise. Am J Clin Nutr. 72:653S-669S, 2000.

113. Senturk, U. K., O. Yalcin, F. Gunduz, O. Kuru, H. J. Meiselman, and O. K. Baskurt. Effect of antioxidant vitamin treatment on the time course of hematological and hemorheological alterations after an exhausting exercise episode in human subjects. $J$ Appl Physiol. 98:1272-1279, 2005.

114. Shang, F., M. Lu, E. Dudek, J. Reddan, and A. Taylor. Vitamin C and vitamin E restore the resistance of GSH-depleted lens cells to H2O2. Free Radic Biol Med. 34:521-530, 2003.

115. Souza, J. M.,I. Choi,Q. Chen, et al. Proteolytic degradation of tyrosine nitrated proteins. Arch Biochem Biophys. 380:360-366, 2000.

116. Sureda, A.,P. Tauler,A. Aguiló, et al. Relation between oxidative stress markers and antioxidant endogenous defences during exhaustive exercise. Free Radic Res. 39:1317$1324,2005$.

117. Tavazzi, B.,D. Di Pierro,A. M. Amorini, et al. Energy metabolism and lipid peroxidation of human erythrocytes as a function of increased oxidative stress. Eur J Biochem. 267:684-689, 2000.

118. Tessier, F., I. Margaritis, M. J. Richard, C. Moynot, and P. Marconnet. Selenium and training effects on the glutathione system and aerobic performance. Med Sci Sports Exerc. 27:390-396, 1995. 
119. Thomas, C.,S. Perrey,H. Ben Saad, et al. Effects of a supplementation during exercise and recovery. Int J Sports Med. 28:703-712, 2007.

120. Thompson, D.,C. Williams,M. Kingsley, et al. Muscle soreness and damage parameters after prolonged intermittent shuttle-running following acute vitamin $\mathrm{C}$ supplementation. Int J Sports Med. 22:68-75, 2001.

121. Urso, M. L.andP. M. Clarkson. Oxidative stress, exercise, and antioxidant supplementation. Toxicology. 189:41-54, 2003.

122. van Essen, M.andM. J. Gibala. Failure of protein to improve time trial performance when added to a sports drink. Med Sci Sports Exerc. 38:1476-1483, 2006.

123. Viappiani, S.andR. Schulz. Detection of specific nitrotyrosine-modified proteins as a marker of oxidative stress in cardiovascular disease. Am J Physiol Heart Circ Physiol. 290:H2167-2168, 2006.

124. Viguie, C. A., B. Frei, M. K. Shigenaga, B. N. Ames, L. Packer, and G. A. Brooks. Antioxidant status and indexes of oxidative stress during consecutive days of exercise. $J$ Appl Physiol. 75:566-572, 1993.

125. Wallace, W. J., R. A. Houtchens, J. C. Maxwell, and W. S. Caughey. Mechanism of autooxidation for hemoglobins and myoglobins. Promotion of superoxide production by protons and anions. J Biol Chem. 257:4966-4977, 1982.

126. Yerer, M. B.andS. Aydogan. The in vivo antioxidant effectiveness of alpha-tocopherol in oxidative stress induced by sodium nitroprusside in rat red blood cells. Clin Hemorheol Microcirc. 30:323-329, 2004. 


\section{Chapter 3}

The effects of an antioxidant nutritional supplement on intense cycling performance

By

\section{Ryan Hobbs}

To be submitted to Medicine and Science in Sport and Exercise 
The effects of an antioxidant nutritional supplement on intense cycling performance

\author{
Ryan T. Hobbs, David A. Donley, Myra E. Woodworth-Hobbs, \\ Stephen E. Alway, G. Gregory Haff, and Randall W. Bryner
}

Division of Exercise Physiology, West Virginia University School of Medicine, Morgantown,
West Virginia

Corresponding Author:

Randall W. Bryner

P.O. Box 9227

8707 Robert C. Byrd Health Sciences Center

Morgantown, WV 26506-9227

Phone: (304) 293-0441

Fax: (304) 293-7105

Email: rbryner@hsc.wvu.edu

Running Title: Antioxidants and intense cycling performance 


\section{ABSTRACT}

PURPOSE: To determine if 5 days of antioxidant supplementation coupled with a pre-ride antioxidant/energy supplement improves cycling performance or reduces oxidative stress in trained cyclists.

METHODS: Eight well-trained cyclists participated in a double-blind cross-over placebocontrolled study. Maximal oxygen consumption $\left(\mathrm{VO}_{2 \mathrm{Max}}\right)$, peak power output $\left(\mathrm{W}_{\mathrm{Max}}\right)$ and total work during a 15-minute time trial were determined. Subjects consumed an antioxidant supplement (S) or a placebo (P) for 5 days before each trial and a pre-exercise supplement or isocaloric placebo ( $\left.4 \mathrm{kcal} \cdot \mathrm{kg}^{-1}\right) 45$ minutes before each trial. Subjects performed an endurance ride of 90 minutes followed immediately by a time trial requiring accumulation of total work equal to the initial time trial.

RESULTS: The GSH:GSSG ratio remained constant prior to both experimental trials, while resting total GSH concentrations exhibited a main effect $(p=0.038)$ in response to step-one of the supplement protocol for basal (S: $1020.2 \pm 135.8 \mu \mathrm{mol} \cdot \mathrm{L}^{-1}$; P: $1000.2 \pm 252.9 \mu \mathrm{mol} \cdot \mathrm{L}^{-1}$ ) vs. pre-endurance (S: $979.2 \pm 155.1 \mu \mathrm{mol} \cdot \mathrm{L}^{-1}$; P: $867.3 \pm 231.2 \mu \mathrm{mol} \cdot \mathrm{L}^{-1}$ ). During the endurance ride, no differences were observed in average power (S: $224.0 \pm 36.5 \mathrm{~W} ; \mathrm{P}: 219.1 \pm 19.2 \mathrm{~W}$ ), oxygen consumption (S: $\left.2.8 \pm 0.4 \mathrm{~L} \cdot \mathrm{min}^{-1} ; \mathrm{P}: 2.8 \pm 0.4 \mathrm{~L} \cdot \mathrm{min}^{-1}\right)$, heart rate (S: $148.4 \pm 3.5$ beats $\cdot \mathrm{min}^{-1}$; P: $146.3 \pm 4.5$ beats $\cdot \mathrm{min}^{-1}$ ), or GSH:GSSG ratio (S: $1.4 \pm 0.7 ; \mathrm{P}: 1.4 \pm 0.9$ ). During the time trial tests, supplementation did not lead to any differences between average power (S: $303.6 \pm 59.2 \mathrm{~W} ; \mathrm{P}: 306.1 \pm 47.0 \mathrm{~W})$, oxygen consumption $\left(\mathrm{S}: 3.5 \pm 0.4 \mathrm{~L} \cdot \mathrm{min}^{-1}\right.$; P: $3.3 \pm 0.6$ $\mathrm{L} \cdot \mathrm{min}^{-1}$ ), heart rate $\left(\mathrm{S}: 171.1 \pm 6.5\right.$ beats $\cdot \mathrm{min}^{-1}$; P: $170.3 \pm 3.5$ beats $\left.\cdot \mathrm{min}^{-1}\right)$, or GSH:GSSG ratio (S: $1.1 \pm 0.6 ;$ P: $0.9 \pm 0.7)$. 
CONCLUSION: Consuming an antioxidant supplement for 5 days coupled with a pre-exercise antioxidant/energy supplement does not result in significant improvements in cycling performance. However, the multiple-step supplementation may attenuate oxidative stress during the cycling bout when compared to a placebo, possibly due to the maintenance of glutathione levels.

Key Words: Bicycling/physiology, Energy Metabolism, Sports/physiology, Physical Endurance/physiology, Oxidative Stress, Glutathione/blood 


\section{INTRODUCTION}

Competitive endurance athletes routinely engage in high intensity exercise during competition (20). During an individual time trial, competitive cyclists spend an average of 20 minutes at $>90 \%$ maximal oxygen consumption $\left(\mathrm{VO}_{2 \mathrm{Max}}\right)(20)$. The analysis of cross-country mountain bike competitions reveals similar intensities as during competitive road cycling time trials. Competitive cross-country mountain cyclists averaged $90 \%$ of maximal heart rate $\left(\mathrm{HR}_{\mathrm{Max}}\right)$ for 5 cross-country races that averaged 147 minutes (36).

In order to meet this work demand, a constant supply of energy to the working muscles must be provided to maintain performance during high intensity aerobic exercise $(39,48)$. The metabolic processes in the mitochondria result in the formation of free radicals and other reactive oxygen species (31), which subsequently leads to the formation of reactive nitrogen species (84). Antioxidants quench free radicals and reactive oxygen and nitrogen species, thereby reducing the severity of oxidative stress (24). Oxidative stress occurs as a result of an imbalance between reactive oxygen and nitrogen species and the antioxidant defense system (41).

The accumulation of reactive oxygen and nitrogen species can occur during high-intensity exercise (25) leading to oxidative stress (42), oxidative red blood cell damage $(75,79)$, and oxidative muscle damage $(27,67)$. Markers of muscle damage are shown to increase after prolonged high-intensity cycling $(27,72,73)$, and this oxidative damage may result in a decrease in endurance performance due to muscle tissue loss and decreased capacity to transport oxygen. The accumulation of oxidative damage is relative to the production of reactive oxygen and nitrogen species (41) and the collective success of the antioxidant defense and muscle repair systems (65). 
Recent studies have examined the effect of various dietary supplements on their ability to enhance endurance performance (53), alter fuel metabolism $(22,57)$, decrease markers of oxidative stress $(54,71)$, and decrease markers of post-exercise muscle damage $(27,65)$. These dietary supplements include carbohydrate $(39,48)$, protein $(51,73,81)$, arginine $(1,57)$, carnitine (8), aspartate (1), tartrate (8), retinol, ascorbic acid, and $\alpha$-tocopherol $(2,11,12,54,62$, 75), selenium (65, 77), allopurinol (27), Siberian ginseng (19), and reduced glutathione (71). Most of these supplements have required long-term ( $\sim 4$ weeks) use to provide the desired effects $(2,12,27,53)$, and most have been studied independently of one another $(11,27,57,62$, 77).

It has been suggested that because most of these supplements work synergistically, they should be consumed in combination as an antioxidant energy substrate cocktail, rather than independently (74). Thus, supplementation with antioxidant energy substrate cocktails has also been evaluated in regards to providing ergogenic effects $(53,78)$. There is evidence that the consumption of an antioxidant energy substrate cocktail for 6 weeks increases endurance performance (53), but the authors failed to identify any underlying mechanisms.

It has recently been proposed that long-term antioxidant supplementation may be detrimental to cellular adaptations that lead to improvements in endurance capacity $(26,31)$. A number of cellular signaling pathways respond to reactive oxygen and nitrogen species, which ultimately contributes to improvements in endurance performance (43). Long-term supplementation may prevent desirable adaptations in inducible antioxidants, limiting the adaptive capacity to deal with reactive oxygen and nitrogen species (43).

Short-term antioxidant supplementation may be an alternative method that avoids the problems associated with long-term antioxidant intervention. These protocols may lead to 
improvements in performance without interrupting cellular adaptations that occur as a result of normal training. A few studies have investigated the effect of short term ( $\leq 14$ days) antioxidant supplementation on oxidative stress and performance $(5,33,79)$. These supplementation protocols varied in timing from 2 hours $(5,79)$ to 14 days $(33)$ prior to exercise. A graded cycling max test coupled with ascorbic acid supplementation taken 2 hours prior to the high intensity aerobic exercise bout was shown to increase plasma ascorbic acid levels and decrease oxidative stress at rest and in response to the exercise in healthy untrained subjects (5). This indicates that short-term supplementation may therefore be beneficial in reducing oxidative stress by attenuating uncontrolled production of reactive oxygen and nitrogen species that can lead to an oxidative stress condition. An antioxidant energy substrate cocktail may provide increased levels of protection beyond that of independently supplementing with only one supplement type, but there currently exists no scientific literature evaluating this concept. Thus, more research on the effects of short term antioxidant cocktail supplementation protocols on cycling performance in trained athletes is warranted. Therefore, the purpose of this project was to determine if a multiple step antioxidant nutritional supplement protocol which includes a 5 day antioxidant cocktail loading phase coupled with a pre-event antioxidant/energy beverage increased performance, reduced markers of oxidative stress, or enhanced fuel metabolism during a high-intensity cycle ergometry exercise test in trained competitive cyclists.

\section{METHODS}

Experimental Design. The present study was conducted using trained cyclists in a repeatedmeasures double-blinded crossover design to investigate the effects of a multiple-step antioxidant energy supplement protocol. Oxygen consumption $\left(\mathrm{VO}_{2}\right)$, heart rate, whole blood 
lactate, plasma glucose, and markers of oxidative stress were determined intermittently during the experimental trials. The subjects were tested on four different occasions. The first testing session was used to determine the cyclists' anthropometrics, body composition, $\mathrm{VO}_{2 \mathrm{Max}}, \mathrm{HR}_{\mathrm{Max}}$, peak power output $\left(\mathrm{W}_{\mathrm{Max}}\right)$, and ventilatory threshold. The second session, which took place 5 days later, was used to determine the maximal amount of work the cyclists could perform during a 15 minute time trial. The third and fourth sessions were the experimental conditions where the cyclists were randomly assigned to either treatment or placebo conditions in a crossover design. The third testing session took place 7 days after the second and the fourth testing session took place 12 days after the third. Refer to Figure 1 for a summary of the testing timeline. Authors controlled for time of day and pre-ride nutrition and training; subjects reported to the testing laboratory and consumed a similar diet and engaged in similar training practices prior to each testing session.

Subjects. Subjects were cyclists with at least two consecutive years of competitive cycling, no current injuries or exercise restrictions, and who had not consumed antioxidant nutritional supplements for the last thirty days prior to the initiation of the study. Eligibility was determined using a health history questionnaire and a separate questionnaire specifically designed to obtain information on cycling background and supplement use. Subjects provide informed consent and received a description of events for the study. The West Virginia University Institutional Review Board approved (\#9999-16954) the study protocol statement including all forms and procedures. A summary of subject characteristics are presented in table 1.

Preliminary Testing. Subjects refrained from intense training for 24 hours prior to all testing procedures but were allowed to follow their usual exercise and competition patterns. Preliminary 
testing began with determination of body composition by air displacement using a BodPod (Life Measurement, Inc., Concord, CA).

The same lab technician determined the cyclists racing bike measurements and reproduced the identical cycling position on all testing bikes for all procedures during the study. The cyclist performed a 10-15 minute warm-up at a self-selected intensity on a fixed-gear CycleOps 300PT (CycleOps, Madison, WI) with the incorporation of two 30 second sprints, a modified version previously used by Dumke et. al. (14). Subjects underwent a continuous incremental cycle test ( $25 \mathrm{~W} /$ minute step increment every 1 minute, initial load $125 \mathrm{~W}$ ) to exhaustion to determine $\mathrm{VO}_{2 \mathrm{Max}}, \mathrm{W}_{\mathrm{Max}}$, and ventilatory threshold on a electronically braked cycle ergometer (LODEExcalibur Sport, Electra Med Corp., Flint, MI) equipped with their own pedals (28). Oxygen consumption was measured continuously by directing expired air to a MedGraphics $\mathrm{CardioO}_{2}$ system (Medical Graphics, St. Paul, MN) (14). Heart rates were monitored continuously using a 4-lead exercise ECG (Welch Allen, CardioPerfect, Skaneateles Falls, NY), and Borg rating of perceived exertion (RPE) was documented for every stage (7). Cyclists maintained a cadence between 80-110 revolutions per minute (rpm) throughout the test (20). Tests were terminated at volitional exhaustion and the criteria for determination of a maximal exercise test, plateau in $\mathrm{VO}_{2}, 90 \%$ of age predicted $\mathrm{HR}_{\mathrm{Max}}$, and respiratory exchange ratio (RER) $\geq 1.15$, was used to determine if the test was maximal (2). The ventilatory threshold was determined from the $\mathrm{VO}_{2 \mathrm{Max}}$ test by standard procedures (4).

Multiple Step Supplement Protocol. Subjects were randomized in a double blind fashion to treatment or placebo upon entry into the study and later crossed-over to serve as their own controls. During step-one of the supplement protocol, subjects were instructed to consume 4 capsules day ${ }^{-1}, 2$ in the a.m. and 2 in the p.m., of treatment, antioxidant supplement (ProStandard 
Endurance ${ }^{\circledR}$, AmeriSciences ${ }^{\circledR}$, Houston, TX), or placebo for five days prior to the first experimental trials. Capsules were identical in appearance and taste. See table 2 for a list of ingredients in the treatment capsules and see table 3 for a list of ingredients in the placebo capsule. In the case of a cyclist forgetting to consume the capsules at any given specified time they were instructed to consume the missed capsules with the next regularly schedule dose. The cyclist completed consumption of the capsules on the evening prior to the experimental trials and all cyclist were able to consume all 20 capsules over the five day step-one loading phase with no reported side effects. The cyclists returned an empty bag that previously contained the capsules with a form containing their signature confirming consumption of the capsules (45). During this five day period subjects completed a training log and dietary recall. During the crossover trial subjects consumed a similar diet and performed a similar training load to the first trial, an additional dietary recall and training log were analyzed and used to determine if discrepancies existed prior to the next trial.

Following a 12 hour overnight fast, subjects consumed the second-step of the multiple step supplement protocol, the morning of the experimental test rides. Upon arrival to the testing facility, after body weight and a resting blood draw, subjects consumed $4 \mathrm{kcal} / \mathrm{kg}$ of body weight of either a treatment, antioxidant/energy (ProStandard PreGame, ${ }^{\circledR}$ AmeriSciences ${ }^{\circledR}$, Houston, TX) beverage or an isocaloric placebo beverage dissolved in $0.281 \mathrm{fl}$.oz. of water per gram of powder. The beverage was consumed in entirety a minimum of 45 minutes prior to the commencement of cycling. The placebo and treatment beverage were identical in color and taste, See table 3 for a list of ingredients in the placebo beverage and table 4 for a list of ingredients in the treatment beverage. All cyclists were able to consume and maintain consumption of the beverages with no side effects. 
After the cyclists completed the first supplement period they entered into a 7 day wash out period (6). After this wash-out the cyclists crossed-over into the second supplement period.

Baseline Trial. At least 72 hours after the maximal test cyclists returned to the lab at 7:00 a.m. for a familiarization ride on the stationary CycleOps 300PT equipped with their own pedals and saddle. The PowerTap power meter (CycleOps, Madison, WI) in the rear hub of the CycleOps 300PT has previously been validated for submaximal endurance test (30). The cyclist used the same warm-up method as previously described during the preliminary testing. The cyclists began the time trial from a standing start and were instructed to complete as much work as possible in 15 minutes. The cyclists had full control of their cadence and resistance during this time trial. The total amount of work was recorded in kilojoules during the time trial. Heart rate, $\mathrm{VO}_{2}$, and RPE were measured during the time trial using the same methods as during the $\mathrm{VO}_{2 \mathrm{Max}}$ test.

Dietary \& Training Control. For 5 days prior to each experimental trial, subjects recorded their dietary intake using a provided diet journal to document the food preparation method and amount consumed. Each subject was provided with detailed instructions for measuring the food and recording it into their 5-day dietary journal. The 5-day dietary recall prior to the first testing session was then used as a menu for the 5 days prior to the second testing session. The subjects were requested to eat foods as similar as possible to those consumed prior to the first testing session. Another journal was filled out prior to the second testing session and reviewed prior to initiation of the second test. If the diet was not found to be similar the testing session was rescheduled or the subject was dropped from the study. This approach to dietary control was modified from a previous version used by Kulik et. al. (47). 
Similarly, training was recorded for 5 days prior to the testing session using a training journal. Subjects provided as much data as possible in the categories of time, average heart rate, average power, type/style of workout, distance, speed, and course. Subjects were to refrain from intense exercise 24 hours prior to each experimental test. The training journal filled out prior to the first testing session was then used as a training plan for the week prior to the second testing session. During the week prior to the second testing session another training journal was filled out. The journal was reviewed prior to the second testing session and if not found to be similar to the first, the subjects was rescheduled or dropped from the study.

Experimental Trials. Cyclists returned to the lab at 7:00 a.m. one week after the time trial for the first of two experimental trials on the CycleOps 300PT. The equipment (i.e. pedals and saddle) and settings on the CycleOps were identical to previous settings used by each cyclist during the time trial. The cyclists performed a 90 min endurance ride at a work load that represented a heart rate of five beats below their ventilatory threshold. During the endurance ride cyclists' heart rate was measured continuously and $\mathrm{RER}, \mathrm{VO}_{2}$, and $\mathrm{RPE}$ were measured for 5 min continuously in 15 min increments, using a modified version of the method of McAnulty et. al. (56). After the endurance ride, cyclists began a high intensity self-paced time trial from a standing start. During the time trial cyclists completed the same amount of work that was achieved during the time trial as quickly as possible. The cyclist had full control of their cadence and resistance during the time trial. The time to complete the amount of work was recorded. During the time trial cyclists' heart rate, $\mathrm{VO}_{2}$, and $\mathrm{RPE}$ were measured using the same methods as during the $\mathrm{VO}_{2 \mathrm{Max}}$ test. After a 7 day wash-out and another 5 day loading phase cyclists returned to the lab for their second endurance ride and second time trial in identical conditions to which the first endurance ride and time trial were performed. 
Sample Collection. All samples were collected from the antecubital vein in the forearm into EDTA vacutainer ${ }^{\circledR}$ blood collection tubes (Becton, Dickinson and Company, Franklin Lakes, NJ) by trained phlebotomists. Hematocrit was determined and samples were further aliquoted into appropriately labeled microcentrifuge tubes for determination of GSH, GSSG, and lactate concentrations. Remaining whole blood was centrifuged (1000 g) for 15 minutes and plasma was aliquoted into appropriately labeled centrifuge tubes for determination of blood glucose and nitrotryosine. All aliquoted samples were immediately frozen at $-80^{\circ} \mathrm{C}$. A blood volume of 18 $\mathrm{mL}$ was collected at each sampling point. Prior to the supplement protocol, a resting baseline blood sample was drawn after 15 min of rest. Another resting sample was drawn after the 5 day step-one supplement loading phase prior to the consumption of the second-step in the supplement protocol on the morning of the endurance ride in similar conditions to the initial resting blood draw. Exercising samples were drawn immediately after the endurance ride and time trial. After a minimum 7-day wash-out period, another baseline sample was drawn at the point of crossing-over to the other treatment and a resting sample prior to the endurance ride, a post endurance ride sample, and a post time trial sample were all drawn in similar conditions to the first testing session. 


\section{ANALYTICAL METHODS}

Dietary and Training. Dietary analyses for total calories, fats, carbohydrates, and proteins were performed using Food Processor Plus for Windows version 6.05 (ESHA Research, Salem, OR). Food Processor Plus was utilized because it has been shown to have a low percentage $(0.03 \%)$ of missing information (49). Training analysis between groups was performed by totaling the number of training sessions. The number of training sessions was the only uniform method used to document training by all subjects.

Hematocrit. Whole blood was immediately collected from EDTA tubes into microcapillary tubes and hematocrit was determined according to standard procedures. Hematocrit changes were used to estimate plasma volume shift for correcting lactate, glucose, glutathione, and nitrotyrosine concentrations (80).

Blood Lactate. Whole blood was immediately aliquoted from EDTA tubes into pre-chilled lactate preservative microcentrifuge tubes (YSI Life Sciences, Inc., Yellow Springs, OH) and used for the determination of lactate concentrations. Preservative tubes were immediately vortexed, frozen, and stored at $-80^{\circ} \mathrm{C}$ until analysis was performed. Lactate analysis was performed in triplicate on a YSI Sport lactate analyzer. The analyzer was calibrated with known concentrations of lactate according to standard procedures and all samples were run in triplicate and averaged. If a value was found to be an outlier it was eliminated and the two remaining values were averaged. The raw data was corrected for plasma volume shifts during the experimental trials. Reliability was considered high as can be seen by the coefficient of variance and intraclass correlations, $1.2 \%$ and 0.99 , respectfully.

Plasma Glucose. For measurement of plasma glucose, whole blood was centrifuged at $1000 \mathrm{~g}$ for 10 min. Plasma was aliquoted into pre-chilled $1 \mathrm{ml}$ microcentrifuge tubes, immediately 
frozen and stored at $-80^{\circ} \mathrm{C}$ until analysis was performed. Plasma glucose concentrations were determined using standard ELISA (Glucose Assay Kit: GAGO20, Sigma, Saint Louis, MO) procedures and all samples were run in triplicate. The raw data was corrected for plasma volume shifts during the experimental trials. Reliability was considered high as can be seen by the coefficient of variance and intraclass correlations, $4.9 \%$ and 0.94 , respectfully.

Total-body fuel oxidation. Total-body rates of fat and $\mathrm{CHO}$ oxidation $\left(\mathrm{g} \cdot \mathrm{min}^{-1}\right)$ were calculated during the cycling experimental test from the rate of $\mathrm{CO}_{2}$ production $\left(\mathrm{VCO}_{2}\right)$ and $\mathrm{VO}_{2}$ by using the nonprotein respiratory exchange ratio values according to the following equations (22):

$$
\begin{aligned}
& \text { Fat oxidation }\left(\mathrm{g} \cdot \mathrm{min}^{-1}\right)=\left[1.695 \times \mathrm{VO}_{2}\left(\mathrm{~L} \cdot \mathrm{min}^{-1}\right)\right]-\left[7.01 \times \mathrm{VCO}_{2}\left(\mathrm{~L} \cdot \mathrm{min}^{-1}\right)\right] \\
& \text { CHO oxidation }\left(\mathrm{g} \cdot \mathrm{min}^{-1}\right)=\left[4.585 \times \mathrm{VCO}_{2}\left(\mathrm{~L} \cdot \mathrm{min}^{-1}\right)\right]-\left[3.226 \times \mathrm{VO}_{2}\left(\mathrm{~L} \cdot \mathrm{min}^{-1}\right)\right]
\end{aligned}
$$

Blood Glutathione. Whole blood was used for determination of GSH and GSSG. Whole blood was aliquoted into pre-chilled microcentrifuge tubes, immediately frozen, and stored at $-80^{\circ} \mathrm{C}$ until GSH analysis. To prevent further oxidation from occurring in GSSG whole blood samples, $10 \mu 1$ of the scavenger 1-methyl-2-vinylpyridinium trifluoromethanesulfonate (M2VP) was placed into pre-chilled microcentrifuge tubes prior to the addition of $100 \mu 1$ of the whole blood sample. GSSG samples were immediately frozen and stored at $-80^{\circ} \mathrm{C}$ until analysis was performed.

Analysis of GSH and GSSG was performed in triplicate using an assay kit (GSH/GSSG-412 assay: Calorimetric determination of reduced and oxidized glutathione, Oxis Research ${ }^{\circledR}$, Portland, OR, USA) according to standard procedures (18). The raw data was corrected for plasma volume shifts during the experimental trials. Reliability was considered high as can be seen by the coefficient of variance and intraclass correlations, $5.0 \%$ and 0.99 , respectfully. 
Plasma Nitrotyrosine. Blood plasma was used for determination of nitrotyrosine concentrations. Whole blood was centrifuged at $1000 \mathrm{~g}$ for $10 \mathrm{~min}$, the supernatant, plasma, was collected without disruption of the white buffy layer of leukocytes. The plasma was aliquoted into pre-chilled $1 \mathrm{ml}$ microcentrifuge tubes, immediately frozen and stored at $-80^{\circ} \mathrm{C}$ until analysis was performed.

Analysis of nitrotyrosine was performed in triplicate using an assay kit (Hbt Nitrotyrosine ELISA kit for calorimetric determination, Cell Sciences ${ }^{\circledR}$, Canton, MA, USA) according to standard procedures. The raw data was corrected for plasma volume shifts during the experimental trials. Coefficient of variance and intraclass correlations were $10.6 \%$ and 0.99 , respectfully.

\section{STATISTICS}

Paired comparisons were utilized in the analysis of dietary and training log data collected during step 1 of the supplement protocol, which encompassed the 5 day supplement period. Additionally, a 2 x 2 (treatment $x$ time) repeated measures analysis of variance (ANOVA) was utilized in order to determine the differences between the markers of oxidative stress and antioxidant defenses in response to the 5 day supplement protocol. Follow-up paired comparisons were utilized in conjunction with a Holm's Bonferroni procedure for controlling type I errors when significant $F$ values $(\mathrm{p} \leq 0.05)$ were determined (34). A $2 \times 3$ (treatment $\mathrm{x}$ time) repeated measures ANOVA were performed to determine significant differences between the 2 treatment trials for lactate, glucose, and markers of oxidative stress at the pre-endurance ride, immediately post endurance ride, and immediately post time trial. When significant $\mathrm{F}$ values were determined $(\mathrm{p} \leq 0.05)$, paired comparisons were used in conjunction with a Holm's Bonferroni method for 
controlling type I errors (34). All data are reported as means \pm standard deviations. Statistical significance was set at the $\mathrm{p} \leq 0.05$ level of confidence. All analyses were performed with SPSS 14.0 (SPSS, Chicago, IL).

\section{RESULTS}

Nutritional intake between the two tests was not significantly different with calories (S: $3407.0 \pm$ 1112.2 kcal; P: $3432.4 \pm 1115.8$ kcal), fats (S: $127.7 \pm 47.6$ g; P: $130.7 \pm 47.6$ ), carbohydrates (S: $442.3 \pm 171.7 \mathrm{~g} ; \mathrm{P}: 437.6 \pm 164.5 \mathrm{~g}$ ), or proteins (S: $126.0 \pm 48.1 \mathrm{~g} ; \mathrm{P}: 123.8 \pm 46.3 \mathrm{~g})$. The number of training sessions between the two tests was not significantly different (S: $5.6 \pm 5.1 \#$; P: $5.4 \pm 5.1 \#)$.

Performance. During the controlled endurance ride portion of the cycling protocol there was no significant difference between absolute or relative indicators of performance (Table 5) or RPE (S: $12.8 \pm 0.9 ; \mathrm{P}: 12.5 \pm 0.9$ ). Economy during the endurance ride significantly increased as the duration increased for in-trial comparisons, 30 -min vs. 60 -min (S: $68.7 \pm 15.3$ vs. $82.6 \pm 16.3$ $\mathrm{W} \cdot \mathrm{L}^{-1} \cdot \mathrm{min}^{-1} ; \mathrm{p}=0.001, \eta^{2}=0.83 ; \mathrm{P}: 69.5 \pm 17.5 \mathrm{vs} .85 .1 \pm 16.1 \mathrm{~W} \cdot \mathrm{L}^{-1} \cdot \mathrm{min}^{-1} ; \mathrm{p}=0.003, \eta^{2}=$ 0.73 ), and 30 -min vs. $90-\min \left(\mathrm{S}: 68.7 \pm 15.3\right.$ vs. $84.2 \pm 12.9 \mathrm{~W} \cdot \mathrm{L}^{-1} \cdot \mathrm{min}^{-1} ; \mathrm{p}=0.001, \eta^{2}=0.83 ; \mathrm{P}$ : $69.5 \pm 17.5$ vs. $86.5 \pm 14.3 \mathrm{~W} \cdot \mathrm{L}^{-1} \cdot \mathrm{min}^{-1} ; \mathrm{p}=0.003, \eta^{2}=0.20$ ) (Figure 4). During the time trial portion of the cycling protocol there were no significant differences between trials in the absolute or relative indicators of performance (Table 5), time (Figure 2), or RPE (S: 17.1 $\pm 1.3 ;$ P: $16.7 \pm$ 1.9). In relation to relative power some cyclists' performance increased during treatment while other cyclists' relative power was in favor of the placebo (Figure 3). Economy during the time trial significantly decreased as the duration increased for in-trial comparisons, 5-min vs. 10-min (S: $94.9 \pm 14.0$ vs. $81.5 \pm 11.8 \mathrm{~W} \cdot \mathrm{L}^{-1} \cdot \mathrm{min}^{-1} ; \mathrm{p}=0.001, \eta^{2}=0.81 ; \mathrm{P}: 100.1 \pm 15.0$ vs. $85.0 \pm 11.3$ 
$\left.\mathrm{W} \cdot \mathrm{L}^{-1} \cdot \mathrm{min}^{-1} ; \mathrm{p}=0.001, \eta^{2}=0.83\right)$, and 5-min vs. $15-\min \left(\mathrm{S}: 94.9 \pm 14.0 \mathrm{vs} .83 .6 \pm 12.6 \mathrm{~W} \cdot \mathrm{L}^{-}\right.$ ${ }^{1} \cdot \min ^{-1} ; p=0.002, \eta^{2}=0.75 ; P: 100.1 \pm 15.0$ vs. $\left.87.9 \pm 9.9 \mathrm{~W} \cdot \mathrm{L}^{-1} \cdot \mathrm{min}^{-1} ; \mathrm{p}=0.002, \eta^{2}=0.77\right)$ (Figure 5).

Lactate. Lactate concentrations were significantly different for in-trial comparisons demonstrating a time effect, pre-endurance ride vs. post endurance ride (S: $0.65 \pm 0.11$ vs. $1.16 \pm$ $\left.0.23 \mathrm{mmol} \cdot \mathrm{L}^{-1} ; \mathrm{p} \leq 0.001, \eta^{2}=0.86\right)$, post endurance ride vs. post time trial (S: $1.16 \pm 0.23 \mathrm{vs}$. $\left.4.52 \pm 1.71 \mathrm{mmol} \cdot \mathrm{L}^{-1} ; \mathrm{p}=0.001, \eta^{2}=0.82\right)$ and $\left(\mathrm{P}: 0.83 \pm 0.24 \mathrm{vs} .5 .42 \pm 1.97 \mathrm{mmol} \cdot \mathrm{L}^{-1} ; \mathrm{p} \leq\right.$ $\left.0.001, \eta^{2}=0.87\right)$, pre-endurance ride vs. post time trial $\left(\mathrm{S}: 0.65 \pm 0.11 \mathrm{vs} .4 .52 \pm 1.71 \mathrm{mmol} \cdot \mathrm{L}^{-1}\right.$; $\left.\mathrm{p} \leq 0.001, \eta^{2}=0.85\right)$ and $\left(\mathrm{P}: 0.89 \pm 0.29\right.$ vs. $\left.5.42 \pm 1.97 \mathrm{mmol} \cdot \mathrm{L}^{-1} ; \mathrm{p} \leq 0.001, \eta^{2}=0.87\right)$ (Figure 6). There was no significant difference for in-trial comparison of pre-endurance ride vs. post endurance ride (P: $0.89 \pm 0.29$ vs. $\left.0.83 \pm 0.24 \mathrm{mmol} \cdot \mathrm{L}^{-1} ; \mathrm{p}=0.643, \eta^{2}=0.03\right)$ (Figure 6).

Glucose. Plasma glucose concentration demonstrated a time-by-treatment interaction $(\mathrm{p}=0.004$, $\left.\eta^{2}=0.92\right)$ when comparing basal (S: $\left.4.76 \pm 0.72 \mathrm{mmol} \cdot \mathrm{L}^{-1} ; \mathrm{P}: 4.51 \pm 0.39 \mathrm{mmol} \cdot \mathrm{L}^{-1}\right)$ vs. preendurance ride $\left(\mathrm{S}: 4.07 \pm 0.66 \mathrm{mmol} \cdot \mathrm{L}^{-1} ; \mathrm{P}: 4.70 \pm 0.62 \mathrm{mmol} \cdot \mathrm{L}^{-1}\right)$ vs. post endurance ride $(\mathrm{S}$ : $\left.4.83 \pm 0.64 \mathrm{mmol} \cdot \mathrm{L}^{-1} ; \mathrm{P}: 3.56 \pm 0.67 \mathrm{mmol} \cdot \mathrm{L}^{-1}\right)$ vs. post time trial $\left(\mathrm{S}: 4.29 \pm 0.64 \mathrm{mmol} \cdot \mathrm{L}^{-1} ; \mathrm{P}\right.$ $\left.4.78 \pm 1.05 \mathrm{mmol} \cdot \mathrm{L}^{-1}\right)$ values.

Total Body Fuel Oxidation. CHO oxidation rates displayed a significant time effect for endurance ride vs. time trial when analyzed by $2 \times 3$ ANOVA (S: $3.11 \pm 0.37$ vs. $5.25 \pm 0.62$ $\mathrm{g} \cdot \mathrm{min}^{-1} ; \mathrm{P}: 2.96 \pm 0.57$ vs. $\left.4.90 \pm 1.42 \mathrm{~g} \cdot \mathrm{min}^{-1} ; \mathrm{p} \leq 0.001, \eta^{2}=0.88\right)$. However, post-hoc analyses were not statistically different (S: $3.11 \pm 0.37$ vs. $5.25 \pm 0.62 \mathrm{~g} \cdot \mathrm{min}^{-1} ; \mathrm{p}=0.069, \eta^{2}=$ 0.96; P: $2.96 \pm 0.57$ vs. $\left.4.90 \pm 1.42 \mathrm{~g} \cdot \mathrm{min}^{-1} ; \mathrm{p}=0.73, \eta^{2}=0.73\right)$. Fat oxidation rates displayed a significant time effect for endurance ride vs. time trial when analyzed by $2 \times 3$ ANOVA (S: $0.26 \pm$ 0.13 vs. $-0.20 \pm 0.15 \mathrm{~g} \cdot \mathrm{min}^{-1} ; \mathrm{P}: 0.27 \pm 0.20$ vs. $\left.-0.17 \pm 0.31 \mathrm{~g} \cdot \mathrm{min}^{-1} ; \mathrm{p} \leq 0.001, \eta^{2}=0.857\right)$. 
However, post-hoc analysis were not statistically different (S: $0.26 \pm 0.13$ vs. $-0.20 \pm 0.15 \mathrm{~g} \cdot \mathrm{min}^{-}$ ${ }^{1} ; p=0.15, \eta^{2}=0.93 ;$ P: $0.27 \pm 0.20$ vs. $\left.-0.17 \pm 0.31 \mathrm{~g} \cdot \mathrm{min}^{-1} ; \mathrm{p}=0.69, \eta^{2}=0.69\right)$.

Glutathione. Resting total GSH concentrations exhibited a main effect $\left(p=0.038, \eta^{2}=0.04\right)$ in response to step-one of the supplement protocol when comparing basal (S: $1020.2 \pm 135.8 \mu \mathrm{mol}^{-}$ ${ }^{1}$; P: $1000.2 \pm 252.9 \mu \mathrm{mol}^{-1}$ ) to pre-endurance ride (S: $979.2 \pm 155.1 \mu \mathrm{mol}^{-1}$; P: $867.3 \pm 231.2$ $\left.\mu \mathrm{mol}^{-1}\right)$. Resting GSSG concentrations were not significantly different $\left(p=0.076, \eta^{2}=0.38\right)$ when comparing basal (S: $311.7 \pm 71.6 \mu \mathrm{mol}^{-1}$; P: $304.1 \pm 37.4 \mu \mathrm{mol}^{-1}$ ) to pre-endurance ride (S: $292.1 \pm 53.8 \mu \mathrm{mol}^{-1}$; P: $274.0 \pm 73.4 \mu \mathrm{mol}^{-1}$ ). The GSH:GSSG ratio was not significantly different $\left(p=0.893, \eta^{2}=0.003\right)$ when comparing basal (S: $\left.1.4 \pm 0.7 ; P: 1.3 \pm 0.8\right)$ to preendurance ride (S: $1.4 \pm 0.7 ;$ P: $1.2 \pm 0.6$ ) (Figure 7).

Total glutathione concentrations were not significantly different $\left(p=0.070, \eta^{2}=0.59\right)$ in response to the cycling protocol when comparing pre-endurance ride (S: $979.2 \pm 155.1 \mu \mathrm{mol}^{-1}$; P: $867.3 \pm 231.2 \mu \mathrm{mol}^{-1}$ ) vs. post endurance ride (S: $953.1 \pm 112.7 \mu \mathrm{mol}^{-1}$; P: $971.1 \pm 191.1$ $\mu \mathrm{mol}^{-1}$ ) vs. post time trial (S: $886.0 \pm 146.8 \mu \mathrm{mol}^{-1} ; \mathrm{P}: 921.2 \pm 185.7 \mu \mathrm{mol}^{-1}$ ). The concentrations of GSSG were not significantly different $\left(p=0.076, \eta^{2}=0.58\right)$ in response to the cycling protocol when comparing pre-endurance ride (S: $292.1 \pm 53.8 \mu \mathrm{mol}^{-1}$; P: $274.0 \pm 73.4$ $\mu \mathrm{mol}^{-1}$ ) vs. post endurance ride (S: $293.0 \pm 61.6 \mu \mathrm{mol}^{-1} ; \mathrm{P}: 298.8 \pm 74.6 \mu \mathrm{mol}^{-1}$ ) vs. post time trial (S: $292.3 \pm 60.1 \mu \mathrm{mol}^{-1}$; P: $330.4 \pm 86.2 \mu \mathrm{mol}^{-1}$ ). The GSH:GSSG approached significance $\left(p=0.057, \eta^{2}=0.62\right)$ for a treatment-by-time effect when comparing pre-endurance ride (S: 1.4 \pm 0.7 ; P: $1.2 \pm 0.6$ ) vs. post endurance ride (S: $1.4 \pm 0.7 ; \mathrm{P}: 1.4 \pm 0.9$ ) vs. post time trial (S: $1.1 \pm$ $0.6, \mathrm{P}: 0.9 \pm 0.7$ ) (Figure 7). 
Nitrotyrosine. Nitrotyrosine concentrations were not significantly different $\left(p=0.445, \eta^{2}=\right.$ $0.10)$ between pre-endurance ride (S: $\left.51.65 \pm 72.41 \mathrm{nmol} \cdot \mathrm{L}^{-1} ; \mathrm{P}: 47.99 \pm 60.36 \mathrm{nmol} \cdot \mathrm{L}^{-1}\right)$ and post time trial $\left(\mathrm{S}: 75.05 \pm 124.00 \mathrm{nmol} \cdot \mathrm{L}^{-1} ; \mathrm{P}: 83.96 \pm 151.11 \mathrm{nmol} \cdot \mathrm{L}^{-1}\right)$.

\section{DISCUSSION}

The present study was designed to test the effects of short-term antioxidant supplementation on prolonged sub-maximal cycling, high-intensity cycling performance, and biochemical markers of oxidative stress while cyclists participated in their typical training and racing schedules. Peak aerobic power values, cycling economy, and racing experience classify the cyclists as well-trained (Table 1) (40). Cyclists of this caliber who regularly engage in highintensity exercise are expected to benefit from antioxidant/nutritional supplementation (72). However, the cyclists in the present study did not demonstrate any performance gains after shortterm supplementation with a multiple-step antioxidant nutritional cocktail.

The main finding of this study was that 5 days of antioxidant supplementation and a preexercise antioxidant/energy supplement approached significance for a treatment-by-time effect on the GSH:GSSG ratio (Figure 7). The supplementation attenuated the decrease in the ratio that was observed with the placebo in response to the time trial. However, the supplement protocol did not result in any improvements in cycling performance when compared to the placebo (Tables 5, Figures 2, 3, 4, and 5).

The performance testing protocol used in the present study has been validated for measuring endurance performance enhancement due to diet interventions (38). The high-intensity portion of the protocol consisted of a maximal self-paced time trial in which the cyclists averaged approximately $85 \% \mathrm{VO}_{2 \mathrm{Max}}$ and $90 \% \mathrm{HR}_{\operatorname{Max}}$ (Table 5). This intensity is similar to what cyclists 
would engage in during a road time trial or mountain bike competition $(36,63)$. Furthermore, the high-intensity nature of the time trial is supported by the lactate data (Figure 5). Lactate concentrations increased significantly during the time trial compared to the endurance ride for both treatment and placebo trials, and the cyclists achieved lactate concentrations above 4 $\mathrm{mmol} \cdot \mathrm{L}^{-1}$ during the time trial, which is similar to data collected on other trained cyclists (14). Thus, we can conclude that similar race intensities were reproduced in the testing scenario. The cyclists' economy for both the endurance ride and time trial (Tables 4 and 5) demonstrated a time effect for both treatment and placebo trials. After an initial increase, the cyclists' economy leveled-off during the later portion of the endurance ride. This initial improvement in cycling economy was most likely due to a delay in aerobic enzymatic activity at the onset of the cycling, while the decrease that occurred during the time trial was most likely due to fatigue that results from cycling at a high-intensity. Typical ratings of economy for trained cyclists are reported to be higher than $72 \mathrm{~W} \cdot \mathrm{L}^{-1} \cdot \min ^{-1}(40)$, and economy values for highly-competitive cyclists have been reported at $85 \mathrm{~W} \cdot \mathrm{L}^{-1} \cdot \mathrm{min}^{-1}(50)$. Cyclists in the present study reached greater than $81 \mathrm{~W} \cdot \mathrm{L}^{-1} \cdot \mathrm{min}^{-1}$ during later portions of the endurance ride and time trial.

Other similarities with cycling literature are the blood glucose concentrations and $\mathrm{CHO}$ oxidation rates of the cyclists. Blood glucose levels ranged from 3.56-4.78 mmol. $\mathrm{L}^{-1}$ throughout the testing protocol. While this seems quite low, the cyclists arrived at the laboratory in a fasted state and ingested only $4 \mathrm{kcal} \cdot \mathrm{kg}$ body weight ${ }^{-1}$ prior to the endurance ride. These values are similar to those reported by Dumke et al. (15), which ranged from 3.5-5.2 mmol. $\mathrm{L}^{-1}$. Total-body rates of $\mathrm{CHO}$ oxidation were calculated from the RER and, as expected, increased significantly 
during the time trial. The values during the endurance ride are also in line with values reported from other sources when measured during an endurance cycling bout $(10,22,32)$.

One aim of this study was to determine if a multiple-step antioxidant nutritional supplement alters markers of oxidative stress. The non-enzymatic antioxidant reduced glutathione has the ability to protect cells from the toxic effects of reactive oxygen species and related products (58). It is also used by glutathione peroxidase to neutralize hydrogen peroxide, resulting in the formation of oxidized glutathione (58), and it enhances the function of other exogenous antioxidants, such as ascorbic acid and $\alpha$-tocopherol $(29,55)$. Blood glutathione oxidation is a consistent determining marker of oxidative stress (74), as a decrease in the reduced glutathione/oxidized glutathione ratio and total glutathione concentration is routinely shown in the blood of exercising humans $(17,18,23,46,77)$, while the oxidized glutathione/total glutathione ratio increases $(9,71)$.

Blood reduced glutathione concentrations are generally between $800-2000 \mu \mathrm{mol} \cdot \mathrm{L}^{-1}(17,18$, 44), and oxidized glutathione concentrations vary depending on free-radical induced oxidative stress but have been found to be between $2.0-800 \mu \mathrm{mol} \cdot \mathrm{L}^{-1}(17,18,44)$. Higher reduced glutathione concentrations are found during rest, and higher oxidized glutathione concentration found during exercise. Concentrations also vary depending on the subject's level of training (46) and nutritional intake $(37,44)$, as well as in response to different types of exercise durations (13, $16,23)$ and intensities $(21,35)$, with greater intensities of exercise resulting in greater decreases in reduced glutathione (21). Training increases the basal reduced glutathione concentration in the blood (17), thereby providing increased protection against oxidative species during exercise. Our data indicate that the use of an all-natural antioxidant for a 5 day loading phase also has the potential to maintain basal total GSH levels during a competitive season $(p=0.038)$. Since total 
GSH is a measure of both GSH and GSSG, the finding that there was not a significant difference in the concentration of GSSG suggests that GSH levels were increased, which could potentially provide an extra level of protection against oxidative stress during exercise.

Furthermore, it is suggested that reactions between reactive oxygen species and nitric oxide result in the formation of nitrogen oxide intermediates, such as peroxynitrite, which nitrate proteins (82). Tyrosine residues found on proteins are susceptible to nitration by peroxynitrite, resulting in alteration of the physiological functions of these proteins and ultimately degradation (76). More specifically, peroxynitrite reacts directly with thiols, such as glutathione, and hemoproteins $(66,60)$. The product of tyrosine nitration, nitrotyrosine, can therefore also be used as a marker of oxidative stress $(3,82)$ and provide an indication of the potential for oxidation of thiols and hemoproteins. However, our data indicated no significant changes in the nitrotyrosine concentrations with exercise.

The non-significant changes in the glutathione antioxidant system and nitrotyrosine concentrations indicate that a 90-min cycling exercise at a heart rate of five beats below the ventilatory threshold, approximately $65 \% \mathrm{VO}_{2 \mathrm{Max}}$, did not appear to induce oxidative stress in trained cyclists, although reductions in the GSH:GSSG ratio did occur during the time trial. The findings during the preload portion of the cycling protocol are inconsistent with the observations from other studies which have used long-duration cycling exercise as a means to induce oxidative stress as indicated by glutathione status $(23,83)$.

A potential reason for the discrepancy in our oxidative stress results could be due to sample collection procedures. While both Gohil et al. (23) and Viguie et al. (83) also reported no change in total GSH levels, they reported increases in GSSG and decreases in GSH. These changes could have occurred during sample collection, where it is possible that GSH was rapidly 
oxidized to form GSSG. The methods used in our study involved the use of a fast-acting scavenger agent M2VP to neutralize any free radicals present at the time of sample collection and prevent any further in vitro oxidation. Therefore, the discrepancy between past and present data is most likely due to the presence of the scavenger in the collection procedure. The concentrations found in our study are in line with those reported by others who have also used $\operatorname{M2VP}(18,17)$.

In addition, data published after the completion of this study suggests that the best time point for sampling blood alterations in the glutathione antioxidant system is 2 hours after the cessation of exercise (59), indicating that our immediately post-exercise sampling point may have potentially been too early to examine the greatest alterations in the glutathione system. However, the study was performed on untrained subjects using an exhaustive treadmill protocol, while our study examined trained cyclists. In addition, another study demonstrated that alterations in the glutathione antioxidant system appear to be diminished 30 minutes after the cessation of exercise in trained cyclists and runners (23). Therefore, the immediate post exercise time point appears to be appropriate with trained athletes such as those in the present study.

To our knowledge, this was the first attempt to use nitrotyrosine as an indicator of oxidative stress in response to cycling. Other studies have successfully used similar cycling protocols to induce oxidative stress on other indices such as protein carbonyls and plasma 8-OHdg levels (61). Nitrotyrosine levels have been shown to increase significantly in response to long-duration running during a consecutive four-day super-marathon totaling $328 \mathrm{~km}$ (67). This rise in protein nitration indicates the occurrence of oxidative stress to proteins in well-trained endurance athletes. While one might argue that an event this extreme may not relate to usual competitions in which most endurance athletes engage, the levels of serum nitrotyrosine increased after the 
first day, which consisted of $93 \mathrm{~km}$ of running, and remained at that level for the duration of the competition (67). In the present study, the nitrotyrosine levels increased in response to cycling, but the subject pool presented with a large individual variation in the levels of resting and exercising nitrotyrosine, which may have masked any significant alterations that may have been present. This individual difference is most likely due to the principle that the accumulation of oxidative damage is relative to the collective success of the antioxidant and muscle repair systems (68), training status $(54,64)$, and intensity of the exercise (35).

This study was designed to provide insight into whether or not short-term antioxidant supplementation is capable of increasing performance by decreasing oxidative stress in trained cyclists in response to a high-intensity cycling test during a competitive cycling season. To directly answer this question, a series of events must occur. First, the exercise protocol must disturb the balance of antioxidants/oxidants to establish a state of oxidative stress in the system. Second, the biological markers used to asses the stress must be sensitive enough to detect any alterations. Third, the subjects must present with increased performance under a state of reduced stress while consuming the treatment. These series of events would lead to a positive correlation that could suggest that short-term antioxidant supplementation may lead to increases in cycling performance. Without the occurrence of all of these events, it is difficult to determine if there is any benefit to consuming an antioxidant supplement for a short loading phase prior to highlyaerobic competitions such as competitive cycling.

Perhaps a more demanding protocol such as 3 consecutive days of high-intensity cycling that closely resembles a stage race could increase oxidative stress levels and subsequently result in greater levels of fatigue. Such a protocol has been used to examine the effects of a beverage containing carbohydrate, protein, and antioxidants over 2 days of consecutive cycling, but while 
levels of creatine kinase were decreased, the authors were unable to show an increase in performance and failed to examine any indicators of oxidative stress (70). Furthermore, during the Tour de France, the administration of allopurinol, an inhibitor of the free radical-generating enzyme xanthine oxidase, did attenuate increases in the marker of lipid peroxidation malondialdehyde but did not result in any increases in performance (27). These data indicate that a multiple-day protocol induces muscle damage and oxidative damage, respectively; therefore, a multiple day protocol could be useful in determining the effects of short-term antioxidant supplementation.

In summary, although this study does not indicate that a short-term multiple-step antioxidant nutritional supplement protocol results in improved cycling performance, according to the data collected on the glutathione antioxidant system it does provide some level of protection against oxidative stress. Even though some adaptation of the antioxidant systems can occur (69), the adaptations may not be adequate to prevent oxidative damage in some athletes (65) or to improve performance. A nutritional supplement that provides antioxidants and energy could be ideal for some endurance athletes $(52,41)$, and research should continue to evaluate its effects on oxidative stress and performance using novel antioxidant supplements. 


\section{REFERENCES}

1. Abel, T., B. Knechtle, C. Perret, P. Eser, P. von Arx, and H. Knecht. Influence of chronic supplementation of arginine aspartate in endurance athletes on performance and substrate metabolism - a randomized, double-blind, placebo-controlled study. Int J Sports Med. 26:344-349, 2005.

2. Aguilo, A., P. Tauler, A. Sureda, N. Cases, J. Tur, and A. Pons. Antioxidant diet supplementation enhances aerobic performance in amateur sportsmen. J Sports Sci. $25: 1203-1210,2007$.

3. Ahn, E. S., C. L. Robertson, V. Vereczki, G. E. Hoffman, and G. Fiskum. Normoxic ventilatory resuscitation following controlled cortical impact reduces peroxynitritemediated protein nitration in the hippocampus. J Neurosurg. 108:124-131, 2008.

4. Amann, M., A. W. Subudhi, and C. Foster. Predictive validity of ventilatory and lactate thresholds for cycling time trial performance. Scand J Med Sci Sports. 16:27-34, 2006.

5. Ashton, T.,I. S. Young,G. W. Davison, et al. Exercise-induced endotoxemia: the effect of ascorbic acid supplementation. Free Radic Biol Med. 35:284-291, 2003.

6. Bloomer, R. J., A. H. Goldfarb, and M. J. McKenzie. Oxidative stress response to aerobic exercise: comparison of antioxidant supplements. Med Sci Sports Exerc. 38:1098-1105, 2006.

7. Borg, G. A. Psychophysical bases of perceived exertion. Med Sci Sports Exerc. 14:377$381,1982$.

8. Broad, E. M., R. J. Maughan, and S. D. Galloway. Effects of four weeks L-carnitine Ltartrate ingestion on substrate utilization during prolonged exercise. Int J Sport Nutr Exerc Metab. 15:665-679, 2005. 
9. Bryer, S. C.andA. H. Goldfarb. Effect of high dose vitamin C supplementation on muscle soreness, damage, function, and oxidative stress to eccentric exercise. Int J Sport Nutr Exerc Metab. 16:270-280, 2006.

10. Currell, K.andA. E. Jeukendrup. Superior endurance performance with ingestion of multiple transportable carbohydrates. Med Sci Sports Exerc. 40:275-281, 2008.

11. Davison, G.andM. Gleeson. The effect of 2 weeks vitamin C supplementation on immunoendocrine responses to $2.5 \mathrm{~h}$ cycling exercise in man. Eur J Appl Physiol. 97:454-461, 2006.

12. Davison, G., M. Gleeson, and S. Phillips. Antioxidant supplementation and immunoendocrine responses to prolonged exercise. Med Sci Sports Exerc. 39:645-652, 2007.

13. Dufaux, B., O. Heine, A. Kothe, U. Prinz, and R. Rost. Blood glutathione status following distance running. Int J Sports Med. 18:89-93, 1997.

14. Dumke, C. L., D. W. Brock, B. H. Helms, and G. G. Haff. Heart rate at lactate threshold and cycling time trials. J Strength Cond Res. 20:601-607, 2006.

15. Dumke, C. L., J. M. McBride, D. C. Nieman, W. D. Gowin, A. C. Utter, and S. R. McAnulty. Effect of Duration and Exogenous Carbohydrate on Gross EfficiencyDuring Cycling. J Strength Cond Res. 21:1214-1219, 2007.

16. Duthie, G. G., J. D. Robertson, R. J. Maughan, and P. C. Morrice. Blood antioxidant status and erythrocyte lipid peroxidation following distance running. Arch Biochem Biophys. 282:78-83, 1990.

17. Elokda, A. S.andD. H. Nielsen. Effects of exercise training on the glutathione antioxidant system. Eur J Cardiovasc Prev Rehabil. 14:630-637, 2007. 
18. Elokda, A. S., R. K. Shields, and D. H. Nielsen. Effects of a maximal graded exercise test on glutathione as a marker of acute oxidative stress. J Cardiopulm Rehabil. 25:215-219, 2005.

19. Eschbach, L. F., M. J. Webster, J. C. Boyd, P. D. McArthur, and T. K. Evetovich. The effect of siberian ginseng (Eleutherococcus senticosus) on substrate utilization and performance. Int J Sport Nutr Exerc Metab. 10:444-451, 2000.

20. Faria, E. W., D. L. Parker, and I. E. Faria. The science of cycling: factors affecting performance - part 2. Sports Med. 35:313-337, 2005.

21. Gambelunghe, C., R. Rossi, A. Micheletti, G. Mariucci, and S. Rufini. Physical exercise intensity can be related to plasma glutathione levels. J Physiol Biochem. 57:9-14, 2001.

22. Glazier, L. R., T. Stellingwerff, and L. L. Spriet. Effects of microhydrin supplementation on endurance performance and metabolism in well-trained cyclists. Int J Sport Nutr Exerc Metab. 14:560-573, 2004.

23. Gohil, K., C. Viguie, W. C. Stanley, G. A. Brooks, and L. Packer. Blood glutathione oxidation during human exercise. $J$ Appl Physiol. 64:115-119, 1988.

24. Goldfarb, A. H. Antioxidants: role of supplementation to prevent exercise-induced oxidative stress. Med Sci Sports Exerc. 25:232-236, 1993.

25. Goldfarb, A. H. Nutritional antioxidants as therapeutic and preventive modalities in exercise-induced muscle damage. Can J Appl Physiol. 24:249-266, 1999.

26. Gomez-Cabrera, M. C., E. Domenech, and J. Vina. Moderate exercise is an antioxidant: Upregulation of antioxidant genes by training. Free Radic Biol Med. 44:126-131, 2008. 
27. Gomez-Cabrera, M. C., F. V. Pallardo, J. Sastre, J. Vina, and L. Garcia-del-Moral. Allopurinol and markers of muscle damage among participants in the Tour de France. Jama. 289:2503-2504, 2003.

28. Gore, C. J. Physiological Tests for Elite Athletes: Human Kinetics, 2000

29. Groussard, C.,F. Rannou-Bekono,G. Machefer, et al. Changes in blood lipid peroxidation markers and antioxidants after a single sprint anaerobic exercise. Eur J Appl Physiol. 89:14-20, 2003.

30. Haff, G. G., B. Ossnebrink, W. A. Sands, and M. H. Stone. Reliability and Validity of the Computrainer and Powertap Power Meter. J Strength Cond Res. 20:e15, 2006.

31. Halliwell, B.andJ. M. Gutteridge. Free radicals in Biology and Medicine (2nd ed.) Oxford: Clarendon Press, pp 136-158. 1989.

32. Halson, S. L., G. I. Lancaster, J. Achten, M. Gleeson, and A. E. Jeukendrup. Effects of carbohydrate supplementation on performance and carbohydrate oxidation after intensified cycling training. J Appl Physiol. 97:1245-1253, 2004.

33. Hartmann, A., A. M. Niess, M. Grunert-Fuchs, B. Poch, and G. Speit. Vitamin E prevents exercise-induced DNA damage. Mutat Res. 346:195-202, 1995.

34. Holm, S. A simple seqentially rejective multiple test procedure. Scand. J. Statistics. 6:6570, 1979.

35. Ilhan, N., A. Kamanli, R. Ozmerdivenli, and N. Ilhan. Variable effects of exercise intensity on reduced glutathione, thiobarbituric acid reactive substance levels, and glucose concentration. Arch Med Res. 35:294-300, 2004. 
36. Impellizzeri, F., A. Sassi, M. Rodriguez-Alonso, P. Mognoni, and S. Marcora. Exercise intensity during off-road cycling competitions. Med. Sci. Sports Exerc. 34:1808-1813, 2002.

37. Jackson, A. A., N. R. Gibson, Y. Lu, and F. Jahoor. Synthesis of erythrocyte glutathione in healthy adults consuming the safe amount of dietary protein. Am J Clin Nutr. 80:101107, 2004.

38. Jeukendrup, A., W. H. Saris, F. Brouns, and A. D. Kester. A new validated endurance performance test. Med Sci Sports Exerc. 28:266-270, 1996.

39. Jeukendrup, A. E. Carbohydrate intake during exercise and performance. Nutrition. 20:669-677, 2004.

40. Jeukendrup, A. E., N. P. Craig, and J. A. Hawley. The bioenergetics of World Class Cycling. J Sci Med Sport. 3:414-433, 2000.

41. Ji, L. L. Antioxidants and oxidative stress in exercise. Proc Soc Exp Biol Med. 222:283292, 1999.

42. Ji, L. L. Oxidative stress during exercise: implication of antioxidant nutrients. Free Radic Biol Med. 18:1079-1086, 1995.

43. Ji, L. L., M. C. Gomez-Cabrera, and J. Viña. Exercise and hormesis: activation of cellular antioxidant signaling pathway. Ann N Y Acad Sci. 1067:425-435, 2006.

44. Ji, L. L., A. Katz, R. Fu, M. Griffiths, and M. Spencer. Blood glutathione status during exercise: effect of carbohydrate supplementation. J Appl Physiol. 74:788-792, 1993.

45. Kirksey, B.,M. Stone,B. Warren, et al. The effects of 6 weeks of creatine monohydrate supplementation on performance measures and body composition in collegiate track and field athletes. J Strength Cond Res. 13:148, 1999. 
46. Kretzschmar, M., D. Müller, J. Hübscher, E. Marin, and W. Klinger. Influence of aging, training and acute physical exercise on plasma glutathione and lipid peroxides in man. Int J Sports Med. 12:218-222, 1991.

47. Kulik, J., C. Touchberry, N. Kawamori, P. Blumert, A. Crum, and G. G. Haff. Supplemental carbohydrate ingestion does not improve performance of high-intensity resistance exercse. J Strength Cond Res. 22:1101, 2008.

48. Lambert, E. V., J. A. Hawley, J. Goedecke, T. D. Noakes, and S. C. Dennis. Nutritional strategies for promoting fat utilization and delaying the onset of fatigue during prolonged exercise. J Sports Sci. 15:315-324, 1997.

49. Lee, R. D., D. C. Nieman, and M. Rainwater. Comparison of eight microcomputer dietary analysis programs with the USDA Nutrient Data Base for Standard Reference. J Am Diet Assoc. 95:858-867, 1995.

50. Lucia, A., J. Hoyos, M. Perez, A. Santalla, and J. L. Chicharro. Inverse relationship between VO2max and economy/efficiency in world-class cyclists. Med Sci Sports Exerc. 34:2079-2084, 2002.

51. Macdermid, P. W.andS. R. Stannard. A whey-supplemented, high-protein diet versus a high-carbohydrate diet: effects on endurance cycling performance. Int J Sport Nutr Exerc Metab. 16:65-77, 2006.

52. Machefer, G.,C. Groussard,H. Zouhal, et al. Nutritional and plasmatic antioxidant vitamins status of ultra endurance athletes. J Am Coll Nutr. 26:311-316, 2007.

53. MacRae, H. S.andK. M. Mefferd. Dietary antioxidant supplementation combined with quercetin improves cycling time trial performance. Int J Sport Nutr Exerc Metab. 16:405419, 2006. 
54. Margaritis, I., S. Palazzetti, A. S. Rousseau, M. J. Richard, and A. Favier. Antioxidant supplementation and tapering exercise improve exercise-induced antioxidant response. $J$ Am Coll Nutr. 22:147-156, 2003.

55. May, J. M., Z.-C. Qu, R. R. Whitesell, and C. E. Cobb. Ascorbate recycling in human erythrocytes: Role of GSH in reducing dehydroascorbate. Free Radic Biol Med. 20:543$551,1996$.

56. McAnulty, S. R.,L. S. McAnulty,D. C. Nieman, et al. Chronic quercetin ingestion and exercise-induced oxidative damage and inflammation. Appl Physiol Nutr Metab. 33:254$262,2008$.

57. McConell, G. K., N. N. Huynh, R. S. Lee-Young, B. J. Canny, and G. D. Wadley. LArginine infusion increases glucose clearance during prolonged exercise in humans. Am J Physiol Endocrinol Metab. 290:E60-E66, 2006.

58. Meister, A. Glutathione metabolism and its selective modification. J Biol Chem. 263:17205-17208, 1988 .

59. Michailidis, Y.,A. Z. Jamurtas,M. G. Nikolaidis, et al. Sampling time is crucial for measurement of aerobic exercise-induced oxidative stress. Med Sci Sports Exerc. 39:1107-1113, 2007.

60. Minetti, M., D. Pietraforte, V. Carbone, A. M. Salzano, G. Scorza, and G. Marino. Scavenging of peroxynitrite by oxyhemoglobin and identification of modified globin residues. Biochemistry. 39:6689-6697, 2000.

61. Morillas-Ruiz, J.,P. Zafrilla,M. Almar, et al. The effects of an antioxidant-supplemented beverage on exercise-induced oxidative stress: results from a placebo-controlled doubleblind study in cyclists. Eur J Appl Physiol. 95:543-549, 2005. 
62. Nieman, D. C.,D. A. Henson,S. R. McAnulty, et al. Vitamin E and immunity after the Kona Triathlon World Championship. Med Sci Sports Exerc. 36:1328-1335, 2004.

63. Padilla, S., I. Mujika, J. Orbananos, and F. Angulo. Exercise intensity during competition time trials in professional road cycling. Med. Sci. Sports Exerc. 32:850-856, 2000.

64. Palazzetti, S., M. J. Richard, A. Favier, and I. Margaritis. Overloaded training increases exercise-induced oxidative stress and damage. Can J Appl Physiol. 28:588-604, 2003.

65. Palazzetti, S., A. S. Rousseau, M. J. Richard, A. Favier, and I. Margaritis. Antioxidant supplementation preserves antioxidant response in physical training and low antioxidant intake. Br J Nutr. 91:91-100, 2004.

66. Quijano, C., B. Alvarez, R. M. Gatti, O. Augusto, and R. Radi. Pathways of peroxynitrite oxidation of thiol groups. Biochem J. 322 ( Pt 1):167-173, 1997.

67. Radák, Z.,H. Ogonovszky,J. Dubecz, et al. Super-marathon race increases serum and urinary nitrotyrosine and carbonyl levels. Eur J Clin Invest. 33:726-730, 2003.

68. Radak, Z., J. Pucsuk, S. Boros, L. Josfai, and A. W. Taylor. Changes in urine 8hydroxydeoxyguanosine levels of super-marathon runners during a four-day race period. Life Sci. 66:1763-1767, 2000.

69. Radak, Z., A. W. Taylor, H. Ohno, and S. Goto. Adaptation to exercise-induced oxidative stress: from muscle to brain. Exerc Immunol Rev. 7:90-107, 2001.

70. Romano-Ely, B. C., M. K. Todd, M. J. Saunders, and T. S. Laurent. Effect of an isocaloric carbohydrate-protein-antioxidant drink on cycling performance. $\mathrm{Med}$ Sci Sports Exerc. 38:1608-1616, 2006. 
71. Sastre, J.,M. Asensi,E. Gascó, et al. Exhaustive physical exercise causes oxidation of glutathione status in blood: prevention by antioxidant administration. Am J Physiol. 263:R992-995, 1992.

72. Saunders, M. J., M. D. Kane, and M. K. Todd. Effects of a carbohydrate-protein beverage on cycling endurance and muscle damage. Med Sci Sports Exerc. 36:1233-1238, 2004.

73. Saunders, M. J., N. D. Luden, and J. E. Herrick. Consumption of an oral carbohydrateprotein gel improves cycling endurance and prevents postexercise muscle damage. $J$ Strength Cond Res. 21:678-684, 2007.

74. Sen, C. K.andL. Packer. Thiol homeostasis and supplements in physical exercise. Am J Clin Nutr. 72:653S-669S, 2000.

75. Senturk, U. K., O. Yalcin, F. Gunduz, O. Kuru, H. J. Meiselman, and O. K. Baskurt. Effect of antioxidant vitamin treatment on the time course of hematological and hemorheological alterations after an exhausting exercise episode in human subjects. $J$ Appl Physiol. 98:1272-1279, 2005.

76. Souza, J. M.,I. Choi,Q. Chen, et al. Proteolytic degradation of tyrosine nitrated proteins. Arch Biochem Biophys. 380:360-366, 2000.

77. Tessier, F., I. Margaritis, M. J. Richard, C. Moynot, and P. Marconnet. Selenium and training effects on the glutathione system and aerobic performance. Med Sci Sports Exerc. 27:390-396, 1995.

78. Thomas, C.,S. Perrey,H. Ben Saad, et al. Effects of a supplementation during exercise and recovery. Int J Sports Med. 28:703-712, 2007. 
79. Thompson, D.,C. Williams,M. Kingsley, et al. Muscle soreness and damage parameters after prolonged intermittent shuttle-running following acute vitamin C supplementation. Int J Sports Med. 22:68-75, 2001.

80. Van Beaumont, W. Red cell volume with changes in plasma osmolarity during maximal exercise. J Appl Physiol. 35:47-50, 1973.

81. van Essen, M.andM. J. Gibala. Failure of protein to improve time trial performance when added to a sports drink. Med Sci Sports Exerc. 38:1476-1483, 2006.

82. Viappiani, S.andR. Schulz. Detection of specific nitrotyrosine-modified proteins as a marker of oxidative stress in cardiovascular disease. Am J Physiol Heart Circ Physiol. 290:H2167-2168, 2006.

83. Viguie, C. A., B. Frei, M. K. Shigenaga, B. N. Ames, L. Packer, and G. A. Brooks. Antioxidant status and indexes of oxidative stress during consecutive days of exercise. $J$ Appl Physiol. 75:566-572, 1993. 
Table 1. Subject Characteristics

\begin{tabular}{lrrc}
\hline Variable & Mean \pm & SD & Range \\
\hline Age (years) & $28.9 \pm$ & 7.2 & $(22-44)$ \\
Body Mass (kg) & $77.5 \pm$ & 7.0 & $(69.5-88.2)$ \\
Height $(\mathrm{cm})$ & $178.1 \pm$ & 6.3 & $(171.8-191.0)$ \\
Racing Experience (years) & $9.9 \pm$ & 4.9 & $(3-20)$ \\
Max heart rate $\left(\mathrm{b} \cdot \mathrm{min}^{-1}\right)$ & $186.5 \pm$ & 7.4 & $(174-198)$ \\
Body fat $(\%)$ & $16.4 \pm$ & 7.4 & $(3.3-24.7)$ \\
$\mathrm{VO}_{2 \max }\left(\mathrm{ml} \cdot \mathrm{kg}^{-1} \cdot \mathrm{min}^{-1}\right)$ & $55.0 \pm$ & 5.5 & $(49.0-65.3)$ \\
$\mathrm{VO}_{2 \max }\left(\mathrm{L} \cdot \mathrm{min}^{-1}\right)$ & $4.2 \pm$ & 0.3 & $(3.9-4.7)$ \\
Max power output $(\mathrm{W})$ & $400.7 \pm$ & 30.7 & $(350.0-443.8)$ \\
Max power output $\left(\mathrm{W} \cdot \mathrm{kg}^{-1}\right)$ & $5.2 \pm$ & 0.7 & $(4.3-6.2)$ \\
\hline
\end{tabular}

Data are presented as mean $\pm \mathrm{SD}$; range is in parentheses; $\mathrm{N}=8$. Max $=$ maximum. 
Table 2. Step-One Treatment Ingredients

Serving Size: 4 Vegetarian Capsules

Amount per

Serving

Vitamin C (as ascorbic acid)

Thiamine (vitamin B1) (as thiamine mononitrate)

$100 \mathrm{mg}$

\% Daily Value

Riboflavin (vitamin B2)

Niacin (as inositol hexanicotinate)

$25 \mathrm{mg}$

$167 \%$

Vitamin B6 (as pyridoxine hydrochloride)

Folate (as folic acid)

Vitamin B12 (as cyanocobalamin)

$25 \mathrm{mg}$

$1667 \%$

$75 \mathrm{mg}$

$1471 \%$

$25 \mathrm{mg}$

$375 \%$

$100 \mathrm{mcg}$

$1250 \%$

Biotin

$200 \mathrm{mcg}$

$25 \%$

Pantothenic Acid (as d-calcium pentothenate)

$20 \mathrm{mcg}$

$3333 \%$

$25 \mathrm{mg}$

$7 \%$

Calcium (from mineralized seaweed)

$100 \mathrm{mg}$

$250 \%$

Iron (as ferrous bisglycinate)

$9 \mathrm{mg}$

$10 \%$

Zinc (as zinc monomethionine)

$10 \mathrm{mg}$

$50 \%$

Selenium (as selenomethionine)

$70 \mathrm{mcg}$

$67 \%$

Chromium (as chromium picolinate)

Endurance Proprietary Blend

$120 \mathrm{mcg}$

$100 \%$

$1,107 \mathrm{mg}$

$100 \%$

Bromelain, Hawthorne Extract (berry), Mullein (leaf),

Quercetin, Eleuthero Extract (root), American Ginseng

Extract (root), Cordyceps Extract (mushroom), Devil's

Claw Extract (root), Milk Thistle Extract (seed), Nettle

Extract (root), Turmeric Extract (root), Prickly Ash (bark),

Cayenne Extract (fruit), Choline (as choline bitartrate), Astragalus Extract (root), Panax Ginseng Extract (root), PABA (as para-aminobenzoic acid), Bioperine ${ }^{\circledR}$ Pepper Extract (fruit), Astaxanthin, Vanadium (as BGOV bisglycinato-oxo-vanadium)

* \% Daily Value not established

OTHER INGREDIENTS:

Cellulose, Maltodextrin, Silicon Dioxide, Magnesium Stearate 
Table 3. Step-One and Step-Two Placebo Ingredients

\begin{tabular}{lcc}
\hline Product (serving size) & Capsules & Beverage (24.5 g) \\
\hline Calories & --- & 100 \\
Total Carbohydrate (g) & -- & 25 \\
Listed Ingredients & $*$ & $* *$ \\
\hline$*$ microcrystalline cellulose, manntitol, FDC yellow \#5 lake, FDC yellow \#6 lake, FDC \\
blue \#2 lake, magnesium stearate, and silicon dioxide \\
$* *$ maltodextrin, dextrose, non-fat dry milk, spirulina, natural and artificial flavors, and \\
stevia extract
\end{tabular}


Table 4. Step-Two Treatment Ingredients

\begin{tabular}{lcc}
\hline Serving Size: 1 packet $(24.5 \mathrm{~g})$ & $\begin{array}{c}\text { Amount } \\
\text { per Serving }\end{array}$ & \% Daily Value \\
\hline Calories & 100 & \\
$\quad$ Calories from Fat & 5 & \\
Total Fat & $0.5 \mathrm{~g}$ & $1 \% \dagger$ \\
$\quad$ Cholesterol & $<5 \mathrm{mg}$ & $1 \% \dagger$ \\
Total Carbohydrate & $14 \mathrm{~g}$ & $5 \% \dagger$ \\
$\quad$ Dietary Fiber & $5 \mathrm{~g}$ & $20 \% \dagger$ \\
$\quad$ Sugars & $4 \mathrm{~g}$ & $*$ \\
Protein & $9 \mathrm{~g}$ & \\
Sodium & $80 \mathrm{mg}$ & $3 \%$ \\
PreGame Proprietary Blend: & $21.2 \mathrm{~g}$ & $*$ \\
\hline * $\%$ Daily Value not established & & \\
$\dagger$ Percent Daily Values are based on a 2,000 calorie diet. & \\
\hline Other Ingredients: & & \\
Non Fat Dry Milk, Natural Flavors, Stevia Leaf Extract & & \\
\hline
\end{tabular}


Table 5. Performance Data

\begin{tabular}{|c|c|c|c|c|c|c|c|c|c|c|c|c|}
\hline \multirow[t]{2}{*}{ Variable } & \multicolumn{2}{|c|}{ Treatment ER } & \multicolumn{2}{|c|}{ Placebo ER } & \multicolumn{2}{|c|}{ t-test } & \multicolumn{2}{|c|}{ Treatment TT } & \multicolumn{2}{|c|}{ Placebo TT } & \multicolumn{2}{|c|}{ t-test } \\
\hline & Mean \pm & SD & Mean \pm & $\mathrm{SD}$ & $\mathrm{p}$ & $\eta^{2}$ & Mean \pm & $\mathrm{SD}$ & Mean \pm & SD & $\mathrm{P}$ & $\eta^{2}$ \\
\hline \multicolumn{13}{|c|}{ Relative Performance } \\
\hline Average $\mathrm{VO}_{2}$ & $36.5 \pm$ & 3.2 & $35.7 \pm$ & 4.5 & 0.35 & 0.12 & $45.3 \pm$ & 3.5 & $42.6 \pm$ & 6.0 & 0.19 & 0.01 \\
\hline Average PWR & $2.8 \pm$ & 0.4 & $2.8 \pm$ & 0.4 & 0.68 & 0.03 & $3.9 \pm$ & 0.8 & $4.0 \pm$ & 0.6 & 0.84 & 0.01 \\
\hline$\% \mathrm{VO}_{2 \max }$ & $66.7 \pm$ & 7.9 & $65.4 \pm$ & 9.2 & 0.34 & 0.12 & $82.6 \pm$ & 5.8 & $78.1 \pm$ & 12.8 & 0.17 & 0.23 \\
\hline \multicolumn{13}{|c|}{ Absolute Performance } \\
\hline Average $\mathrm{VO}_{2}$ & $2.8 \pm$ & 0.4 & $2.8 \pm$ & 0.4 & 0.39 & 0.11 & $3.5 \pm$ & 0.4 & $3.3 \pm$ & 0.6 & 0.21 & 0.01 \\
\hline Average HR & $148.4 \pm$ & 3.5 & $146.3 \pm$ & 4.5 & 0.20 & 0.08 & $171.1 \pm$ & 6.5 & $170.3 \pm$ & 3.5 & 0.79 & 0.01 \\
\hline Average PWR & $224.0 \pm$ & 36.5 & $219.1 \pm$ & 19.2 & 0.58 & 0.05 & $303.6 \pm$ & 59.2 & $306.1 \pm$ & 47.0 & 0.84 & 0.01 \\
\hline$\% \mathrm{VO}_{2 \max }$ & $66.9 \pm$ & 7.7 & $65.8 \pm$ & 9.7 & 0.46 & 0.11 & $83.3 \pm$ & 5.7 & $78.8 \pm$ & 13.2 & 0.21 & 0.21 \\
\hline Time (s) & & & & & & & $923.0 \pm$ & 118.5 & $901.5 \pm$ & 89.7 & 0.68 & 0.03 \\
\hline
\end{tabular}

Note: Data are presented as mean \pm standard deviation $(\mathrm{SD}) ; \mathrm{N}=8$; Significance was set at $\mathrm{p} \leq 0.05 ; \eta^{2}=$ effect size, ER $=$ endurance ride, $\mathrm{TT}=$ time trial, Relative performance is expressed per $\mathrm{kg}, \mathrm{VO}_{2}=$ oxygen consumption $\left(\mathrm{ml} \cdot \mathrm{min}^{-1}\right)$ or absolute $\left(\mathrm{L} \cdot \mathrm{min}^{-1}\right), \mathrm{PWR}=$ relative power output $(\mathrm{W}), \% \mathrm{VO}_{2 \mathrm{Max}}=\operatorname{avg}$ percentage $\mathrm{VO}_{2 \mathrm{Max}}\left(\mathrm{ml} \cdot \mathrm{min}^{-1}\right)$ or $\left(\mathrm{L} \cdot \mathrm{min}^{-1}\right)$, and $\mathrm{t}-$ test $=$ paired comparison . 


\section{Figure Captions}

Figure 1. Outline of the experimental approach for the study. RB1 = resting basal blood sample one, $\mathrm{RB} 2$ = resting basal blood sample two, $\mathrm{RS} 1$ = resting pre-endurance ride blood sample one, $\mathrm{RS} 2=$ resting pre-endurance ride blood sample two, ER1 = post endurance ride blood sample one, $\mathrm{ER} 2$ = post endurance ride blood sample two, TT1 = post time trial blood sample one, TT2 $=$ post time trial blood sample two.

Figure 2. Cluster plot graph representing the time to finish the time trial portion of the cycle ergometry test.

Figure 3. Cluster plot graph representing the maximal and average relative power during the time trial test.

Figure 4. Line graph of the economy at the 30,60, and 90 minute time points during the endurance ride with standard deviation bars.

Figure 5. Line graph of the economy at the 5, 10, and 15 minute time points during the time trial with standard deviation bars.

Figure 6. Line graph of the lactate concentration at the pre-endurance ride, post endurance ride, and post time trial time points during the cycle ergometry test with standard deviation bars.

Figure 7. Bar graph of the ratio of GSH:GSSG at the specified time points throughout the study with standard deviation bars. 


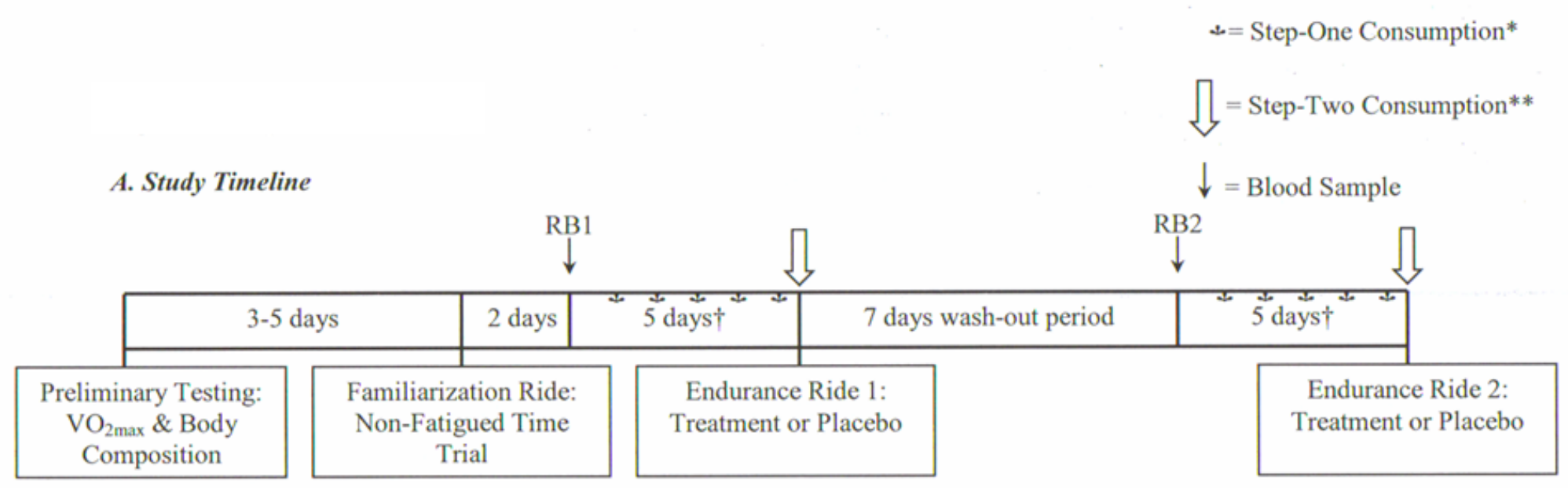

B. Testing Protocol for Experimental Trials

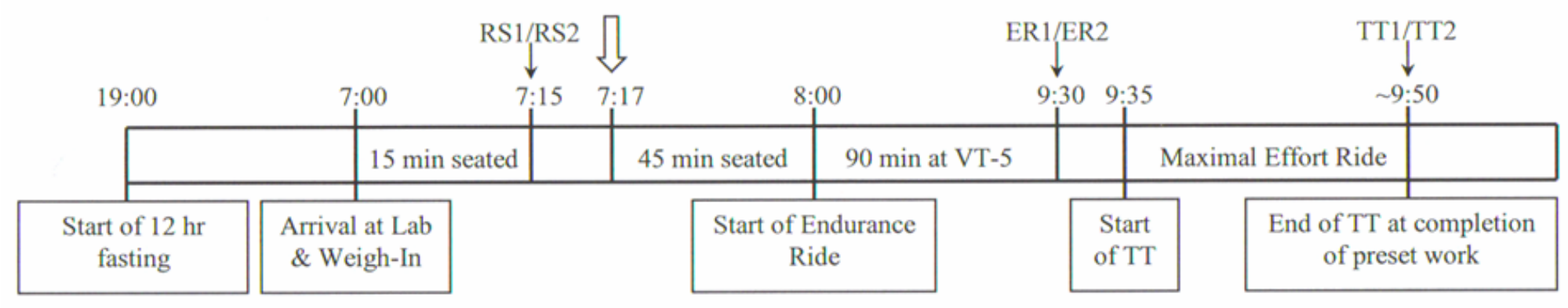

*Step-One Consumption consisted of Endurance Blend $\circledast$ capsules or placebo capsules ( 2 capsules $2 \mathrm{x} /$ day)
**Step-Two Consumption consisted of Pregame $\Vdash$ beverage or isocaloric placebo beverage $(4 \mathrm{kcal} / \mathrm{kg})$ $\dagger$ During this five day period of step-one consumption subjects completed a five day dietary recall and five day training $\log$

Figure 1 


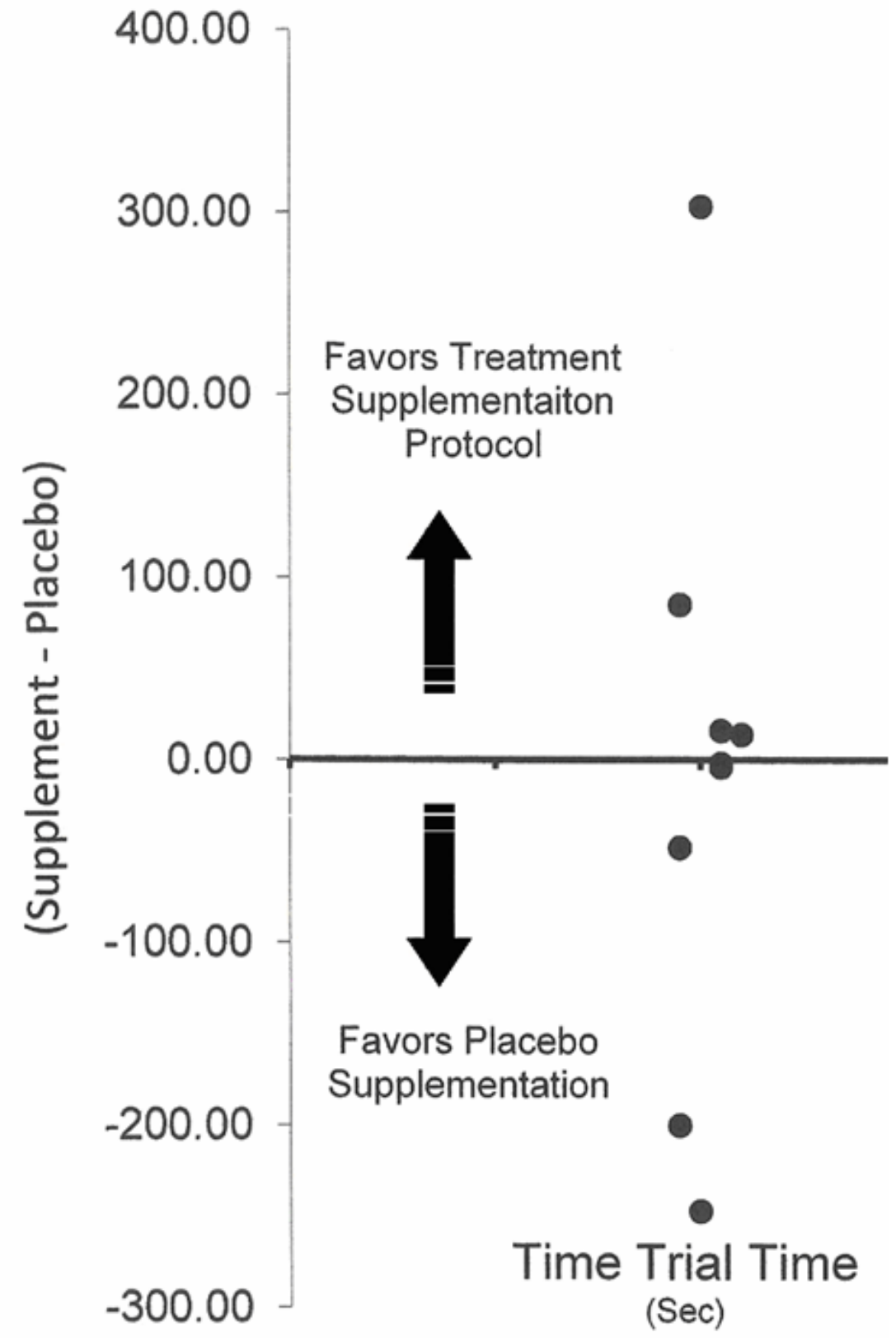

Figure 2 


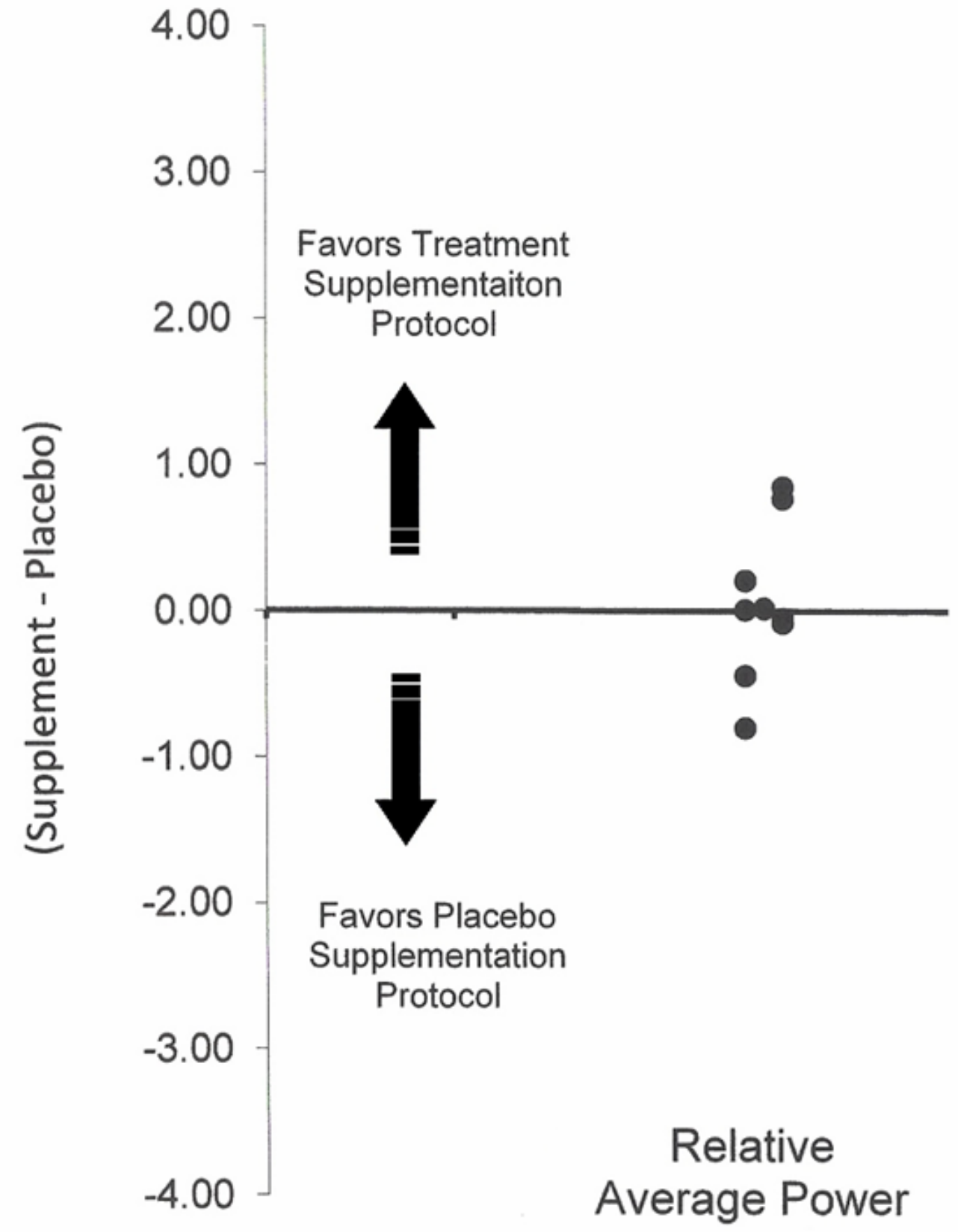

Figure 3 


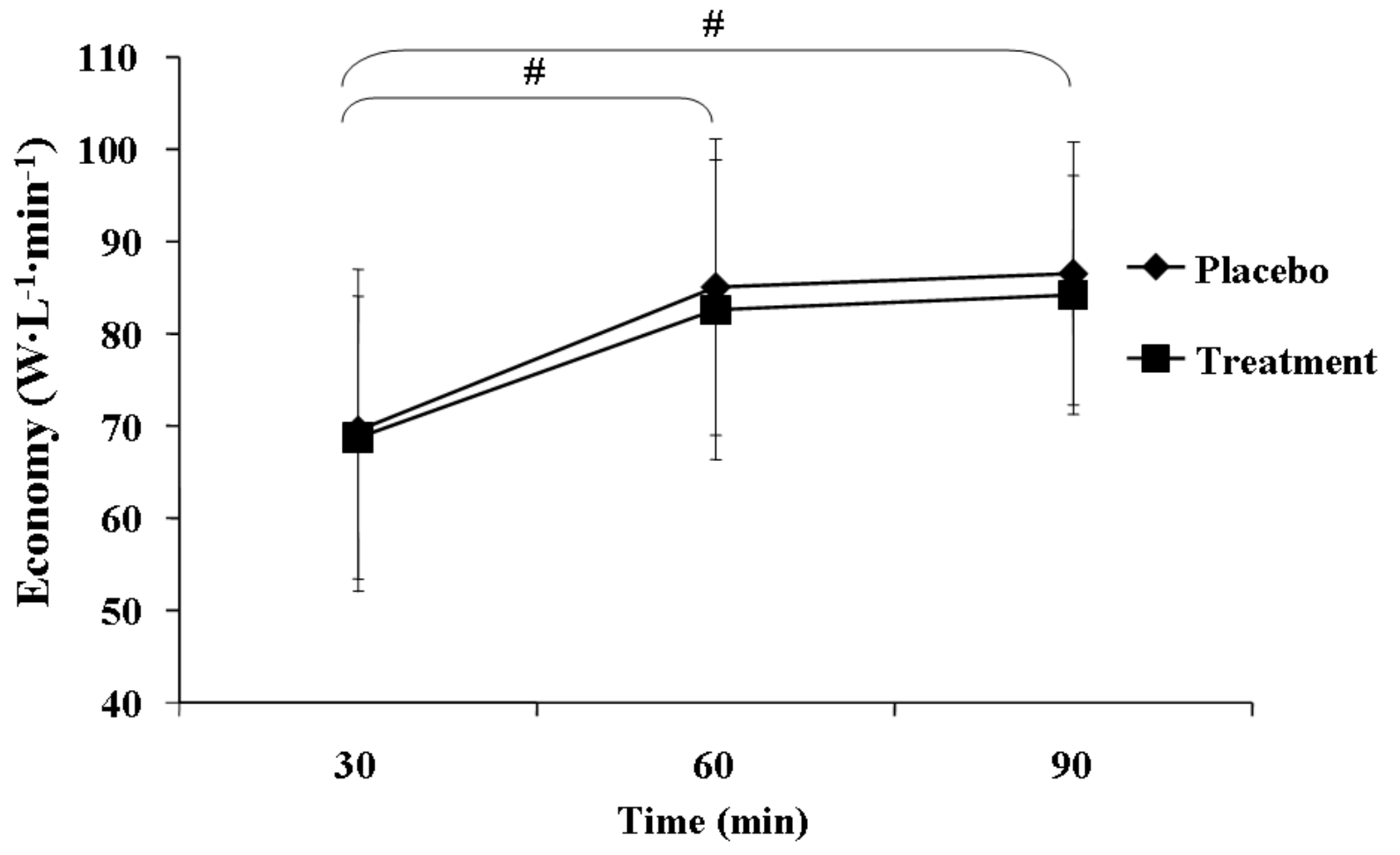

Figure 4 


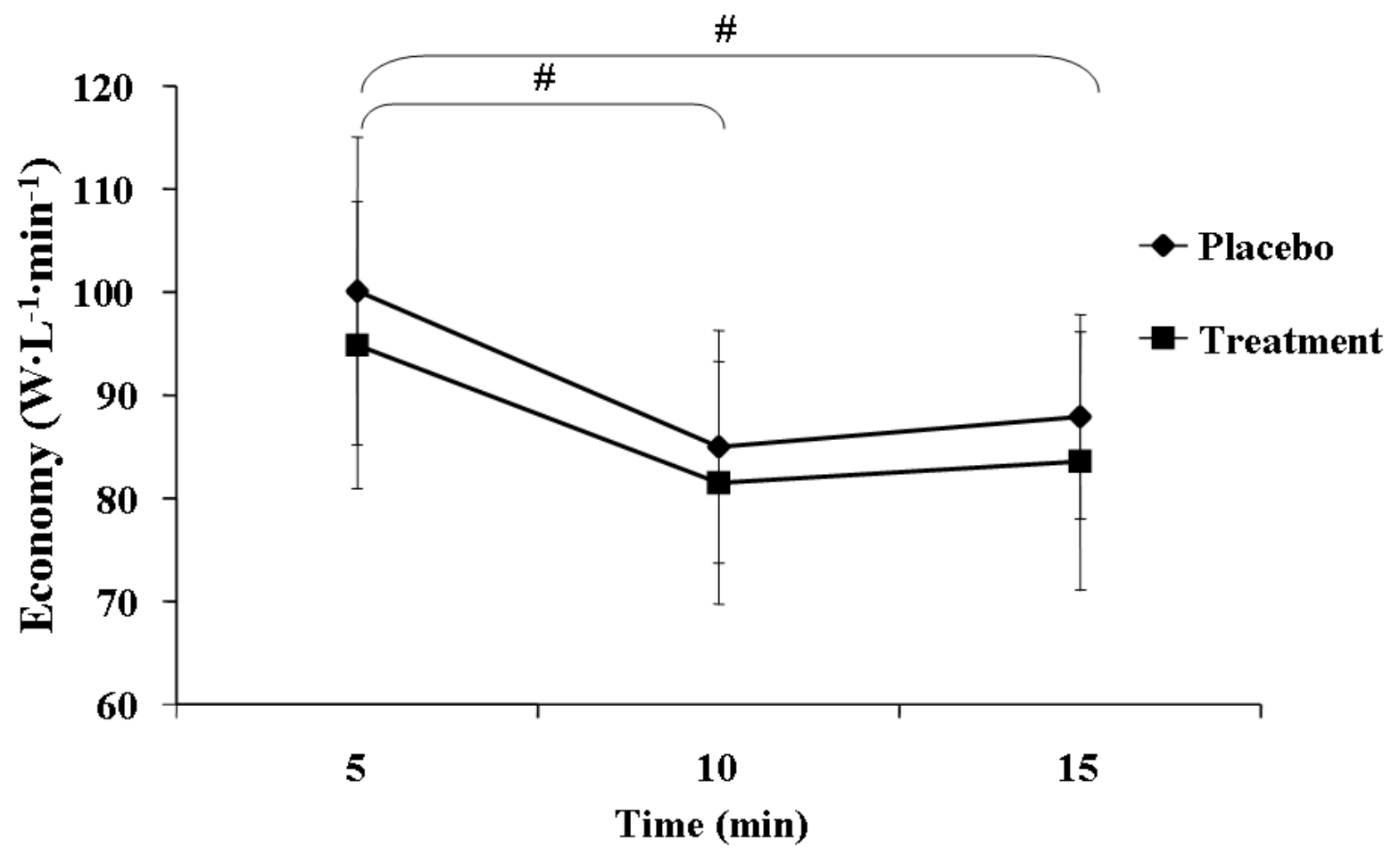

Figure 5 


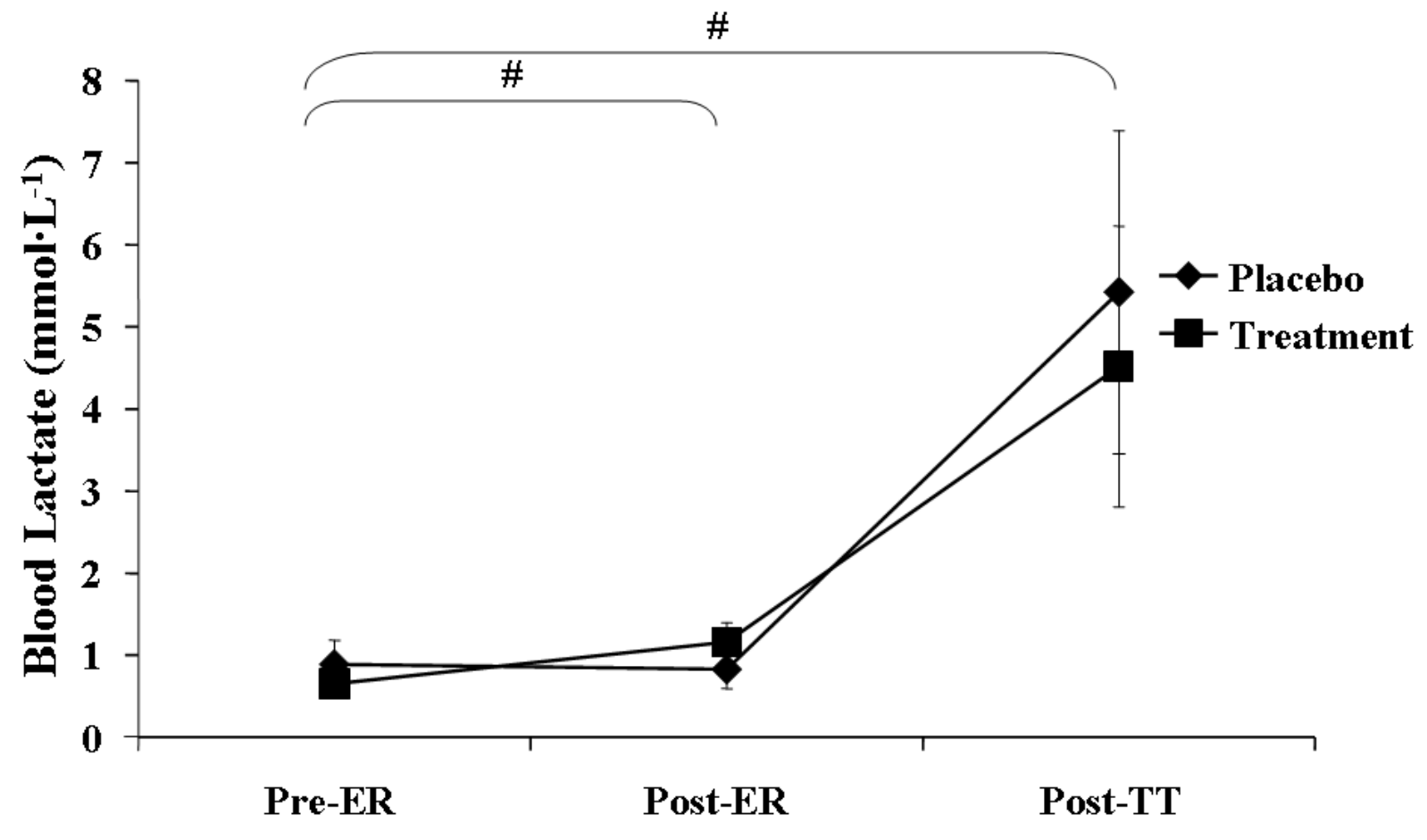

Figure 6 


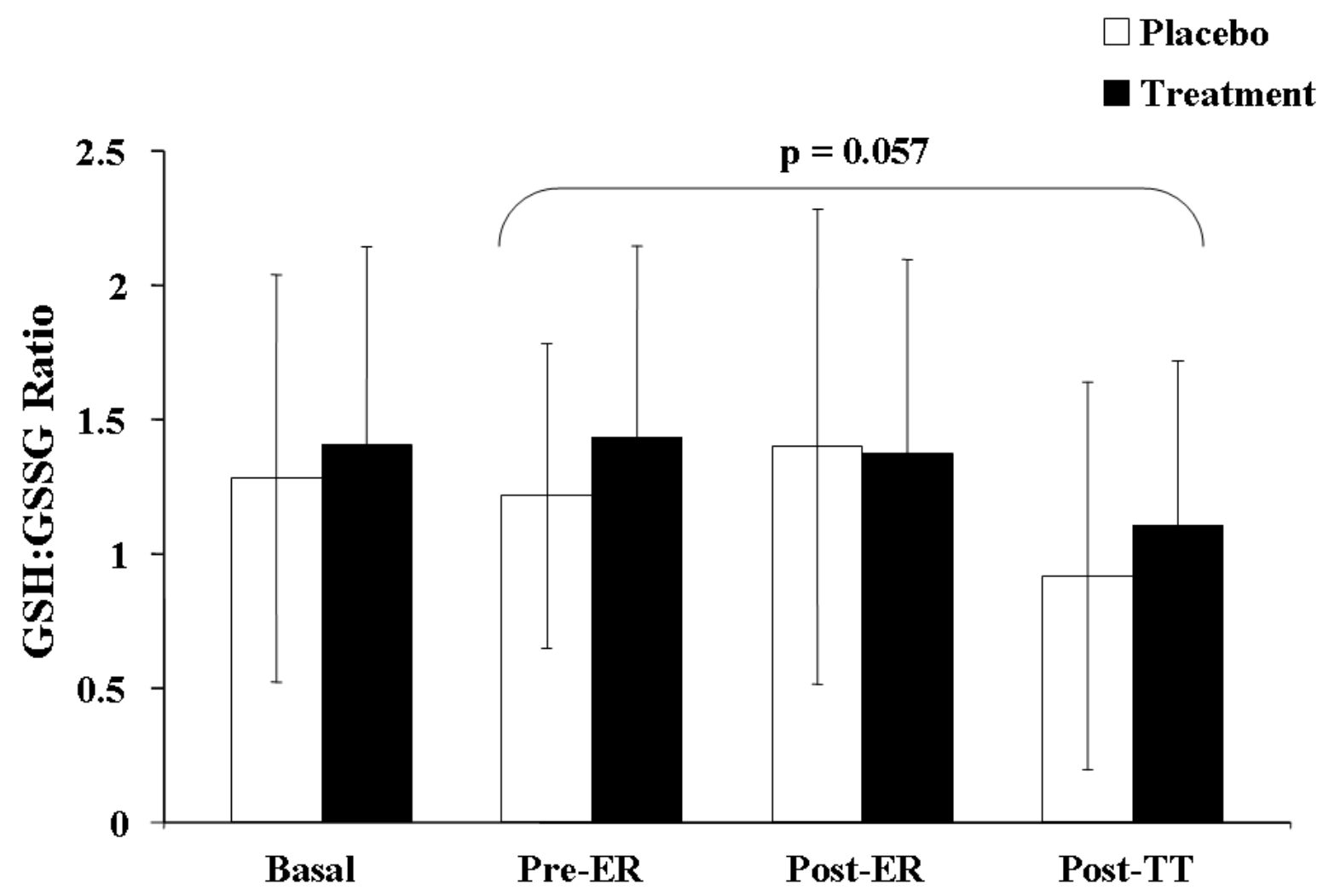

Figure 7 
Appendix A: IRB 
Form Revised Dec 2004

\title{
Continuing Protocol Review West Virginia University Institutional Review Board PO Box 6845
}

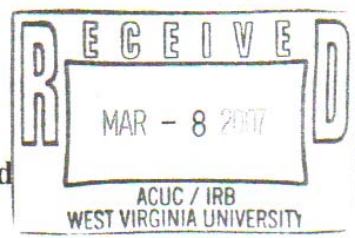

\author{
To: Bryner, Randall W \\ 1st Reminder 3/1/07 \\ Co-Investigators: Haff, Gregory; Lively, Mathew W \\ From: Lilo Ast, \\ Senior Program Coordinator for Research Compliance \\ Ingredients on Prolonged High-Intensity Cycling Performance and Oxidative Stress \\ Last Annual Review Date: 6/14/2006 \\ Review Category: Full Board \\ Date Last Consent Approved: 6/14/2006
}

Project Title: 16954 - The Effects of a Commercially Available Nutritional Supplement Which Combines Multiple Natura

The Institutional Review Board (IRB) grants one-year approvals for the use of human subjects. The anniversary date on this project is approaching.

If checking $\mathrm{A}, \mathrm{B}$, or $\mathrm{C}$ below, attach a Progress Report (see page 2) and required additional pages. The IRB will notify you of the results of its review. The clean copy of the consent form, assent form, advertisement, and/or cover letter submitted with this review form, will be reviewed and, when approved, stamped and returned for use with future subjects. Attach a copy of all new information, letters, or text of verbal updates that have been approved by the IRB. Additional updates not previously approved should also be included at this time.

If checking A, B, C, or D below, ensure that all key project personnel have received Human Participant Protections Training (and HIPAA Training, when applicable) prior to the renewal/approval date. For Training Requirements see http://www.wvu.edu/ rc/irb/index.htm. Also see http://www.wvu.edu/ osp/coi_drpl.htm for Adhoc Reporting of Conflict of Interest in Research.

Check all that apply:

A. Enrollment of subjects began on (date) and will continue beyond the anniversary date. (Submit a clean, unstamped copy—on letterhead - of current Consent form / Assent form / Ad / Cover letter with the latest submission date printed in the bottom left hand corner of each page.)

B. Project is closed to enrollment and one of the following applies:

$\square$ Research is active only for data analysis

$\square$ Subjects have completed all research-related interventions and will undergo long-term follow-up only.

Subjects are still undergoing research-related treatment.

C. Research began on (date). Contact with human subjects will not continue beyond the anniversary date. Please close this file. For drug/device studies, attach a copy of the investigator's final report to the sponsor.

$\checkmark$ D. Funding or start of research is pending. Please keep this file active. (Submit a clean, unstamped copy-on letterhead-of current Consent form / Assent form / Ad / Cover letter with the latest submission date printed in the bottom left hand corner of each page.)

- Ar project was nefer begun. Please close this file.

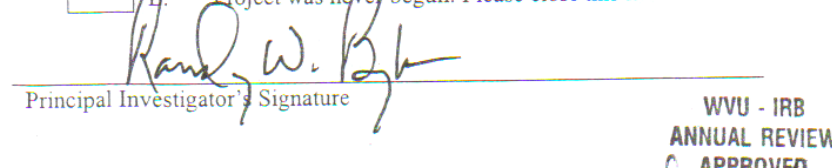

New Co-investigator's Signature (if applicable)

ANNUAL REVIEW

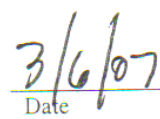

PERIOD OF:




\section{Institutional Review Board Protocol Amendment Font \\ Use this form to request approval for changes to an approved protocol. Send the original of ims attachments plus 2 copies (if expedited) OR 21 copies (if full board), to IRB, PO Box 6845. Revis WEST/4BRG}

should satisfy any sponsor requirements e.g. protocol numbers, version dates.

Principal Investigator:

IRB \#:

16954

Randy W. Bryner

IRB Internal Tracking \#:

(IRB Office Use ONLY)
Date:

$3 / 5 / 07$

Requesting Expedited Review (minor changes):

For a definition of major and minor changes see Chapter V. Section A

Protocol Title:* The effects of a commercially available nutritional supplement which combines multiple natural ingredients on prolonged high-intensity cycling performance and oxidative stress.

*The protocol title should include the version and date for all addendums, investigator brochures, etc.

Revision or Addition Description: Revised Protocol Date: Revised Consent Form Date: $\quad$ 3/05/07 Revised Investigator Brochure Date: Other (specify):

*MANDATORY: Why are the changes being made? For all required submissions see Chapter V. Section B.

Recently published data (Holden et al., 2006) has indicated that a loading phase is necessary in order for dietary antioxidant supplementation to significantly improve high-intensity cycling performance while at the same time limiting oxidative stress. The primary purpose of this study is to determine if a nutritional supplement which combines multiple natural ingredients will prolong high-intensity cycling performance and limit indices of oxidative stress. AmeriScience, the sponsoring company, has an all natural nutritional supplementation which has been hypothesized to be able to limit oxidative stress during high-intensity exercise. This supplement needs to be taken for approximately five days prior to the athletic event. It is our goal to combine a five-day loading phase of this supplement with the supplement already approved in the original application. The combination has been hypothesized to enhance endurance performance and limit oxidative stress.

(Holden S-H MacRae and Kari M. Mefferd. Dietary Supplementation Combined with Quercetin Improves Cycling Time Trial Performance. Int. J. Sport Nutri. Exerc. Metabol., 2006, 16, 405-419.)

*MANDATORY: Where are the changes made?

We are requesting permission to add the five-day loading phase of the supplement prior to each of the two experimental cycling trials. In addition, we are requesting permission to draw a single blood sample on the day prior to the first day of supplementation to determine baseline values. The additional ingredients for the loading supplement have been added to the consent form. Both supplements that will be used in this study are currently available to the public and have been used commercially for some time. In addition, both supplements have been tested and determined to be free of any banned substances. The additional changes to the study should cause minimal risk to the subjects. 


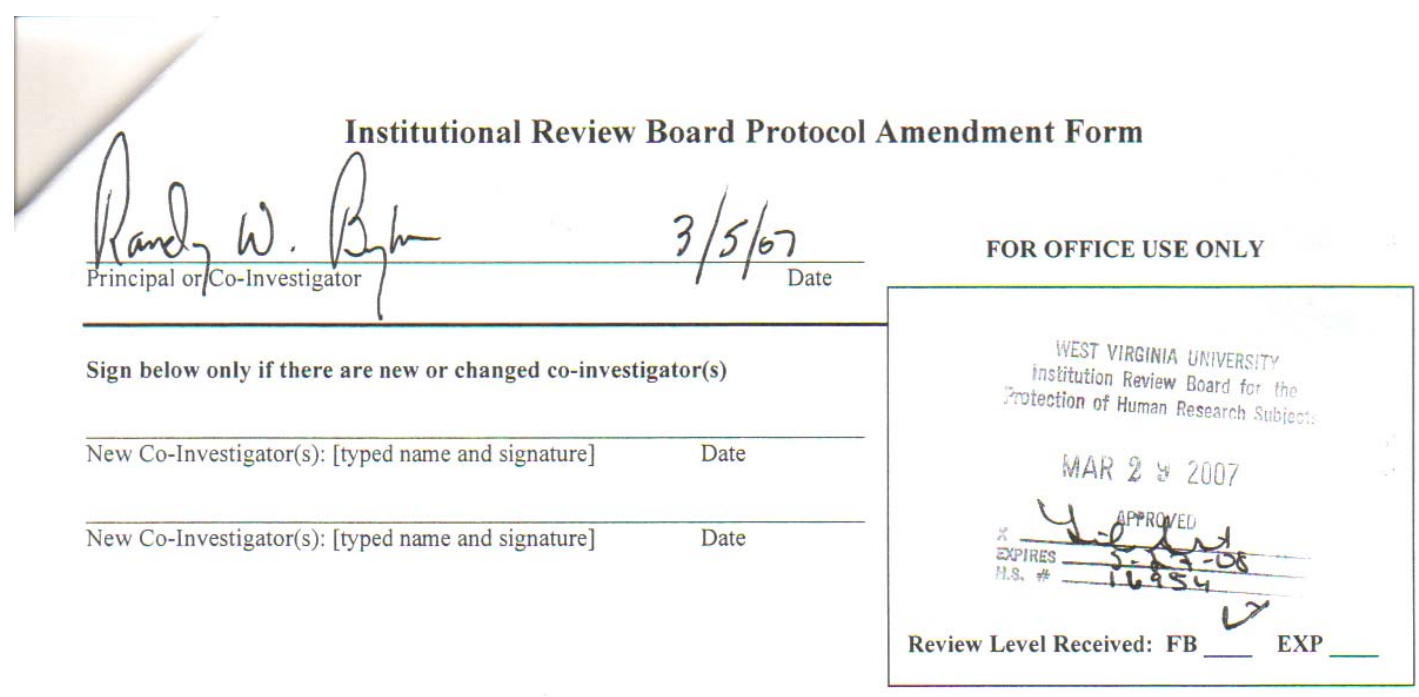

Form Revised May 2006 
Appendix B: Informed Consent 
West VirginiaUniversity

\section{CONSENT AND INFORMATION FORM}

The effects of a commercially available nutritional supplement which combines multiple natural ingredients on prolonged high-intensity cycling performance and oxidative stress.

\section{Introduction}

You, have been asked to participate in this research study, which has been explained to you by Randy W. Bryner, Ed.D. This study is being conducted by Randy W. Bryner, Ed.D. Greg Haff, Ph.D., Mathew Lively, D.O., and Christopher Rassekh, M.D. in the Department of Human Performance and Applied Exercise Sciences at West Virginia University with funding provided by Amerisciences, Inc., Houston TX.

\section{Purposes of the Study}

The ability to perform high intensity exercise for a prolonged period of time requires a significant increase in oxygen consumption and a constant supply of energy by and to the working muscle, respectively. High intensity exercise results in a high level of stress on the working muscle and body as a whole and may lead to cell damage because of products produced in the blood by the exercise.. The purpose of this study is to learn more about how a nutritional supplement affects your ability to perform high intensity exercise for extended time periods. The study will also examine how the nutritional supplement may protect your muscles from damage caused by the exercise. WVU expects to enroll approximately 15 subjects in total for this study.

\section{Description of Procedures}

The first phase of the study will be to determine if you are eligible to be in the study and to explain all of the procedures to you thoroughly. You have had at least two consecutive years of competitive cycling, no current injuries or exercise restrictions, and have not consumed any antioxidant nutritional supplement within the previous thirty days.

You will then schedule an appointment at the Human Performance laboratory (Experimental Day 1) where you will be given a maximal cycle ergometer test for base-line measurements. You will undergo a symptom-limited maximal graded exercise test performed on a cycle ergometer. ECG, heart rate $(\mathrm{HR})$ and blood pressure will be monitored at rest and during exercise. Oxygen consumption will be measured continuously. After a three minute warm-up you will complete 1 minute stages beginning at $150 \mathrm{~W}$. After each minute the workload will be increased a small amount (by $25 \mathrm{~W}$ ) until you are too tired to continue. You will be encouraged to go as long as you possibly can but will be able to stop the test at any point that you feel is necessary. The investigators will stop the test early if they observe an abnormal response to your heart rate, heart function as measured by ECG, or blood pressure. Your body composition will also be determined in the Bod Pod, an instrument used to determine your amount of fat and lean tissue.

\section{Submission date $3 / 05 / 07$. Page 1 of 4}


The effects of a commercially available nutritional supplement which combines multiple natural ingredients on prolonged high-intensity cycling performance and oxidative stress.

At least 72 hours after the maximal exercise test, you will return to the lab to complete a familiarization training ride. This ride will be for 120 minutes at a work load that represents a moderately hard work load, followed immediately by the completion of as much work as possible in 15 minutes.

At least 48 hours after the completion of the familiarization training ride, you will return to the Human Performance Laboratory to have a single blood sample (approximately 3 table spoons) taken from a vein in your forearm. You will then be given either the experimental nutritional supplement or something that tastes very similar but has no nutritional value (the placebo) and ask to begin taking it the next day. The supplement will be in pill form and you will be instructed to consume 4 pills per day for the next five days.

The day following the consumption of the final four pills, the first of two trials will be conducted. You will be randomly assigned to perform either the experimental trial ride or the placebo control ride, followed by the opposite one week later. You will be given a different experimental nutritional supplement or something that tastes very similar but has no nutritional value (the placebo) before the ride is conducted. One week later, you will return and perform the same cycling protocol with the exception of consuming the opposite (nutritional supplement or placebo). For each of the two experimental trials, you will ride for 120 minutes at the same moderately hard workload as during the familiarization training ride. This will be followed immediately by a high intensity self paced ride. You will be asked to complete the same amount of work as performed during the previous 15 -min testing period as fast as possible. The time required to complete this task will be recorded. How hard you breathe, how much carbon dioxide you are blowing off, your heart rate, and how hard you feel you are working will be recorded every 15 minutes throughout the ride._At the start of each of the two experimental rides, you will be given a small amount of water (approximately one half of a litter) to ingest followed by about $150 \mathrm{ml}$ water every $15 \mathrm{~min}$ until $120 \mathrm{~min}$ to ensure that you do not dehydrate. A small cannula (plastic tube) will be placed in a forearm vein at least 15 minutes prior to the collection of a baseline blood sample and the start of exercise. Approximately two tablespoons of blood will be collected: 1) at rest, 2) after 30, 60, 90 and 120 minutes of submaximal exercise, 3) immediately after high-intensity exhaustive exercise, and 4) after $1 \mathrm{~h}$ of recovery.

You will keep a five-day dietary and exercise record prior to the familiarization and experimental training rides. You will follow a similar dietary and exercise pattern for five days prior to each ride. In addition, you will refrain from any strenuous exercise during the 24-hour period prior to all testing sessions.

Risks and Discomforts

A list of the ingredients in the nutritional supplement is as follows: Whey Protein Isolate, Larginine USP, Tonalin CLA, L-arginine Ketoglutanate, Spirulina (blue green algae), Lglutamine, Lactase, L-Carnitine, L-tartrate, Taurine, Bromelain, Quercetin, American Ginseng, Gingseng root, Astaxanthin, Hawthorne berry, Mullein, Eleuthero, Cordyceps, Milk Thistle,

Submission date 3/05/07

Page 2 of 4

$\overline{\text { Initials }} \quad \overline{\text { date }}$


The effects of a commercially available nutritional supplement which combines multiple natural ingredients on prolonged high-intensity cycling performance and oxidative stress.

Tumeric, Prickly Ash, Cayenne, Choline, inositol, Astrgalus, PABA, Bioperine. Though no major adverse effects have been reported with the experimental nutritional supplement, you may experience slight gastrointestinal discomfort. If you have a milk allergy or are allergic to any of the listed ingredients you should not take the supplement. If you are pregnant or nursing you should also avoid taking the supplement. Drawing blood and the use of an indwelling cannula may result in pain or bruising as well as infection at the collection site. Although not expected because of your fitness level, maximal and endurance exercise testing may result in muscle soreness.

\section{Benefits}

You may not receive any direct benefit from this study. The knowledge gained from this study may eventually benefit others. However, you will be given all of the results from your exercise tests. As a trained cyclist, you may benefit from knowing this testing information (e.g., $\mathrm{VO}_{2}$ $\max$, lactate and ventilatory threshold, maximum HR, body composition, etc.) because data could be used to help develop cycling specific training programs.

\section{Financial Considerations}

No payments will be made for participating in the study. You will receive all testing and analysis at no cost to you.

\section{Confidentiality}

Any information about you that is obtained as a result of your participation in this research will be kept as confidential as legally possible. Your research records and test results, just like hospital records, may be subpoenaed by court order or may be inspected by federal regulatory authorities without your additional consent.

In any publications that result from this research, neither your name nor any information from which you might be identified will be published without your consent.

\section{Voluntary Participation}

Participation in this study is voluntary. You are free to withdraw your consent to participate in this study at any time.

Refusal to participate or withdrawal will not affect your future care, [or your employee status at West Virginia University or your class standing or grades, as appropriate] and will involve no penalty to you.

In the event new information becomes available that may affect your willingness to participate in this study, this information will be given to you so that you can make an informed decision about whether or not to continue your participation.

You have been given the opportunity to ask questions about the research, and you have received answers concerning areas you did not understand.

Submission date $3 / 05 / 07$

Page 3 of 4

$\overline{\text { Initials }} \overline{\text { date }}$


The effects of a commercially available nutritional supplement which combines multiple natural ingredients on prolonged high-intensity cycling performance and oxidative stress.

Upon signing this form, you will receive a copy

I willingly consent to participate in this research.

Signature of Subject or Subject's Legal Representative

Printed Name

Date Time

The participant has had the opportunity to have questions addressed. The participant willingly agrees to be in the study. Signature of Investigator or Co-Investigator Printed Name

Date Time

\section{Contact Persons}

In the event you experience any side effects or injury related to this research, you should contact Dr. Mathew Lively at (304) 293-2804. For more information about this research and about research-related risks or injury, you can contact Dr. Randy Bryner at (304) 293-0441, Dr Greg Haff at (304)293-4299, or Dr. Christopher Rassekh. For information regarding your rights as a research subject, you may contact the Office of Research Compliance at 304/293-7073. 
Appendix C: Health History Questionnaire 


\section{WVU HUMAN PERFORMANCE LABORATORY \\ Health History for PEIA}

\section{GENERAL INFORMATION}

Date

Personal \& Specialized Physicians(list all)

Name

Age Date of Birth $\mathrm{Ht}$ Wt__@age 21

Address

Home Phone Office Phone

Occupation/Retired

Marital Status

\# Children Education (highest level completed)

Soc. Sec. \#

IN CASE OF EMERGENCY, CONTACT:

Name

Phone

PEIA Insurance Info Policy \#

MEDICAL / SURGICAL HISTORY (Mark X if answer is yes)

Have you EVER bad:

rheumatic heart disease

- heart murmur

- high blood pressure

- gout

— varicose veins

- injuries to back, neck, etc.

_ lung disease

— epilepsy

_ diabetes

- heart disease

- heart surgery

_ $\quad$ kidney disease

— stomach ulcers

- arthritis

— cardiac catheterization

strokes

_ thyroid problems

_ dizziness or fainting spells

_ nervous or emotional problems

— allergies

_ phlebitis

- cardiac arrest

— hospitalizations

\section{MEDICATJONS}

Drug

Dosage

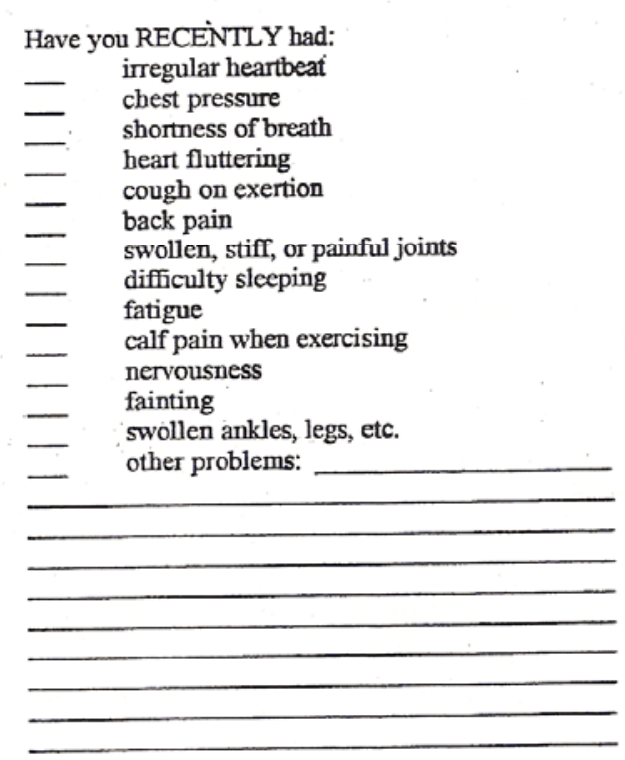

$\longrightarrow$




\section{FAMILY HISTORY}

Have any of your relatives had:

$\left.\begin{array}{llll}\text { - heart attacks } \\ \text { high blood pressure } \\ \text { high blood fats } \\ \text { obesity } \\ \text { stroke } \\ \text { diabetes } \\ \text { Other beart disease }\end{array}\right)$

\section{KING}

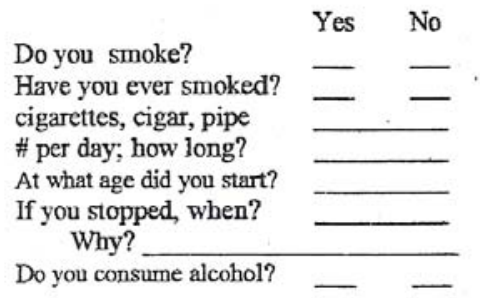

STRESS: Rate yourself in relation to tension:

_ Usually relaxed___ Relaxed, but occasionally tense __ Tense more often than relaxed _ Very tense

Little Rate the amount of stress in your job:

NUTRITION

What did you weigh one year ago?

Rate your diet in relation to fat content (e.g., butter, eggs, whole milk, other dairy products, red meat, fried foods):

$\begin{array}{ll}\text { Are you on a special diet? } & \text { Type: } \\ \text { Are you adhering to this diet? } & \text { Yes } \\ \text { Do you snack frequently? } & \text { Yes } \\ \text { Caffeine consumption per day } & \text { No If yes, then what kind of snacks }\end{array}$

Who does most of the cooking at home? What are your cholesterol levels? TC $\mathrm{LDL}$

Where are most meals eaten?

PHYSICAL FITNESS: How oflen do you engage in VIGOROUS activities for 20 minutes or more?

Activity

Rumning or Jogging

Hiking or Outdoor Walking

Bicycling

Swimming

Tennis

Vigorous Gardening

Dancing

Other (Please Specify)

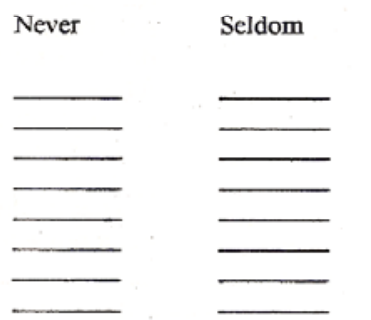

$1-2 x /$ wk

$3-6 \mathrm{x} / \mathrm{wk}$

Every Day
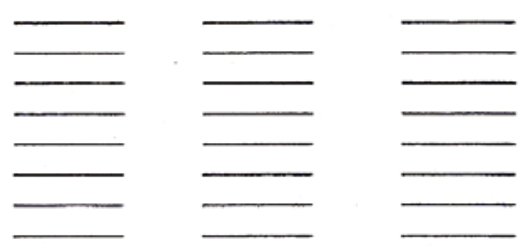

How physically fit do you feel at the present time?
Unfit
Below Average

- Below Average
_ Very Fit

_ Average __ Above Average 
Appendix D: Eligibility Questionnaire 


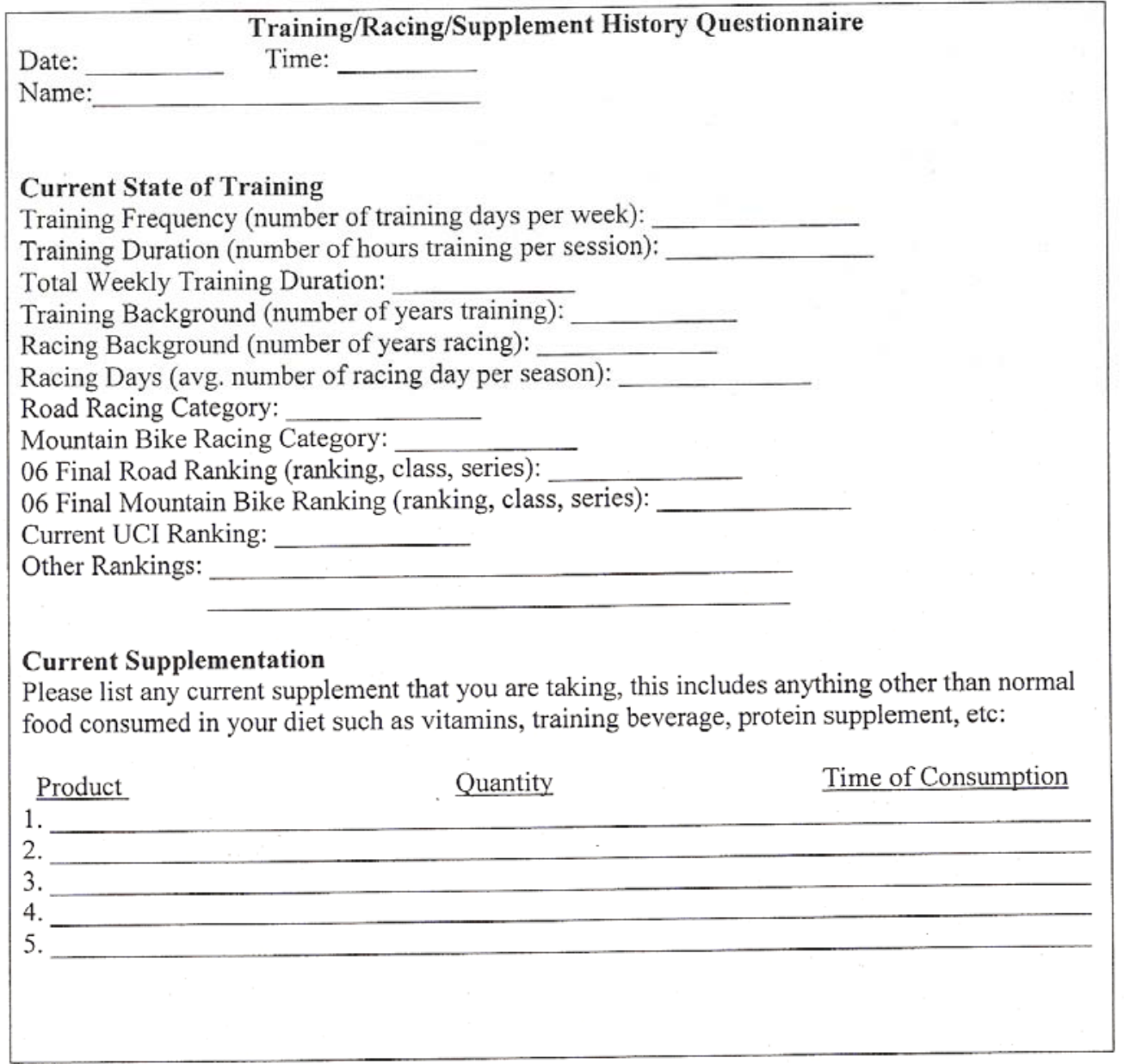


Appendix E: Relevant Supplementation Studies 


\begin{tabular}{|c|c|c|c|c|}
\hline Study & Treatment & Model/Subjects & Protocol & Results \\
\hline Abel, $2005^{1}$ & 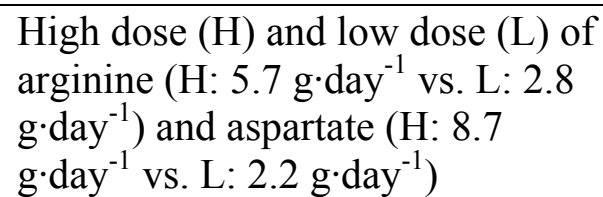 & $\begin{array}{l}30 \text { male trained } \\
\text { cyclists/triathletes }\end{array}$ & $\begin{array}{l}4 \text { wks of training with } \\
H(n=10), L(n=10) \\
\text { or placebo }(n=10)\end{array}$ & $\begin{array}{l}\leftrightarrow \text { in performance or lactate } \\
\text { concentration in response to } \\
\text { cycling }\left(\mathrm{VO}_{2 \text { Max }} \text { test }\right)\end{array}$ \\
\hline Aguilo, $2007^{2}$ & $\begin{array}{l}\alpha-\text { tocopherol }\left(500 \mathrm{mg} \cdot \mathrm{day}^{-1}\right), \beta- \\
\text { carotene }\left(30 \mathrm{mg} \cdot \mathrm{day}^{-1}\right), \text { and } \\
\text { ascorbic acid }\left(1000 \mathrm{mg} \cdot \mathrm{day}^{-1}\right) \text { all } \\
\text { taken twice daily }\end{array}$ & $\begin{array}{l}15 \text { trained male } \\
\text { endurance } \\
\text { cyclists/duathlon- } \\
\text { athletes }\end{array}$ & $\begin{array}{l}3 \text { mo of training with } \\
\alpha \text {-tocopherol and } \beta \text { - } \\
\text { carotene and } 15 \text { days } \\
\text { with ascorbic acid } \\
\text { (crossover design) }\end{array}$ & $\begin{array}{l}\uparrow \% \mathrm{VO}_{2 \mathrm{Max}} \text { at } 4 \mathrm{mM} \text { [lactate] } \\
\text { significantly higher than } \\
\text { training alone in response to } \\
\text { cycling }\left(\mathrm{VO}_{2 \mathrm{Max}} \text { test) }\right.\end{array}$ \\
\hline Broad, $2005^{14}$ & $\begin{array}{l}\text { carnitine and tartrate } \\
\left(\sim 3.0 \mathrm{mg} \cdot \mathrm{day}^{-1}\right)\end{array}$ & $\begin{array}{l}15 \text { trained male } \\
\text { endurance athletes }\end{array}$ & $\begin{array}{l}4 \text { wks of treatment or } \\
\text { placebo (crossover } \\
\text { design) }\end{array}$ & $\begin{array}{l}\leftrightarrow \text { substrate oxidation or } \\
\text { cycling performance }(90 \mathrm{~min} \\
\text { preload + time trial) }\end{array}$ \\
\hline Davison, $2006^{22}$ & ascorbic acid $\left(1000 \mathrm{mg} \cdot \mathrm{day}^{-1}\right)$ & $\begin{array}{l}9 \text { male trained } \\
\text { endurance athletes }\end{array}$ & $\begin{array}{l}2 \text { wks of treatment or } \\
\text { placebo } \\
\text { (crossover design) }\end{array}$ & $\begin{array}{l}\downarrow \text { cortisol, neutrophilia, and } \\
\text { leukocytosis in response to } \\
\text { cycling }\left(2.5 \text { at } 60 \% \mathrm{VO}_{2 \mathrm{Max}}\right)\end{array}$ \\
\hline Davison, $2007^{23}$ & $\begin{array}{l}\text { ascorbic acid }\left(1000 \mathrm{mg} \cdot \mathrm{day}^{-1}\right) \text { and } \\
\alpha \text {-tocopherol }\left(400 \mathrm{IU} \cdot \mathrm{day}^{-1}\right)\end{array}$ & $\begin{array}{l}20 \text { male recreational } \\
\text { athletes }\end{array}$ & $\begin{array}{l}4 \text { wks of } \\
\text { treatment }(\mathrm{N}=10) \text { or } \\
\text { placebo( } \mathrm{N}=10)\end{array}$ & $\begin{array}{l}\downarrow \text { cortisol in response to } \\
\text { cycling }\left(2.5 \text { at } 60 \% \mathrm{VO}_{2 \mathrm{Max}}\right)\end{array}$ \\
\hline $\begin{array}{l}\text { Eschbach, } \\
2000^{34}\end{array}$ & $\begin{array}{l}\text { Siberian ginseng }\left(1,200 \mathrm{mg} \cdot \mathrm{day}^{-1}\right. \\
\text { standardized extract of ciwujia) } \alpha \\
\text {-tocopherol }\left(60 \mathrm{IU} \cdot \mathrm{day}^{-1}\right)\end{array}$ & $\begin{array}{l}9 \text { male club level } \\
\text { cyclists }\end{array}$ & $\begin{array}{l}7 \mathrm{~d} \text { of treatment or } \\
\text { placebo (crossover } \\
\text { design) }\end{array}$ & $\begin{array}{l}\leftrightarrow \text { in performance or } \\
\text { substrate utilization in } \\
\text { response to cycling (preload } \\
+ \text { time trial) }\end{array}$ \\
\hline $\begin{array}{l}\text { Gomez-Cabrera, } \\
2003^{46}\end{array}$ & Allopurinol $\left(300 \mathrm{mg} \cdot\right.$ day $\left.^{-1}\right)$ & $\begin{array}{l}9 \text { male world-class } \\
\text { cyclists }\end{array}$ & $\begin{array}{l}3 \text { wks of treatment } \\
(\mathrm{N}=4) \text { or placebo } \\
(\mathrm{N}=5)\end{array}$ & $\begin{array}{l}\downarrow \text { lipid peroxidation, } \downarrow \text { muscle } \\
\text { damage, and } \leftrightarrow \text { performance } \\
\text { in response to cycling (during } \\
\text { the Tour de France) }\end{array}$ \\
\hline
\end{tabular}




\begin{tabular}{|c|c|c|c|c|}
\hline $\begin{array}{l}\text { Margaritis, } 2003 \\
\text { M4 }\end{array}$ & $\begin{array}{l}\text { selenium }\left(150 \mu \mathrm{g}^{\circ} \cdot \mathrm{day}^{-1}\right) \text {, vitamin } \\
\text { A }\left(2000 \mathrm{IU}^{-} \mathrm{day}^{-1}\right) \text {, ascorbic acid } \\
\left(120 \mathrm{mg}^{-1} \cdot \mathrm{day}^{-1}\right), \alpha \text {-tocopherol }(15 \\
\left.\text { IU } \cdot \text { day }^{-1}\right)\end{array}$ & $\begin{array}{l}16 \text { male professional } \\
\text { long-distance } \\
\text { triathletes }\end{array}$ & $\begin{array}{l}2 \text { wks of taper training } \\
\text { with treatment }(\mathrm{N}=7) \\
\text { or placebo }(\mathrm{N}=9)\end{array}$ & $\begin{array}{l}\text { attenuation of } \downarrow \text { in reduced } \\
\text { glutathione/oxidized } \\
\text { glutathione ratio and no } \\
\text { effect on muscle damage in } \\
\text { response to duathlon (running } \\
\text { and cycling test) }\end{array}$ \\
\hline $\begin{array}{l}\text { McConell, } \\
2006^{99}\end{array}$ & $\begin{array}{l}\text { Arginine infusion }(30 \mathrm{~g} \text { at } \\
0.5 \mathrm{~g} / \mathrm{min}) \text { during final } 60 \mathrm{~min} \text { of } \\
\text { cycling }\end{array}$ & $\begin{array}{l}9 \text { male endurance } \\
\text { trained athletes }\end{array}$ & $\begin{array}{l}\text { Cycling test with } \\
\text { treatment on placebo } \\
\text { (crossover design) }\end{array}$ & $\begin{array}{l}\uparrow \text { skeletal muscle glucose } \\
\text { clearance with } \leftrightarrow \text { on } \\
\text { performance in response to } \\
\text { cycling test (preload + time } \\
\text { trial) }\end{array}$ \\
\hline MacRae, $2006^{93}$ & $\begin{array}{l}\text { free radical scavenger cocktail } \\
(\text { FRS-Q)* or free radical } \\
\text { scavenger cocktail with quercetin } \\
(\text { FRS })^{* *}\left(600 \mathrm{ml} \cdot \text { day }^{-1}\right)\end{array}$ & 11 male elite cyclists & $\begin{array}{l}6 \text { wks of treatment } \\
\text { with FRS or FRS-Q } \\
\text { (crossover design) }\end{array}$ & $\begin{array}{l}\text { FRS } \uparrow \text { performance during a } \\
\text { cycling test ( } 30 \mathrm{~km} \text { time trial) }\end{array}$ \\
\hline Nieman, $2004^{108}$ & $\alpha$-tocopherol $\left(800 \mathrm{IU} \cdot \mathrm{day}^{-1}\right)$ & $\begin{array}{l}38 \text { world class } \\
\text { triathletes }\end{array}$ & $\begin{array}{l}2 \text { mo of treatment } \\
(\mathrm{N}=19) \text { or placebo } \\
(\mathrm{N}=17)\end{array}$ & $\begin{array}{l}\uparrow \text { lipid peroxidation and } \\
\text { inflammation in response to } \\
\text { triathlon (World } \\
\text { Championship, HI) }\end{array}$ \\
\hline $\begin{array}{l}\text { Palazzetti, } \\
2004^{112}\end{array}$ & $\begin{array}{l}\text { selenium }\left(150 \mu \mathrm{g} \cdot \text { day }^{-1}\right), \text { retinyl } \\
\text { acetate }\left(1 \mathrm{mg}^{-1} \text { day }^{-1}\right) \text {, ascorbic acid } \\
\left(120 \mathrm{mg} \cdot \text { day }^{-1}\right), \alpha \text {-tocopherol } \\
\left(1 \mathrm{mg} \cdot \text { day }^{-1}\right)\end{array}$ & $\begin{array}{l}17 \text { male well-trained } \\
\text { triathletes }\end{array}$ & $\begin{array}{l}4 \text { wk of normal } \\
\text { training and } 4 \text { wk } \\
\text { induced over-training } \\
\text { with treatment }(n=7) \\
\text { or placebo }(n=10)\end{array}$ & $\begin{array}{l}\uparrow \text { in basal reduced glutathione } \\
\text { level and basal glutathione } \\
\text { peroxidase activity; } \\
\text { attenuated creatine kinase } \uparrow, \\
\text { and } \uparrow \text { glutathione peroxidase } \\
\text { activity in response to a } \\
\text { duathlon (running and } \\
\text { cycling test) }\end{array}$ \\
\hline Sastre, $1992^{123}$ & $\begin{array}{l}\text { reduced glutathione }\left(1 \mathrm{~g} \cdot \mathrm{day}^{-1}\right) \\
\text { and ascorbic acid } \\
\left(2 \mathrm{~g} \cdot \mathrm{day}^{-1}\right)\end{array}$ & $\begin{array}{l}5 \text { male national-level } \\
\text { athletes }\end{array}$ & $\begin{array}{l}\text { treatment for } 7 \text { days } \\
\text { (crossover design) }\end{array}$ & $\begin{array}{l}\text { attenuation of } \uparrow \text { in oxidized } \\
\text { glutathione/reduced } \\
\text { glutathione ratio in response } \\
\text { to running }\left(\mathrm{VO}_{2 \mathrm{Max}} \text { test) }\right.\end{array}$ \\
\hline
\end{tabular}




\begin{tabular}{|c|c|c|c|c|}
\hline Senturk, $2005^{128}$ & 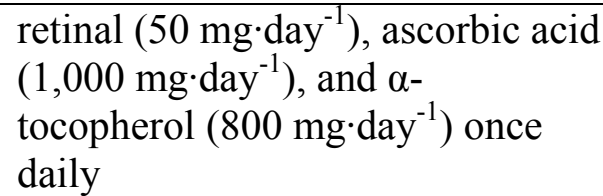 & $\begin{array}{l}9 \text { male trained } \\
\text { students }\end{array}$ & 2 mo of treatment & $\begin{array}{l}\text { attenuation of } \uparrow \text { in red blood } \\
\text { cell lipid peroxidation in } \\
\text { response to cycling }\left(\mathrm{VO}_{2 \mathrm{Max}}\right. \\
\text { test) }\end{array}$ \\
\hline Tessier, $1995^{133}$ & selenium $(180 \mu \mathrm{g})$ & 24 male students & $\begin{array}{l}10 \text { weeks of } \\
\text { endurance training } \\
\text { with treatment }(n=12) \\
\text { or placebo }(n=12)\end{array}$ & $\begin{array}{l}\uparrow \text { basal plasma glutathione } \\
\text { peroxidase level, } \leftrightarrow \text { on } \\
\text { physical performance }\end{array}$ \\
\hline Thomas, $2007^{134}$ & $\begin{array}{l}\text { protein hydrosylate sachet } \\
\left(2 \cdot \text { day }^{-1}\right) \dagger\end{array}$ & $\begin{array}{l}28 \text { male } \\
\text { trained/recreational } \\
\text { athletes }\end{array}$ & $\begin{array}{l}28 \text { days of treatment } \\
\text { or placebo }\end{array}$ & $\begin{array}{l}\uparrow \text { basal plasma glutathione } \\
\text { peroxidase level and a } \downarrow \text { in } \\
\text { basal plasma lipid } \\
\text { peroxidation; enhanced } \\
\text { lactate metabolism in } \\
\text { response to cycling (multiple } \\
\text { sprint test) }\end{array}$ \\
\hline
\end{tabular}

*Complete list of ingredients in the FRS-Q cocktail (per $300 \mathrm{ml}$ serving): green tea extract (300 mg), ascorbic acid (150 mg), $\alpha$ tocopherol $(50 \mathrm{mg})$, caffeine $(45 \mathrm{mg})$, niacin $(25 \mathrm{mg})$, taurine $(9 \mathrm{mg})$, vitamin B-6 (2.5 mg), vitamin B-2 (2.1 mg), vitamin B-1 (1.9 $\mathrm{mg})$, vitamin B-12 $(0.008 \mathrm{mg})$, and glucose $(60 \mathrm{~kJ})$.

**Complete list of ingredients in FRS cocktail (per $300 \mathrm{ml}$ serving): quercetin (300 mg) plus the ingredients in the FRS-Q cocktail. $\dagger$ Complete list of ingredients in the protein hydrosylate (per sachet): protein $(8.3 \mathrm{~g})$, carbohydrate $(2.0 \mathrm{~g})$, lipids $(0.8 \mathrm{~g})$, sodium $(141$ $\mathrm{mg}$ ), potassium (26 mg), calcium (38 mg), magnesium (189 mg), iron (14 mg), zinc (15 mg), copper (2 mg), manganese (3.5 mg), chromium $(25 \mu \mathrm{g})$, selenium $(75 \mu \mathrm{g})$, ascorbic acid $(120 \mathrm{mg}), \alpha$-tocopherol $(10 \mathrm{mg})$, niacin (18 mg), vitamin B12 (1 $\mu \mathrm{g})$, folic acid $(0.2 \mathrm{mg})$, thiamin $(1.4 \mathrm{mg})$, riboflavin $(1.6 \mathrm{mg})$, vitamin B6 $(2 \mathrm{mg})$, biotin $(0.15 \mathrm{mg})$, vitamin A $(2664 \mathrm{IU})$, isoleucine $(0.55 \mathrm{~g})$, leucine $(1.07 \mathrm{~g})$, lysine $(0.80 \mathrm{~g})$, methionine $(0.25 \mathrm{~g})$, cystein $(0.33 \mathrm{~g})$, phenylalanine $(0.36 \mathrm{~g})$, tyrosine $(0.35 \mathrm{~g})$, alanine $(0.43 \mathrm{~g})$, threonine $(0.47 \mathrm{~g})$, tryptophan $(0.19 \mathrm{~g})$, histidine $(0.16 \mathrm{~g})$, arginine $(0.22 \mathrm{~g})$, aspartic acid $(0.99 \mathrm{~g})$, serine $(0.36 \mathrm{~g})$, praline $(0.45 \mathrm{~g})$, glycine $(0.40$ $\mathrm{g})$, glutamic acid (1.62 g), valine (0.50 g), essential amino acids (3.74 g), BCAA (2.12 g). 
Appendix F: Raw Data 


\section{F.1. Biometrics Data Table}

\begin{tabular}{lcccc}
\hline Biometrics & \multicolumn{3}{c}{} \\
\hline Subject \# & $\begin{array}{c}\text { Age } \\
\text { (years) }\end{array}$ & Height $(\mathrm{cm})$ & Body Mass (kg) & Body Fat (\%) \\
\hline 111 & 44 & 176.5 & 73.58 & 12.86 \\
112 & 22 & 171.8 & 77.81 & 24.65 \\
114 & 31 & 180.5 & 71.43 & 19.10 \\
115 & 22 & 173.0 & 85.90 & 24.70 \\
116 & 25 & 182.0 & 69.51 & 3.30 \\
117 & 26 & 191.0 & 81.70 & 12.90 \\
118 & 29 & 176.0 & 72.14 & 12.42 \\
119 & 32 & 174.0 & 88.17 & 21.42 \\
\hline Mean & 29 & 178.1 & 77.53 & 16.42 \\
Standard Deviation & 7.18 & 6.3 & 7.04 & 7.38 \\
\hline
\end{tabular}


F.2. $\mathrm{VO}_{2 \max }$ Testing Data Table

\begin{tabular}{lccccc}
\hline $\mathrm{VO}_{2 \max }$ & \multicolumn{3}{c}{} & & \\
\hline Subject \# & $\begin{array}{c}\text { Relative } \\
\left(\mathrm{ml} \cdot \mathrm{kg}^{-1} \cdot \mathrm{min}^{-1}\right)\end{array}$ & $\begin{array}{c}\text { Absolute } \mathrm{VO}_{2 \max } \\
\left(\mathrm{L} \cdot \mathrm{min}^{-1}\right)\end{array}$ & $\begin{array}{c}\text { Relative Max } \\
\text { Power }(\mathrm{W} \cdot \mathrm{kg})\end{array}$ & $\begin{array}{c}\text { Absolute Max } \\
\text { Power }(\mathrm{W})\end{array}$ & $\begin{array}{c}\text { Max Heart Rate } \\
\left(\text { beats} \cdot \mathrm{min}^{-1}\right)\end{array}$ \\
\hline 111 & 55.3 & 3.889 & 6.03 & 443.75 & 189 \\
112 & 50.0 & 3.879 & 4.94 & 384.58 & 189 \\
114 & 54.5 & 3.858 & 4.90 & 350.00 & 185 \\
115 & 52.5 & 4.714 & 4.51 & 387.50 & 198 \\
116 & 65.3 & 4.474 & 6.17 & 429.17 & 192 \\
117 & 53.0 & 4.352 & 5.33 & 435.42 & 185 \\
118 & 60.7 & 4.321 & 5.54 & 400.00 & 180 \\
119 & 49.0 & 4.350 & 4.25 & 375.00 & 174 \\
\hline Mean & 55.0 & 4.230 & 5.21 & 400.68 & 187 \\
Standard Deviation & 5.5 & 0.320 & 0.69 & 32.80 & 7.35 \\
\hline
\end{tabular}




\section{F.3. Performance Data Tables}

\section{Table F.3.1. HR Data}

\begin{tabular}{lcccc}
\hline $\begin{array}{l}\text { HR } \\
\left(\text { beats } \cdot \min ^{-1}\right)\end{array}$ & \multicolumn{2}{c}{ Endurance Ride } & \multicolumn{2}{c}{ Time Trial } \\
\hline Subject \# & Placebo & Treatment & Placebo & Treatment \\
\hline 111 & 145.78 & 147.09 & 176.86 & 169.79 \\
112 & 148.92 & 148.10 & 173.02 & 174.86 \\
114 & 145.32 & 146.78 & 167.32 & 170.92 \\
115 & 140.26 & 151.59 & 167.65 & 184.79 \\
116 & 148.52 & 147.19 & 172.03 & 163.00 \\
117 & 148.92 & 152.86 & 168.34 & 170.50 \\
118 & 152.98 & 151.32 & 170.33 & 167.95 \\
119 & 139.68 & 142.15 & 166.70 & 166.86 \\
\hline Mean & 146.30 & 148.38 & 170.28 & 171.08 \\
SD & 4.50 & 3.50 & 3.50 & 6.50 \\
\hline
\end{tabular}


Table F.3.2 Absolute $\mathrm{VO}_{2}$ Data

\begin{tabular}{lcccc}
\hline $\begin{array}{l}\text { Absolute } \\
\begin{array}{l}\text { VO } \\
\left(\mathrm{L} \cdot \min ^{-1}\right)\end{array}\end{array}$ & \multicolumn{2}{c}{ Time Trial } \\
\hline Subject \# & Placebo & Treatment & Placebo & Treatment \\
\hline 111 & 2.92 & 2.79 & 3.65 & 3.35 \\
112 & 2.59 & 2.69 & 3.10 & 3.35 \\
114 & 2.70 & 2.50 & 2.45 & 2.82 \\
115 & 2.91 & 3.17 & 3.94 & 3.89 \\
116 & 1.96 & 2.20 & 2.44 & 3.42 \\
117 & 3.02 & 3.22 & 3.51 & 3.87 \\
118 & 3.12 & 3.03 & 3.68 & 3.64 \\
119 & 2.92 & 3.00 & 3.88 & 3.85 \\
\hline Mean & 2.77 & 2.83 & 3.33 & 3.52 \\
SD & 0.37 & 0.35 & 0.60 & 0.37 \\
\hline
\end{tabular}


Table F.3.3. Relative $\mathrm{VO}_{2}$ Data

\begin{tabular}{lcccc}
\hline $\begin{array}{l}\text { Relative } \mathrm{VO}_{2} \\
\left(\mathrm{ml} \cdot \mathrm{kg}^{-1} \cdot \mathrm{min}^{-1}\right)\end{array}$ & \multicolumn{2}{c}{ Endurance Ride } & \multicolumn{2}{c}{ Time Trial } \\
\hline Subject \# & Placebo & Treatment & Placebo & Treatment \\
\hline 111 & 39.42 & 38.15 & 49.27 & 45.93 \\
112 & 33.61 & 34.73 & 40.16 & 43.24 \\
114 & 37.49 & 35.20 & 34.10 & 39.71 \\
115 & 33.66 & 36.93 & 45.67 & 45.37 \\
116 & 28.26 & 31.44 & 35.30 & 48.93 \\
117 & 36.87 & 39.11 & 42.86 & 47.05 \\
118 & 42.87 & 41.76 & 50.82 & 50.23 \\
119 & 33.50 & 34.30 & 42.54 & 42.06 \\
\hline Mean & 35.71 & 36.45 & 42.59 & 45.32 \\
SD & 4.45 & 3.22 & 6.01 & 3.52 \\
\hline
\end{tabular}


Table F.3.4. Absolute Power Data

\begin{tabular}{lccrc}
\hline $\begin{array}{l}\text { Absolute } \\
\text { Power (W) }\end{array}$ & \multicolumn{2}{c}{ Endurance Ride } & \multicolumn{2}{c}{ Time Trial } \\
\hline Subject \# & Placebo & Treatment & Placebo & Treatment \\
\hline 111 & 240 & 236 & 345 & 313 \\
112 & 212 & 209 & 277 & 293 \\
114 & 197 & 164 & 222 & 166 \\
115 & 206 & 219 & 328 & 329 \\
116 & 214 & 237 & 267 & 326 \\
117 & 242 & 290 & 361 & 363 \\
118 & 242 & 238 & 337 & 331 \\
119 & 200 & 199 & 312 & 308 \\
\hline Mean & 219.13 & 224.00 & 306.13 & 303.63 \\
SD & 19.22 & 36.53 & 46.97 & 59.26 \\
\hline
\end{tabular}


Table F.3.5. Relative Average Power Data

\begin{tabular}{lcccc}
\hline $\begin{array}{l}\text { Relative } \\
\text { Power } \\
\left(\mathrm{W} \cdot \mathrm{kg}^{-1}\right)\end{array}$ & \multicolumn{2}{c}{ Time Trial } \\
\hline Subject \# & Placebo & Treatment & Placebo & Treatment \\
\hline 111 & 3.26 & 3.21 & 4.69 & 4.25 \\
112 & 2.72 & 2.69 & 3.56 & 3.77 \\
114 & 2.76 & 2.30 & 3.12 & 2.32 \\
115 & 2.40 & 2.55 & 3.82 & 3.83 \\
116 & 3.08 & 3.41 & 3.84 & 4.69 \\
117 & 2.96 & 2.80 & 4.42 & 4.44 \\
118 & 3.35 & 3.30 & 4.67 & 4.59 \\
119 & 2.27 & 2.26 & 3.54 & 3.49 \\
\hline Mean & 2.80 & 2.80 & 4.00 & 3.90 \\
SD & 0.40 & 0.40 & 0.60 & 0.80 \\
\hline
\end{tabular}


Table F.3.6. RPE

\begin{tabular}{lcccc}
\hline RPE & \multicolumn{2}{c}{ Endurance Ride } & \multicolumn{2}{c}{ Time Trial } \\
\hline Subject \# & Placebo & Treatment & Placebo & Treatment \\
\hline 111 & 13.34 & 14.20 & 19.35 & 20.00 \\
112 & 12.30 & 12.89 & 17.99 & 16.08 \\
114 & 12.41 & 11.28 & 12.95 & 16.72 \\
115 & 11.12 & 12.17 & 16.87 & 17.29 \\
116 & 11.19 & 12.98 & 16.66 & 15.85 \\
117 & 13.03 & 12.63 & 17.78 & 17.48 \\
118 & 13.50 & 12.81 & 16.58 & 16.03 \\
119 & 12.83 & 13.43 & 15.49 & 17.00 \\
\hline Mean & 12.47 & 12.80 & 16.71 & 17.06 \\
SD & 0.91 & 0.86 & 1.91 & 1.34 \\
\hline
\end{tabular}


Table F.3.7. RER

\begin{tabular}{lcccc}
\hline $\begin{array}{l}\text { Respiratory } \\
\text { Exchange } \\
\text { Ratio }\end{array}$ & \multicolumn{2}{c}{ Endurance Ride } & \multicolumn{2}{c}{ Time Trial } \\
\hline Subject \# & Placebo & Treatment & Placebo & Treatment \\
\hline 111 & 1.00 & 0.99 & 1.12 & 1.06 \\
112 & 0.97 & 0.96 & 1.03 & 1.05 \\
114 & 0.93 & 0.98 & 0.94 & 1.02 \\
115 & 0.90 & 0.93 & 1.04 & 1.03 \\
116 & 0.92 & 0.95 & 1.00 & 1.01 \\
117 & 0.90 & 0.92 & 1.00 & 1.02 \\
118 & 0.91 & 0.92 & 0.98 & 0.98 \\
119 & 0.92 & 0.94 & 1.05 & 1.05 \\
\hline Mean & 0.93 & 0.95 & 1.02 & 1.03 \\
SD & 0.04 & 0.03 & 0.05 & 0.03 \\
\hline
\end{tabular}


Table F.3.8. Time Trial Time

\begin{tabular}{lrc}
\hline Time (s) & \multicolumn{2}{c}{ Time Trial } \\
\hline Subject \# & Placebo & Treatment \\
\hline 111 & 803 & 888 \\
112 & 900 & 852 \\
114 & 897 & 1208 \\
115 & 912 & 908 \\
116 & 1102 & 902 \\
117 & 854 & 852 \\
118 & 906 & 922 \\
119 & 838 & 852 \\
\hline Mean & 901.50 & 923.00 \\
SD & 89.72 & 118.47 \\
\hline
\end{tabular}


Table F.3.9. Endurance Economy

\begin{tabular}{lcccccc}
\hline $\begin{array}{l}\text { ER Economy } \\
\left(\mathrm{W} \cdot \mathrm{L}^{-1} \cdot \mathrm{min}^{-1}\right)\end{array}$ & \multicolumn{7}{c}{ Endurance Ride } \\
\hline \multicolumn{2}{c}{ 30-min } & \multicolumn{2}{c}{60 -min } & \multicolumn{2}{c}{90 -min } \\
\hline Subject \# & Placebo & Treatment & Placebo & Treatment & Placebo & Treatment \\
\hline 111 & 78.91 & 79.73 & 87.32 & 93.13 & 87.96 & 89.80 \\
112 & 74.73 & 68.32 & 85.57 & 80.73 & 87.17 & 83.75 \\
114 & 75.24 & 62.41 & 71.87 & 67.75 & 73.48 & 70.27 \\
115 & 50.54 & 62.93 & 73.11 & 73.05 & 73.87 & 73.46 \\
116 & 104.06 & 99.10 & 122.13 & 117.85 & 117.75 & 111.36 \\
117 & 56.28 & 51.02 & 83.18 & 77.73 & 88.14 & 81.82 \\
118 & 59.15 & 71.95 & 81.83 & 80.17 & 87.86 & 87.60 \\
119 & 57.09 & 54.39 & 75.39 & 70.30 & 75.94 & 75.57 \\
\hline Mean & 69.50 & 68.73 & 85.05 & 82.59 & 86.52 & 84.20 \\
SD & 17.48 & 15.34 & 16.05 & 16.25 & 14.26 & 12.93 \\
\hline
\end{tabular}


Table F.3.10. Time Trial Economy

\begin{tabular}{lrrrrrr}
\hline $\begin{array}{l}\text { TT Economy } \\
\left(\mathrm{W} \cdot \mathrm{L}^{-1} \cdot \mathrm{min}^{-1}\right)\end{array}$ & \multicolumn{7}{c}{ Time Trial } \\
\hline \multicolumn{2}{c}{ 5-min } & \multicolumn{2}{c}{ 10-min } & \multicolumn{2}{c}{ 15-min } \\
\hline Subject \# & Placebo & Treatment & Placebo & Treatment & Placebo & Treatment \\
\hline 111 & 98.09 & 99.76 & 93.26 & 93.45 & 91.01 & 94.06 \\
112 & 99.65 & 94.04 & 81.77 & 82.10 & 85.68 & 83.31 \\
114 & 74.41 & 67.87 & 69.09 & 54.80 & 72.93 & 54.67 \\
115 & 91.64 & 88.48 & 74.28 & 80.67 & 84.91 & 85.13 \\
116 & 122.18 & 117.49 & 102.83 & 88.31 & 102.98 & 91.65 \\
117 & 118.28 & 100.08 & 92.96 & 88.58 & 98.01 & 86.90 \\
118 & 99.18 & 99.34 & 88.11 & 84.86 & 90.06 & 92.08 \\
119 & 97.37 & 91.75 & 77.59 & 79.17 & 77.61 & 80.93 \\
\hline Mean & 100.10 & 94.85 & 84.99 & 81.49 & 87.90 & 83.59 \\
SD & 14.94 & 13.95 & 11.29 & 11.77 & 9.91 & 12.56 \\
\hline
\end{tabular}




\section{F.4. Lactate Data Table}

\begin{tabular}{lcccccc}
\hline $\begin{array}{l}\text { Lactate } \\
\left(\mathrm{mmol} \cdot \mathrm{L}^{-1}\right)\end{array}$ & \multicolumn{7}{c}{} \\
\hline \multicolumn{2}{c}{ Pre-ER } & \multicolumn{2}{c}{ Post-ER } & \multicolumn{2}{c}{ Post-TT } \\
\hline Subject \# & Placebo & Treatment & Placebo & Treatment & Placebo & Treatment \\
\hline 111 & 1.56 & 0.76 & 0.83 & 1.28 & 6.75 & 3.44 \\
112 & 0.76 & 0.75 & 0.57 & 0.85 & 2.43 & 3.35 \\
114 & 0.79 & 0.65 & 0.96 & 1.20 & 3.37 & 2.64 \\
115 & 0.89 & 0.67 & 0.62 & 0.97 & 6.62 & 6.91 \\
116 & 0.85 & 0.60 & 0.80 & 1.20 & 4.07 & 3.01 \\
117 & 0.80 & 0.50 & 0.78 & 1.05 & 6.50 & 5.02 \\
118 & 0.54 & 0.49 & 0.72 & 1.10 & 5.45 & 4.76 \\
119 & 0.90 & 0.78 & 1.33 & 1.63 & 8.20 & 6.99 \\
\hline Mean & 0.89 & 0.65 & 0.83 & 1.16 & 5.42 & 4.52 \\
SD & 0.29 & 0.11 & 0.24 & 0.23 & 1.97 & 1.71 \\
\hline
\end{tabular}


F.5. Glucose Data Table

\begin{tabular}{lcccccccc}
\hline \multicolumn{1}{l}{ Glucose $\left(\mathrm{mmol} \cdot \mathrm{L}^{-1}\right)$} & \multicolumn{2}{c}{ Pre-ER } & \multicolumn{2}{c}{ Post-ER } & \multicolumn{2}{c}{ Post-TT } \\
\hline $\begin{array}{l}\text { Subject } \\
\#\end{array}$ & \multirow{2}{*}{ Placebo } & Treatment & \multirow{2}{*}{ Placebo } & Treatment & Placebo & Treatment & Placebo & Treatment \\
\hline 111 & 4.21 & 4.92 & 4.47 & 3.19 & 5.13 & 5.30 & 4.81 & 4.29 \\
112 & 3.97 & 4.10 & 5.32 & 4.35 & 3.03 & 5.58 & 3.71 & 4.08 \\
114 & 5.19 & 4.35 & 5.19 & 5.44 & 3.20 & 4.94 & 3.71 & 4.42 \\
115 & 4.62 & 6.28 & 4.78 & 3.53 & 3.09 & 4.89 & 4.67 & 5.06 \\
116 & 4.81 & 4.01 & 5.47 & 3.95 & 3.55 & 3.57 & 5.19 & 3.90 \\
117 & 4.21 & 5.00 & 4.30 & 4.10 & 3.61 & 5.33 & 4.85 & 4.21 \\
118 & 4.43 & 4.63 & 4.44 & 3.88 & 3.36 & 4.51 & 4.26 & 3.19 \\
119 & 4.61 & 4.84 & 3.62 & 4.14 & 3.52 & 4.52 & 7.00 & 5.21 \\
\hline Mean & 4.51 & 4.76 & 4.70 & 4.07 & 3.56 & 4.83 & 4.78 & 4.29 \\
SD & 0.39 & 0.72 & 0.62 & 0.66 & 0.67 & 0.64 & 1.05 & 0.64 \\
\hline
\end{tabular}


F.6. Total Body Fuel Oxidation Tables

Table F.6.1 CHO Oxidation

\begin{tabular}{lcccc}
\hline $\begin{array}{l}\text { CHO } \\
\text { Oxidation } \\
\left(\mathrm{g} \cdot \mathrm{min}^{-1}\right)\end{array}$ & \multicolumn{2}{c}{ Endurance Ride } & \multicolumn{2}{c}{ Time Trial } \\
\hline Subject \# & Placebo & Treatment & Placebo & Treatment \\
\hline 111 & 4.00 & 3.72 & 6.97 & 5.56 \\
112 & 3.22 & 3.14 & 4.66 & 5.31 \\
114 & 3.20 & 2.82 & 2.69 & 4.15 \\
115 & 2.65 & 3.30 & 6.18 & 5.90 \\
116 & 1.98 & 2.47 & 3.38 & 4.84 \\
117 & 2.79 & 3.22 & 4.84 & 5.70 \\
118 & 2.91 & 3.01 & 4.64 & 4.74 \\
119 & 2.93 & 3.23 & 5.82 & 5.81 \\
\hline Mean & 2.96 & 3.11 & 4.90 & 5.25 \\
SD & 0.57 & 0.37 & 1.42 & 0.62 \\
\hline
\end{tabular}


Table F.6.2 Fat Oxidation

\begin{tabular}{lccrc}
\hline $\begin{array}{l}\text { Fat Oxidation } \\
\left(\mathrm{g} \cdot \mathrm{min}^{-1}\right)\end{array}$ & \multicolumn{2}{c}{ Endurance Ride } & \multicolumn{2}{c}{ Time Trial } \\
\hline Subject $\#$ & Placebo & Treatment & Placebo & Treatment \\
\hline 111 & -0.03 & 0.01 & -0.76 & -0.39 \\
112 & 0.10 & 0.18 & -0.19 & -0.30 \\
114 & 0.06 & 0.30 & 0.22 & -0.14 \\
115 & 0.46 & 0.35 & -0.33 & -0.25 \\
116 & 0.24 & 0.18 & -0.04 & -0.09 \\
117 & 0.47 & 0.41 & -0.04 & -0.18 \\
118 & 0.47 & 0.39 & 0.09 & 0.08 \\
119 & 0.37 & 0.29 & -0.31 & -0.33 \\
\hline Mean & 0.27 & 0.26 & -0.17 & -0.20 \\
SD & 0.20 & 0.13 & 0.31 & 0.15 \\
\hline
\end{tabular}




\section{F.7. Glutathione Data Tables}

Table D.7.1. Resting GSH

Resting total GSH $\left(\mu \mathrm{mol} \cdot \mathrm{L}^{-1}\right)$

\begin{tabular}{lrrrr}
\hline & \multicolumn{2}{c}{ Basal } & Placebo & Treatment \\
\hline Subject \# & Placebo & Treatment & 1056.01 & 1017.79 \\
111 & 1075.48 & 1067.47 & 834.55 & 729.00 \\
112 & 897.77 & 859.24 & 908.83 & 964.60 \\
115 & 1160.01 & 1204.47 & 709.57 & 831.58 \\
116 & 847.97 & 799.11 & 399.84 & 893.43 \\
117 & 477.78 & 1020.18 & 1058.09 & 1079.61 \\
118 & 1106.66 & 1078.21 & 868.17 & 1143.04 \\
119 & 1261.41 & 1138.73 & 1103.69 & 1174.16 \\
\hline Mean & 1174.25 & 994.06 & 867.34 & 979.15 \\
SD & 1000.17 & 1020.19 & 231.17 & 155.10 \\
\hline
\end{tabular}


Table F.7.2. Resting GSSG

Resting GSSG $\left(\mu \mathrm{mol} \cdot \mathrm{L}^{-1}\right)$

\begin{tabular}{lcccc}
\hline & \multicolumn{2}{c}{ Basal } & \multicolumn{2}{c}{ Pre-ER } \\
\hline Subject \# & Placebo & Treatment & Placebo & Treatment \\
\hline 111 & 329.20 & 265.56 & 384.02 & 270.60 \\
112 & 264.49 & 264.87 & 250.61 & 255.20 \\
114 & 328.48 & 330.80 & 280.93 & 289.34 \\
115 & 346.11 & 479.15 & 312.64 & 409.65 \\
116 & 252.39 & 268.67 & 122.63 & 236.36 \\
117 & 289.81 & 300.64 & 293.75 & 284.94 \\
118 & 344.71 & 305.95 & 284.42 & 321.74 \\
119 & 277.54 & 277.92 & 263.21 & 268.86 \\
\hline Mean & 304.09 & 311.69 & 274.03 & 292.09 \\
SD & 37.40 & 71.59 & 73.41 & 53.76 \\
\hline
\end{tabular}


Table F.7.3. Resting GSH:GSSG

Resting GSH:GSSG

\begin{tabular}{lcccc}
\hline & \multicolumn{2}{c}{ Basal } & \multicolumn{2}{c}{ Pre-Endurance Ride } \\
\hline Subject \# & Placebo & Treatment & Placebo & Treatment \\
\hline 111 & 1.27 & 2.02 & 0.75 & 1.76 \\
112 & 1.39 & 1.24 & 1.33 & 0.86 \\
114 & 1.53 & 1.64 & 1.24 & 1.33 \\
115 & 0.45 & -0.33 & 0.27 & 0.03 \\
116 & -0.11 & 1.80 & 1.26 & 1.78 \\
117 & 1.82 & 1.59 & 1.60 & 1.79 \\
118 & 1.66 & 1.72 & 1.08 & 1.55 \\
119 & 2.23 & 1.58 & 2.19 & 2.37 \\
\hline Mean & 1.28 & 1.41 & 1.22 & 1.43 \\
SD & 0.76 & 0.74 & 0.57 & 0.71 \\
\hline
\end{tabular}


Table F.7.4. Exercising GSH

Exercising total $\mathrm{GSH}\left(\mu \mathrm{mol} \cdot \mathrm{L}^{-1}\right)$

\begin{tabular}{lrrrr}
\hline & \multicolumn{2}{c}{ Endurance Ride } & \multicolumn{2}{c}{ Time Trial } \\
\hline Subject \# & Placebo & Treatment & Placebo & Treatment \\
\hline 111 & 917.73 & 968.13 & 885.13 & 980.03 \\
112 & 781.51 & 878.82 & 759.15 & 629.33 \\
114 & 1184.89 & 1071.69 & 1173.67 & 1059.01 \\
115 & 739.37 & 761.69 & 719.82 & 755.02 \\
116 & 838.56 & 987.88 & 798.37 & 854.48 \\
117 & 1158.05 & 1086.85 & 966.82 & 929.64 \\
118 & 1221.92 & 1014.20 & 1216.61 & 1041.00 \\
119 & 927.11 & 855.31 & 849.72 & 839.85 \\
\hline Mean & 971.14 & 953.07 & 921.16 & 886.04 \\
SD & 191.07 & 112.66 & 185.71 & 146.81 \\
\hline
\end{tabular}


Table F.7.5. Exercising GSSG

Exercising GSSG $\left(\mu \mathrm{mol} \cdot \mathrm{L}^{-1}\right)$

\begin{tabular}{lcccc}
\hline & \multicolumn{2}{c}{ Endurance Ride } & \multicolumn{2}{c}{ Time Trial } \\
\hline Subject \# & Placebo & Treatment & Placebo & Treatment \\
\hline 111 & 350.75 & 245.81 & 437.85 & 252.53 \\
112 & 210.02 & 299.69 & 211.59 & 231.62 \\
114 & 348.99 & 311.80 & 350.16 & 312.15 \\
115 & 318.21 & 429.67 & 337.40 & 407.88 \\
116 & 161.54 & 263.01 & 213.56 & 249.18 \\
117 & 306.87 & 285.57 & 287.76 & 278.57 \\
118 & 377.69 & 279.67 & 396.33 & 347.86 \\
119 & 316.60 & 228.45 & 408.46 & 258.24 \\
\hline Mean & 298.83 & 292.96 & 330.39 & 292.25 \\
SD & 74.57 & 61.65 & 86.20 & 60.13 \\
\hline
\end{tabular}


Table F.7.6. Exercising GSH:GSSG

Exercising GSH:GSSG

\begin{tabular}{lcccc}
\hline & \multicolumn{2}{c}{ Endurance Ride } & \multicolumn{2}{c}{ Time Trial } \\
\hline Subject \# & Placebo & Treatment & Placebo & Treatment \\
\hline 111 & 0.62 & 1.94 & 0.02 & 1.88 \\
112 & 1.72 & 0.93 & 1.59 & 0.72 \\
114 & 1.40 & 1.44 & 1.35 & 1.39 \\
115 & 0.32 & -0.23 & 0.13 & -0.15 \\
116 & 3.19 & 1.76 & 1.74 & 1.43 \\
117 & 1.77 & 1.81 & 1.36 & 1.34 \\
118 & 1.24 & 1.63 & 1.06 & 0.99 \\
119 & 0.93 & 1.74 & 0.08 & 1.25 \\
\hline Mean & 1.40 & 1.38 & 0.92 & 1.11 \\
SD & 0.88 & 0.72 & 0.72 & 0.61 \\
\hline
\end{tabular}


F.8. Nitrotyrosine Data Table

Nitrotyrosine $\left(\mathrm{nmol} \cdot \mathrm{L}^{-1}\right)$

\begin{tabular}{lrrrr}
\hline & \multicolumn{2}{c}{ Pre-ER } & \multicolumn{2}{c}{ Post-TT } \\
\hline Subject \# & Placebo & Treatment & 53.15 & Treatment \\
\hline 111 & 53.20 & 40.92 & 2.83 & 33.28 \\
112 & 1.33 & 5.63 & 27.26 & 27.43 \\
114 & 30.16 & 22.95 & 38.50 & 55.50 \\
115 & 33.03 & 44.97 & 1.34 & 1.03 \\
116 & 47.99 & 51.65 & 38.08 & 39.05 \\
117 & 33.86 & 30.19 & 424.06 & 352.74 \\
118 & 178.81 & 211.99 & 3.84 & 4.31 \\
119 & 5.57 & 4.89 & 73.63 & 65.80 \\
\hline Mean & 47.99 & 51.65 & 142.92 & 117.75 \\
SD & 55.88 & 67.04 & & \\
\hline
\end{tabular}


F.9. Dietary Consumption Data Table

\begin{tabular}{lccrrrrrr}
\hline & \multicolumn{2}{c}{ Calories (kcal) } & \multicolumn{2}{c}{ Carbohydrate $(\mathrm{g})$} & \multicolumn{2}{c}{ Fat $(\mathrm{g})$} & \multicolumn{2}{c}{ Protein $(\mathrm{g})$} \\
\hline $\begin{array}{l}\text { Subject } \\
\text { \# }\end{array}$ & Placebo & Treatment & \multirow{2}{*}{ Placebo } & Treatment & Placebo & Treatment & \multirow{2}{*}{ Placebo } & Treatment \\
\hline 111 & 3967.76 & 3968.76 & 603.06 & 603.06 & 132.28 & 132.28 & 90.41 & 90.41 \\
112 & 2714.89 & 2762.20 & 309.64 & 312.62 & 104.61 & 111.63 & 136.64 & 129.23 \\
114 & 4337.41 & 4310.55 & 437.94 & 429.33 & 207.37 & 194.04 & 198.96 & 219.96 \\
115 & 3473.94 & 3355.32 & 427.85 & 456.73 & 119.48 & 129.16 & 117.88 & 103.07 \\
116 & 5348.31 & 5310.28 & 701.37 & 731.23 & 199.10 & 197.55 & 183.24 & 176.28 \\
117 & 2413.65 & 2421.39 & 288.88 & 290.22 & 104.47 & 97.17 & 70.87 & 105.47 \\
118 & 3309.64 & 3303.37 & 513.77 & 503.32 & 102.64 & 99.43 & 105.49 & 103.09 \\
119 & 1893.26 & 1824.46 & 218.57 & 211.87 & 75.87 & 60.04 & 87.00 & 80.29 \\
\hline Mean & 3432.36 & 3407.04 & 437.64 & 442.30 & 130.73 & 127.66 & 123.81 & 125.98 \\
SD & 1115.78 & 1112.24 & 164.45 & 171.74 & 47.58 & 47.62 & 46.27 & 48.10 \\
\hline
\end{tabular}

